University of Redlands

\title{
A Web-Based Application for the Redlands Fire Department
}

A Major Individual Project submitted in partial satisfaction of the requirements for the degree of Master of Science in Geographic Information Systems

by

Yusuf Albanki

Fang Ren, Ph.D., Committee Chair

Douglas Flewelling, Ph.D.

July 2012 
A Web-Based Application for the Redlands Fire Department

Copyright (C) 2012

by Yusuf Albanki 
The report of Yusuf Albanki is approved.
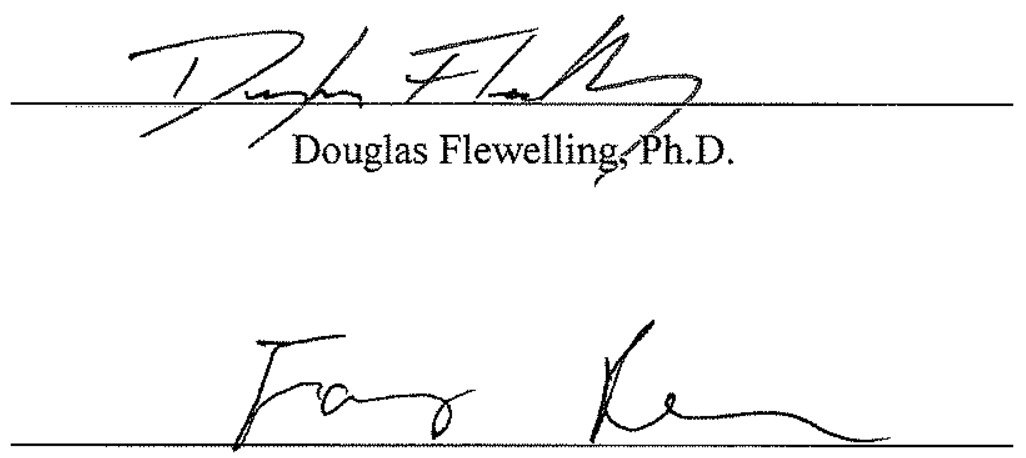

Fang Ren, Ph.D., Committee Chair

July 2012 



\section{Acknowledgements}

First and foremost I would like to express my sincere thanks and gratitude to God Almighty for all the blessings. This success was achieved only thanks to the Almighty and his mercy.

I would like to thank His Excellency the Minister of Interior-Kingdom of Bahrain, Sheikh Rashid bin Abdulla Al-Khalifa, His Excellency the Minister of Housing Eng. Bassim bin

Yaqoob Al Hamar, and Lt. Col Waleed Al Hamdan for the opportunity to study in the University of Redlands.

I would like to thank my wife Noora for her patience during my absence and bear the responsibility of small daughter alone, and I would like to tell her that I wish to stay together forever. I would also like to thank my father and my mother and my brothers and my sister to the unlimited support that you have received them during the period of my studies.

I would like to thank the members of International Friendship Connection (IFC), especially my brothers Bob and Brian for Their friendship. Also, I would like to thank Ali and Aseel for their hospitality.

I would like to thank the University of Redlands and the faculty for their considerable efforts; they have made use, especially, my second mother Debbie, my advisor Dr. Fang Ren, and Dr. Douglas Flewelling for encouraging me during the year.

Also, I would like to express my thanks to Mr. Philip Mielke for his cooperation. Special thanks to my friends Yaser, Abdul and Mohammed for everything. At the end, I will not forget Redlands, Cohort 20, Apartment 15 and everybody. Thanks 



\begin{abstract}
A Web-Based Application for the Redlands Fire Department

by

Yusuf Albanki
\end{abstract}

The Redlands Fire Department wanted to use Geographic Information System (GIS) technology in their analysis processes, to improve and enhance their services. Thus, a web-based application was developed to satisfy their needs. The main goal of the application was to help incidents analysts in studying fire incidents. Four objectives were set to meet this goal. The first objective was to show different summary statistics using a dashboard design. The second objective was to add different network analysis functions to help it understand the nature of its coverage areas. The third objective was to visualize the incidents using different mapping techniques. The fourth objective was to allow the user to determine and analyze the incidents that had a long emergency response time. Using this application, the Redlands Fire Department can manage its resources, identify the needs of its stations, understand the road networks, visualize performance history, predict coverage capacity, determine the locations that have a high concentration of incidents, and improve its services. 



\section{Table of Contents}

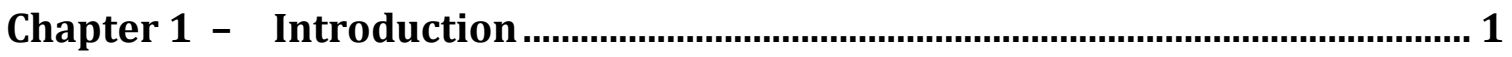

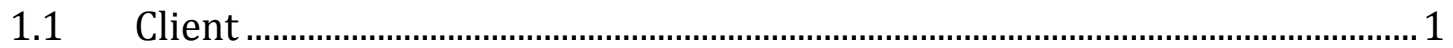

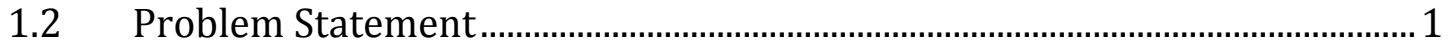

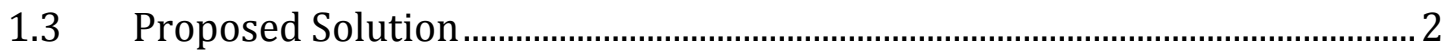

1.3.1 Goals and Objectives …………………………………………………….... 2

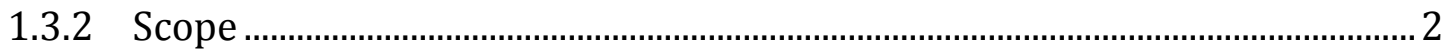

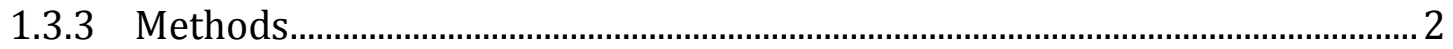

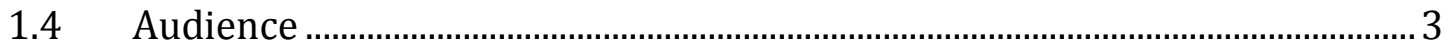

1.5 Overview of the Rest of this Report .................................................................... 3

Chapter 2 - Background and Literature Review..................................................... 5

$2.1 \quad$ GIS and Public Safety....................................................................................... 5

2.2 Dashboard Design ....…………………………………………………………. 6

2.3 The Development of Web GIS ............................................................................

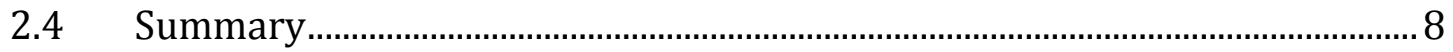

Chapter 3 - Systems Analysis and Design …....................................................... 9

$3.1 \quad$ Problem Statement ..........................................................................................

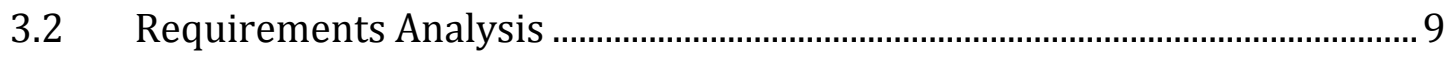

3.2.1 Functional Requirements.............................................................................. 10

3.2.2 Non-Functional Requirements...................................................................... 10

3.3 System Design .................................................................................................. 11

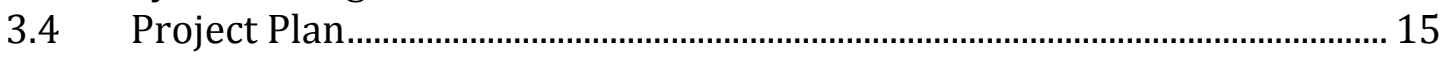

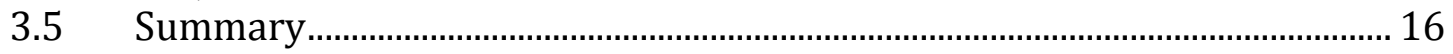

Chapter 4 - Database Design ..............................................................................17

4.1 Conceptual Data Model .................................................................................. 17

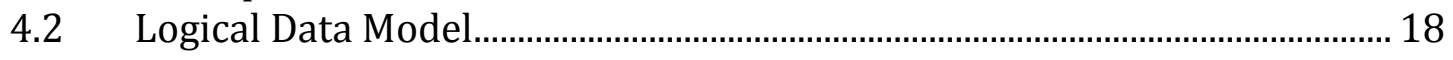

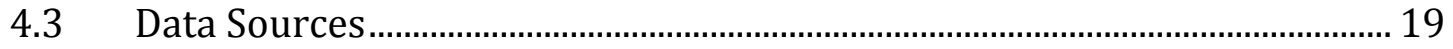

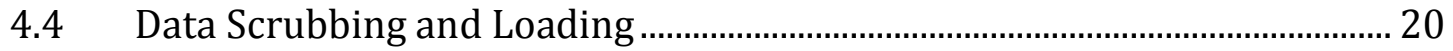

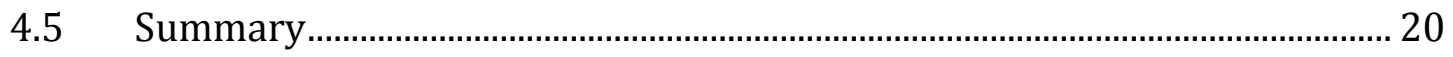

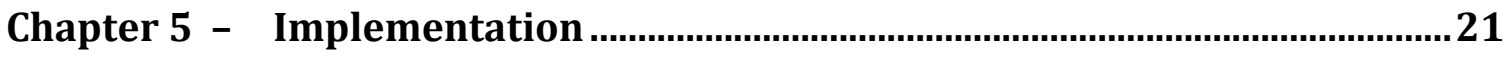

$5.1 \quad$ Import Incidents Tool................................................................................. 21

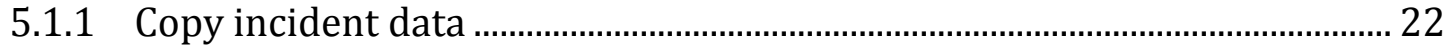

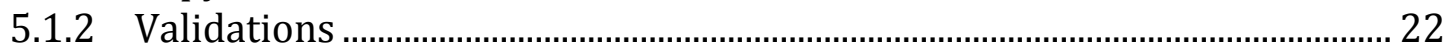

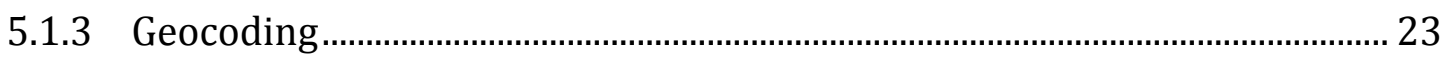

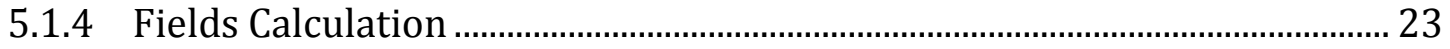

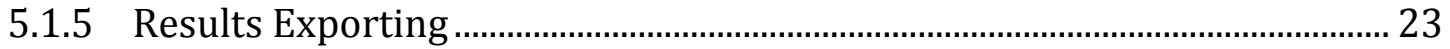

5.2 The Web Application Development .................................................................. 26

5.2.1 Publishing the Map Services ……………………………………………….... 26

5.2.2 Building the Web Application......................................................................... 28

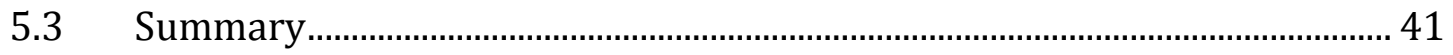

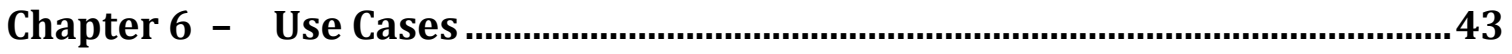


6.1 Exploring Incidents within a Specific Duration .............................................. 43

6.2 Analyzing Emergency Response Time ……………………………………...50

6.3 Finding Service Areas and Closest Fire Station................................................. 51

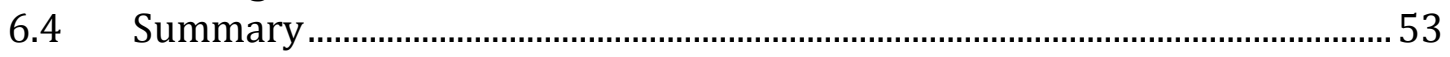

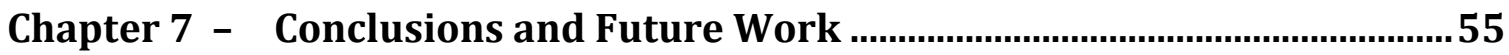

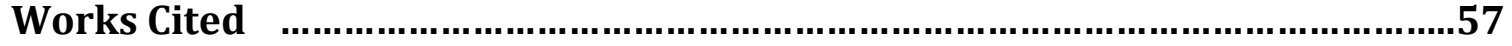

Appendix A. Import Incidents Tool Model...........................................................59

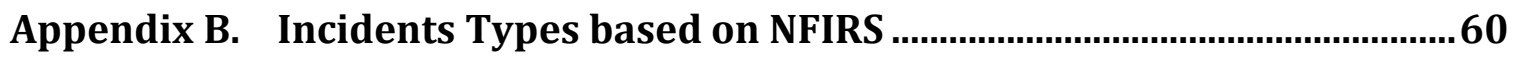

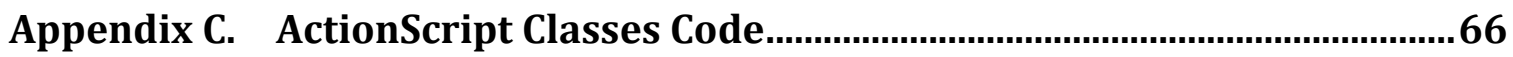




\section{Table of Figures}

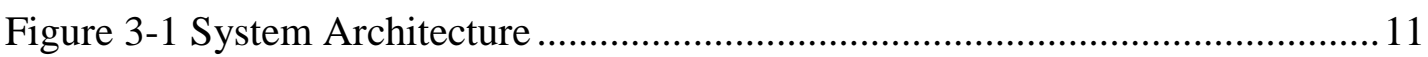

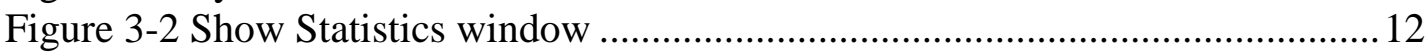

Figure 3-3 Analyze Emergency Response Time window.......................................... 13

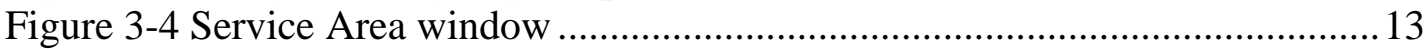

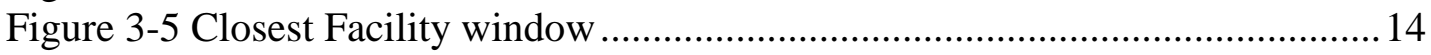

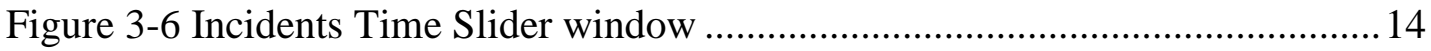

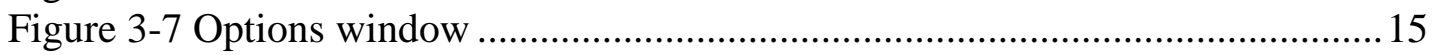

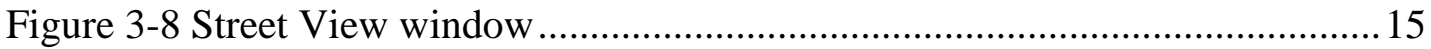

Figure 4-1 Conceptual Data Model of the project ………………………................ 17

Figure 4-2 Logical Data Model of the project ...................................................... 18

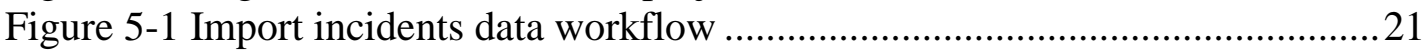

Figure 5-2 Import incident tool interface ...........................................................22

Figure 5-3 Time properties of the incidents layer....................................................2

Figure 5-4 Map without Clustering and Map with Clustering......................................31

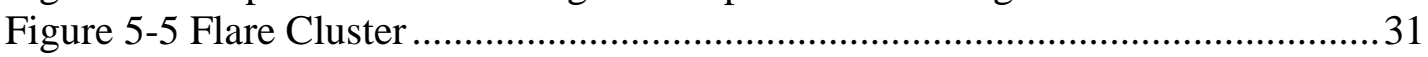

Figure 5-6 Different Interfaces for Street View........................................................33

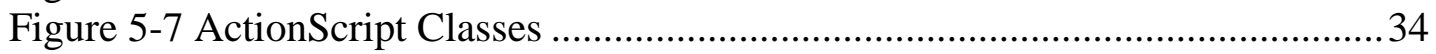

Figure 5-8 Navigation between Incident Types Levels .............................................36

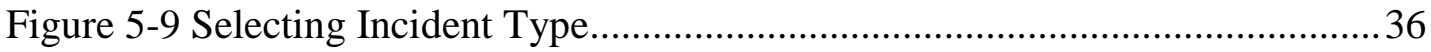

Figure 5-10 Fire Stations Column Bar Chart.............................................................37

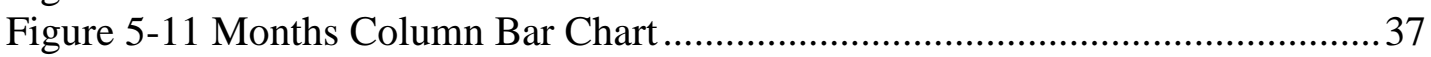

Figure 5-12 Distribution of the Incidents by Weeks..................................................38

Figure 5-13 Distribution of the Incidents by Hours..................................................38

Figure 5-14 Minimum and Maximum Emergency Response Time ............................38

Figure 5-15 Analyze Emergency Response Time Window..........................................39

Figure 5-16 Configuration File ......................................................................... 41

Figure 6-1 Incidents between October 2010 to March 2011 .......................................4

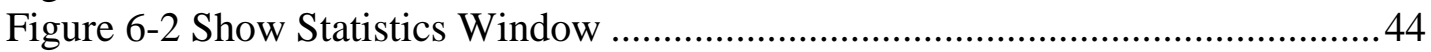

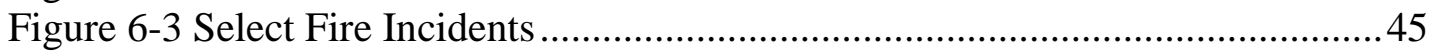

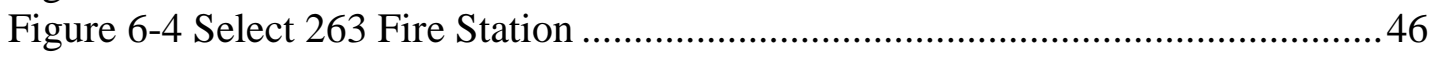

Figure 6-5 Distribution of the Incidents over Days and Hours...................................4

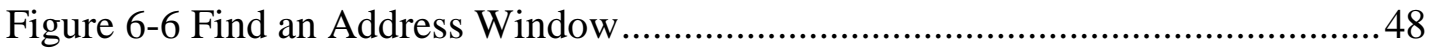

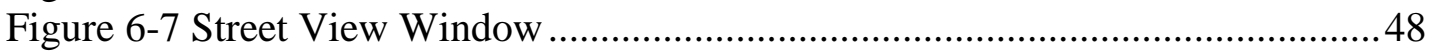

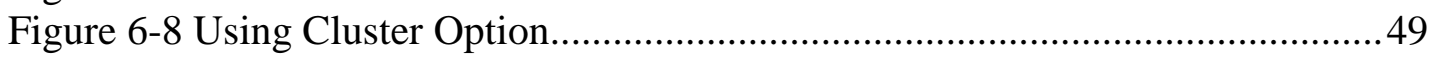

Figure 6-9 Distribution of the Incidents by Months .............................................50

Figure 6-10 Analyze Emergency Response Time Window........................................51

Figure 6-11 Service Area Analysis ...................................................................52

Figure 6-12 Closest Facility Analysis .....................................................................53 



\section{List of Tables}

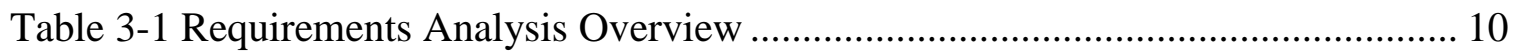

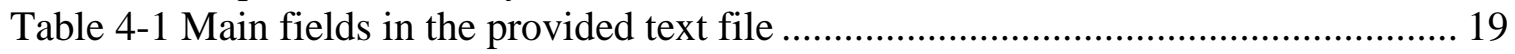

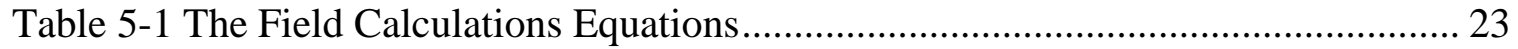

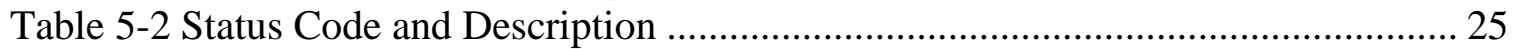

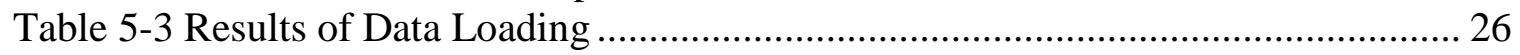

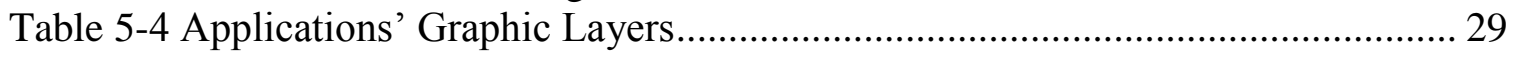

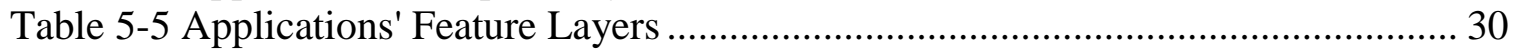

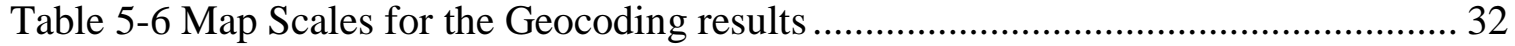

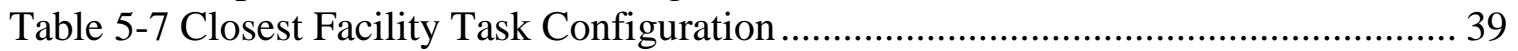

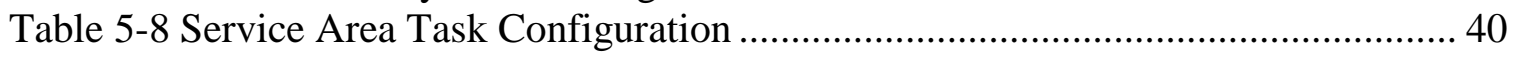





\section{List of Acronyms and Definitions}

$\begin{array}{ll}\text { GIS } & \text { Geographic Information System } \\ \text { API } & \text { Application Programming Interface } \\ \text { Esri } & \text { Environmental Systems Research Institute } \\ \text { SDK } & \text { Software Development Kit } \\ \text { IDE } & \text { Integrated Development Environment } \\ \text { UML } & \text { Unified Model Language } \\ \text { HTTP } & \text { Hypertext Transfer Protocol } \\ \text { HTML } & \text { Hypertext Markup Language } \\ \text { URL } & \text { Universal Resource Locator } \\ \text { XML } & \text { Extensible Markup Language } \\ \text { WWW } & \text { World Wide Web } \\ \text { FTP } & \text { File Transfer Protocol } \\ \text { NFIRS } & \text { National Fire Incident Reporting System } \\ \text { RIA } & \text { Rich Internet Application } \\ \text { CSV } & \text { Comma-Separated Values } \\ \text { EMR } & \text { Emergency Response } \\ \text { ANI } & \text { Automatic Number Identification } \\ \text { ALI } & \text { Automatic Location Identification } \\ \text { SWC } & \text { Shockwave Flash Component }\end{array}$





\section{Chapter 1 - Introduction}

Data and the process of deriving information from data are important for organizations. The information helps the organizations to discover the positive and negative indicators such as risks so they can take appropriate actions and make critical decisions to increase their productivity. Because information is valuable in the emergency response field, the Redlands Fire Department wanted an application that could turn their archived incidents data into useful information, and display the information using charts and maps. They also wanted functions like determining the nearest fire stations to a selected point and calculating the estimated coverage area for the fire stations to help them in minimizing their emergency response times.

An executive summary of the project is provided in this chapter. The first section introduces the project client. The problem addressed in this project is defined in the second section. The third section describes the goals, objectives, and methods used to implement the project. The fourth section addresses the report audience. The final section outlines an overview of the reset of the report.

\subsection{Client}

The client of this project was the Redlands Fire Department which is responsible for the public safety and firefighting in the City of Redlands. The point of contact for the project was Mr. Philip Mielke, who is the City of Redlands GIS Administrator. The client was interested in developing an online mapping application to analyze fire incidents to improve their performance in serving the citizens of Redlands.

\subsection{Problem Statement}

Time is extremely crucial for firefighting and rescue services. Many lives could be saved, and a lot of damages could be minimized by a quick response. Because of that, the Redlands Fire Department wanted a tool to help them to understand and minimize emergency response time. Currently, the Redland Fire Department stores and manages their incident records in a computer-aided dispatch system, which does not allow them to visualize the incidents on a map and conduct various analyses such as evaluating the distribution of the incidents and determining the locations that have a high response time. As such, it was difficult to make decisions about placement of resource. In addition to incidents analyses, the Fire Department also needed to identify the best routes for emergency response and evaluate the coverage areas of their fire stations. This could not be done with their current system. Thus, a better system were in demand that can help the Redlands Fire Department to understanding and evaluating the factors like incident locations, emergency response times, peak hours, and incident types, because understanding these factors and their relationship are crucial for the decision makers to better manage their resources to enhance their services. 


\subsection{Proposed Solution}

In order to meet the client's requirements, the goals and the objectives were clearly identified. Project creep was avoided by determining the project scope precisely. These elements and techniques are described in the following sections.

\subsubsection{Goals and Objectives}

The primary goal of this project was to help the Redlands Fire Department minimize their emergency response time by developing a web-based application to analyze incidents. Three objectives were set to meet this goal.

The first objective was to show different summary statistics using a dashboard design. These incidents statistics summarized in the forms of tables and charts can help the client better understand the data. For example, the client can identify the workloads on each fire station, or the average emergency time of each fire station. Based on this information, the client can make plans to deal with the incidents.

The second objective was to add different network analysis functions to help them understand the nature of their coverage areas. Choosing wrong routes or assigning wrong fire stations to deal with an incident will increase the emergency response time. Using network analysis, different plans can be created to deal with roads conditions and to assign further incidents to the correct fire station.

The third objective was to map the incidents on a map using different mapping techniques. For example, clustering mapping can allow the client quickly identify where the fire incidents concentrated. Linking the map with the charts and tables for the summary statistics will further enhance client's understanding of selected incident records.

By meeting these goals and objectives, the Redlands Fire Department can use the application to make critical decisions, like resources redistribution and requesting new resources.

\subsubsection{Scope}

The project scope was composed of three components. The first component was an ArcSDE SQL Server geodatabase to store incidents data. The second component was a tool to import incidents data to the created geodatabase. The final component was a webbased application where the client can view the incidents in the form of linked graphs, tables, and maps. The application should allow the client to conduct analyses such as finding the closest fire station, calculating the service area of a fire station, and examining the spread of incidents over a specified time frame.

\subsubsection{Methods}

Several techniques and methods were used in each phase of the project's development life cycle. In the system analysis and design phase, similar projects were studied and multiple meetings were held with the client to define the requirements. The collected requirements were then classified into functional requirements and non-functional requirements. 
The conceptual data model and logical data model were then designed to determine the needed data and build the database schema. The geodatabase was created on ArcSDE SQL Server, and a tool to import incidents data was implemented using model builder and Python script.

A web-based application was developed using Flex SDK 4.6 and ArcGIS API for Flex version 2.5 in the implementation phase. The required map services were published to ArcGIS Server 10 using ArcGIS Desktop 10. Different analyses were added to the developed application, such as network analysis. Finally, a dashboard design was used to display the required incidents statistics using different elements such as charts, tables and maps.

\subsection{Audience}

The intended audience of this report is the Redlands Fire Department employees. This project could also be useful to an audience with an introductory knowledge in GIS, programming, public safety, and the emergency response fields.

\subsection{Overview of the Rest of this Report}

The rest of this report describes how the main project components were implemented. Chapter 2 outlines the background and literature review. Chapter 3 describes the analysis and design of the project. The database design, data scrubbing, and loading are discussed in Chapter 4. The implementation of the import incidents tool and the web-based application is described in detail in Chapter 5. Chapter 6 illustrates several use cases of the application. Finally, the conclusions and future works are discussed in Chapter 7. 



\section{Chapter 2 - Background and Literature Review}

A literature review was conducted before the project development phase, and three topics that are relevant to this project were reviewed. The first topic discussed in this chapter is how GIS technology became one of the essential technologies in the public safety field and has been used in most of the public safety areas, such as emergency management, disaster management, and decisions making (Section 2.1). The concept of dashboard design is introduced in Section 2.2, and Section 2.3 shows the role of web GIS in facilitating the spatial data sharing and accessing.

\subsection{GIS and Public Safety}

The term "public safety" includes any actions or procedures that are taken to protect people and their property from current and future threats. These threats could be natural or human made, and their effects could be direct or indirect on the surrounding areas (Caplan, 2010). Today, public safety systems are used by public safety agencies to help them in responding to the threats and events. The mission of public safety agencies is to respond quickly to reduce the losses in lives and properties (Leitinger, 2004). Due to the current increase in population, economic development, and urban development the mission of public safety agencies has become harder to accomplish. To improve public safety agencies' services and speed up the emergency response process, GIS technology has been included in many public safety systems. This is because GIS is capable of analyzing spatial and tabular data, like populations, disasters, and critical infrastructure that are critical for decisions making in an emergency situation. Different kinds of information can also be generated and displayed on the map using queries and analysis tools. In addition, showing live data feeds - that are coming from different sources - on the map provides a common operational picture to the commanders, and this helps them in decisions making as well (Esri, 2008).

Common GIS functions used in the public safety systems include geocoding function, which is used to find incidents locations, and cartographic visualization, in which the necessary data are displayed on the map with appropriate symbologies. Some public safety systems contain the models for determining the areas that may be affected by a specific threat, such as a simulation of atmospheric dispersion of hazardous materials (Caplan, 2010). In addition, various spatial analyses and network analyses can be used to assess the distribution of the resources. For example, allocation analysis examines the efficiency of the service area for the resources under certain constraints like time. This information is important for public safety agencies because it allows them to evaluate the coverage area for their facilities.

The other type of commonly used analysis is location-allocation analysis where a set of facilities to be optimally sited under certain objectives and constraints like distance or time (Chang, 2011; Waters, 1999). Hotspot analysis is also used to identify the concentration and the spatial pattern of geographic objectives of interest, such as crime incidents and traffic accidents. This analysis is used by public safety agencies to study hotspots to take appropriate actions to reduce the number of the incidents. 
The benefits of GIS to public safety could be enhanced by integrating it with other technologies (Esri, 2007). For example, the integration of GIS with automatic number identification (ANI) and automatic location identification (ALI) technologies speeds up the call taking process because the caller information and the location are detected directly when the call is received by the operators. Moreover, the integration between GIS with the automatic vehicle location helps the dispatcher send the closest resources to the incidents and track them. Thus, the integration between GIS and other technologies provides situational awareness to decision makers.

GIS also plays an important role in disaster management that is another essential subject in public safety. In order to minimize the effects of disasters, five phases should be considered and studied (Leitinger, 2004). The first phase is planning, in which the potential risks and disasters are analyzed to evaluate their possible effects. In this phase, GIS has been used for risk assessment, such as natural hazard assessment and vulnerability assessment (Cova, 1999). The second phase is mitigation, which includes the activities that should be performed to minimize the effects or to avoid the identified disasters. In this phase, GIS can be used in risk mapping and determining priorities (Cova, 1999). The contingency plans to minimize the damages are developed in the preparedness phase, and they are executed in the response phase. In these phases, GIS can be used for emergency vehicle routing, evacuation planning, and zoning planning. After the disaster, several activities should be taken to recover from the disaster. In this phase, GIS can be used to make damage assessments and recovery analyses (Cova, 1999).

\subsection{Dashboard Design}

An effective representation of needed information is very important for decision makers. Thus, choosing an appropriate design to show the data and information is an essential issue to be address in the development of decision support systems. Many systems fail because their designers focus on the beauty of the design more than on the goal of the system (Few, 2006).

According to Pousman and Stasko (2006), the design patterns for information systems can be classified into four categories: the Symbolic Sculptural Displays which uses water, light and others to view very few pieces of information; the Information Monitor Displays, a peripheral part of a computer desktop; the High Throughput Textual Displays, where the information is represented by using text and simple graphics; and the Multiple Information Consolidators which combine pieces of information from different sources on one screen and use techniques like blinking to inform the user about the changes in the information. The dashboard can be classified in this last category.

Few (2006) defines dashboard design as a "visual display of the most information needed to achieve one or more objectives which fits entirely on a single computer screen so it can be monitored at a glance" (p.34). Few's definition of dashboards means dashboards should use graphics, gauges, charts, and maps more than using text. In doing so, the user can understand the information quickly and clearly. To make the design fit the computer screen, scroll bars should be avoided. The definition also indicates that dashboards should be designed to meet specific goals. Without addressing the goals and objectives, a dashboard will be merely an artwork. 
Among different types of dashboards, the performance dashboards "translate the organization's strategy into objectives, metrics, initiatives and tasked customized to each group and individual in the organization" (Eckerson, 2011, p. 4). Unlike other dashboard types, performance dashboards are developed based on performance matrices and performance indicators like risks indicators and activity matrices that are used to measure business achievements by comparing the current status to business goals. The performance dashboards allow users to monitor their work, analyze the problems based on various data, and manage their resources. There are three types of performance dashboards: the operational dashboards, which focus on monitoring and give alerts if something wrong is happening; the tactical dashboards, which are used to analyze the information to solve problems; and the strategic dashboards, which focus on management more than analysis or monitoring and they are used by executives to manage the implementation of the strategic plans (Eckerson, 2011).

The concept of dashboard design has been included in many applications in the public safety field. For example, a web-based dashboard was implemented by Esri North Africa (Esri NeA) in 2009 to control and manage the emergency response processes (EsriNeA, n.d.). Another example was the fire view dashboard that was implemented by The Omega Group. This application allows the user to analyze fire incidents and provide the information in different views, such as charts, maps, and reports (The Omega Group, n.d.).

\subsection{The Development of Web GIS}

Web technologies have been a huge revolution in most of industries. They change the way of sharing, accessing, and using data. Many workflows are improved by using the web. Like other technologies, GIS was influenced by this revolution. Today, web GIS is one of the most important divisions in GIS industry, together with other related divisions such as Internet GIS, and Internet distributed GIS services (Dragićević, 2004). In fact, web GIS is a subset of Internet GIS. Unlike web GIS that is limited on using World Wide Web (WWW) and HTTP to manipulate spatial data, other protocols like File Transfer Protocol (FTP) and Telnet can be used in Internet GIS (Peng, 1999).

Web GIS offers GIS functions on the web so that spatial data can be stored, analyzed, and visualized using HTML and HTTP (Penev, 2006). This minimizes the restrictions, such as the time and location of distributing and processing spatial data (Alesheikh, Helali, \& Behroz, 2002).

Since web GIS is a combination of web and GIS, this gives it many advantages over the traditional GIS. First is the simplicity of its applications compared to the desktop applications. Most of web interfaces are not as complex as the desktop GIS interfaces, so the audience is a wide range of users including professionals and the public. Second, the updating process is done only on the application server. This feature reduces the time required for applications updates, since there is no need to update the clients' machines. Third, unlike with desktop applications, many users can use and access applications at same time, which greatly facilitate information dissemination. This is done by using web browsers with necessary plug-ins, and the end users do not need to have expensive commercial software. In general, using web GIS can reduce the costs of training, licenses, and the required criteria of the client's machine (Fu \& Sun, 2010). 
An example of web GIS is the E-government project implemented by UK's government to integrate local authorities' systems, services, and spatial data. Many benefits were gained from using web GIS. Each department can have access to the spatial data owned by other departments and can create mashup applications to display the data from different sources. Having access to all data supports the decision making process. The management and maintenance problems were solved by dedicating servers to store all the data. Ultimately, this architecture saves time and cost because all information is available and there is no need for searching or buying new data (Stachowicz, 2004).

The main challenging in web GIS is the speed, since a large amount of data need be exchanged between clients and server (Alesheikh, Helali, \& Behroz, 2002). This problem can be solved by using appropriate web GIS architecture. The choice depends on the requirements and the available environment. The first architecture is called "Thick Client/ Thin Server." In this architecture, all processing is completed on the server side and the client can display the results. Any machine can be used on the client side. However, the response time will be long. The second architecture is "Thin Client/ Thick Server." In this architecture, the processing is done on the client side and the server sends the needed data. This architecture is influenced by network speeds, since a large amount of data need be transferred in the processing. Also, this architecture requires a powerful client machine to handle all processes. The last architecture is "Medium Client and Server." The processes are done on both sides (Ewald, 2004). This architecture becomes favorable when the processing loads are balanced between the client side and server side.

\subsection{Summary}

The goal of this project was to implement a web GIS application to support the client in the decision making process by providing different analysis tools and showing the statistics using dashboard design concept. Since this project will be used in the public safety field, many custom functions and analyses were added, such as closest facility analysis and service area analysis. Finally, the project was implemented based on web GIS technology, so that the application can be used by many users at the same time with low costs. The next chapter describes the system analysis and design of this project. 


\section{Chapter 3 - Systems Analysis and Design}

The analysis and design phase is very important in the project's development life cycle because the following phases will highly depend on that phase. This chapter discusses the various elements of the system analysis and design. First, it highlights the client problem that was solved by the proposed system. Then, it explains the functional and nonfunctional requirements that were considered in the system development and how these requirements were met. Finally, it shows the project plan that identifies the major tasks which were done to implement the system.

\subsection{Problem Statement}

The Redlands Fire Department wanted a web-based GIS application to analyze fire incidents, and to improve their services. By using this application, proactive actions can be taken to decrease the emergency response time. Also, critical decisions like resources redistribution, ordering new resources, and building new fire stations can be made. In order to make this web application useful for the decision makers, the client wanted to examine several factors related to their services, such as the distribution of the fire incidents in relation to the fire stations, the incidents types, the peak hours, the areas that have a high concentration of incidents, and emergency response time. Moreover, these factors should be represented by interactive charts and map.

\subsection{Requirements Analysis}

Several meetings with the client were held to understand their requirements. The results of these meetings were divided into functional requirements and non-functional requirements. Non-function requirements consist of technical requirements, operational requirements, and transitional requirements (Table 3-1). 
Table 3-1 Requirements Analysis Overview

\section{Functional Requirements}

Displaying the information and the distribution of the incidents using tables, charts, and map

Searching for incidents that have emergency response times greater than specified time

Examine the spread of the incidents

Service area analysis

Closest facility analysis

\begin{tabular}{|c|l|}
\hline \multicolumn{2}{|c|}{ Non-Functional Requirements } \\
\hline \multirow{2}{*}{ Technical Requirements } & Using the Esri software suite \\
\cline { 2 - 3 } & Using an Adobe Flex framework \\
\hline \multirow{2}{*}{ Operational Requirements } & Operational environment updates \\
\cline { 2 - 3 } & Geodatabase archiving \\
\hline \multirow{2}{*}{ Transitional Requirements } & $\begin{array}{l}\text { A tool to import the exported incidents data to } \\
\text { a system geodatabase }\end{array}$ \\
\hline
\end{tabular}

\subsubsection{Functional Requirements}

The functional requirements determine the capabilities the system should have to solve the client's problem. According to the client, the system should allow the user to see the distribution of the incidents - based on the selected duration - over fire stations, months, days, hours, and areas using charts, tables, and maps. The system should also allow the user to determine the incidents that have emergency response times greater than the specified time. In addition, the system should allow the user to examine the spread of the incidents over time, find closest fire station to a selected point, and identify the coverage area of their fire stations.

\subsubsection{Non-Functional Requirements}

The technical requirements focus on the required technologies to build the system. Based on the client's requirements, the system was developed using the Esri software suite, so the web services were authorized using ArcGIS Desktop 10 and published using ArcGIS Server 10. The web application was developed using Flash Builder 4.6 with Flex SDK 4.6 and ArcGIS API for Flex version 2.5 was used as the Integrated Development 
Environment (IDE). Since the application was developed using the latest version of Flex SDK, the client web browsers need Flash Player 11 or higher to access the application.

The operational requirements state the required processes to keep the system up and running. The archiving process will be done by the client either daily or weekly, based on their plan. The client is also responsible for operational environment updates. Data conversion can be categorized as transitional requirements. Since incidents data was provided in its original text format, a tool was developed to load these incidents to the geodatabase developed for the web application. The validation process, geocoding process, and adding the valid incidents into the geodatabase were the main functions of this tool.

\subsection{System Design}

The system design was dependent on the results of the requirements analysis. This section illustrates the system architecture and the design of the user interface.

Figure 3-1 shows the system architecture that consists of two tiers. The first tier is a server tier or web server, which contains the ArcGIS Server and application server. This connects to the system geodatabase. The second tier is the client tier; the client can access the application using any web browser with Flash Player 11 or higher.

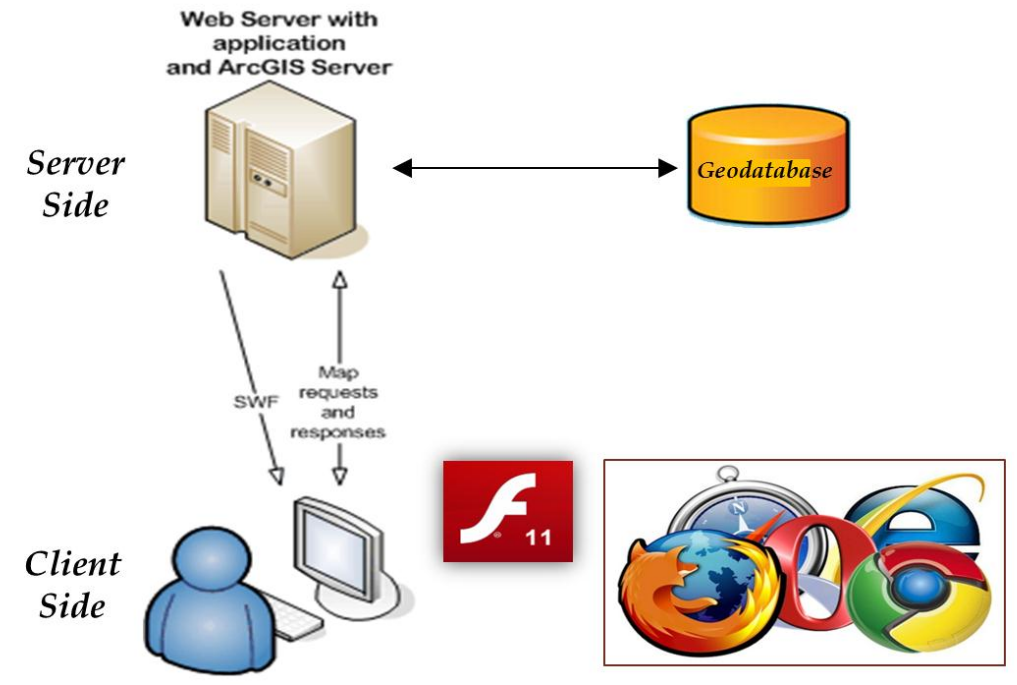

Figure 3-1 System Architecture

As for the interface design, several required components were laid out during the design process and refined during the implementation phase. For example, the incidents map was designed to include a tool tip that shows incident type and a popup window that shows the incident information, such as incident ID, emergency response time, and clear time. After discussion with the client, a world topographic map, one of the Esri web services, was used as a basemap.

An important function of the web application is to show statistics about the retrieved incidents. The Show Statistics window was designed to include five sections (Figure 3-2). 
First, incidents types are represented using a pie chart. Different levels of incidents details can be viewed using the pie chart, the user can navigate from one level to another by clicking on the incident type. Second, the fire stations section is a column chart showing the distribution of the incidents over the fire stations. The third section shows the distribution of the incidents over the months using a column chart. Fourth, a calendar of the selected month shows the distribution of the incidents over the days. The last section shows the distribution of the incidents over the hours of the selected day. The charts are interactive. When the user changes their queries by incidents or by fire stations, the charts, tables, and the map will be automatically updated. The title bar shows the average emergency response time of the selected incidents.

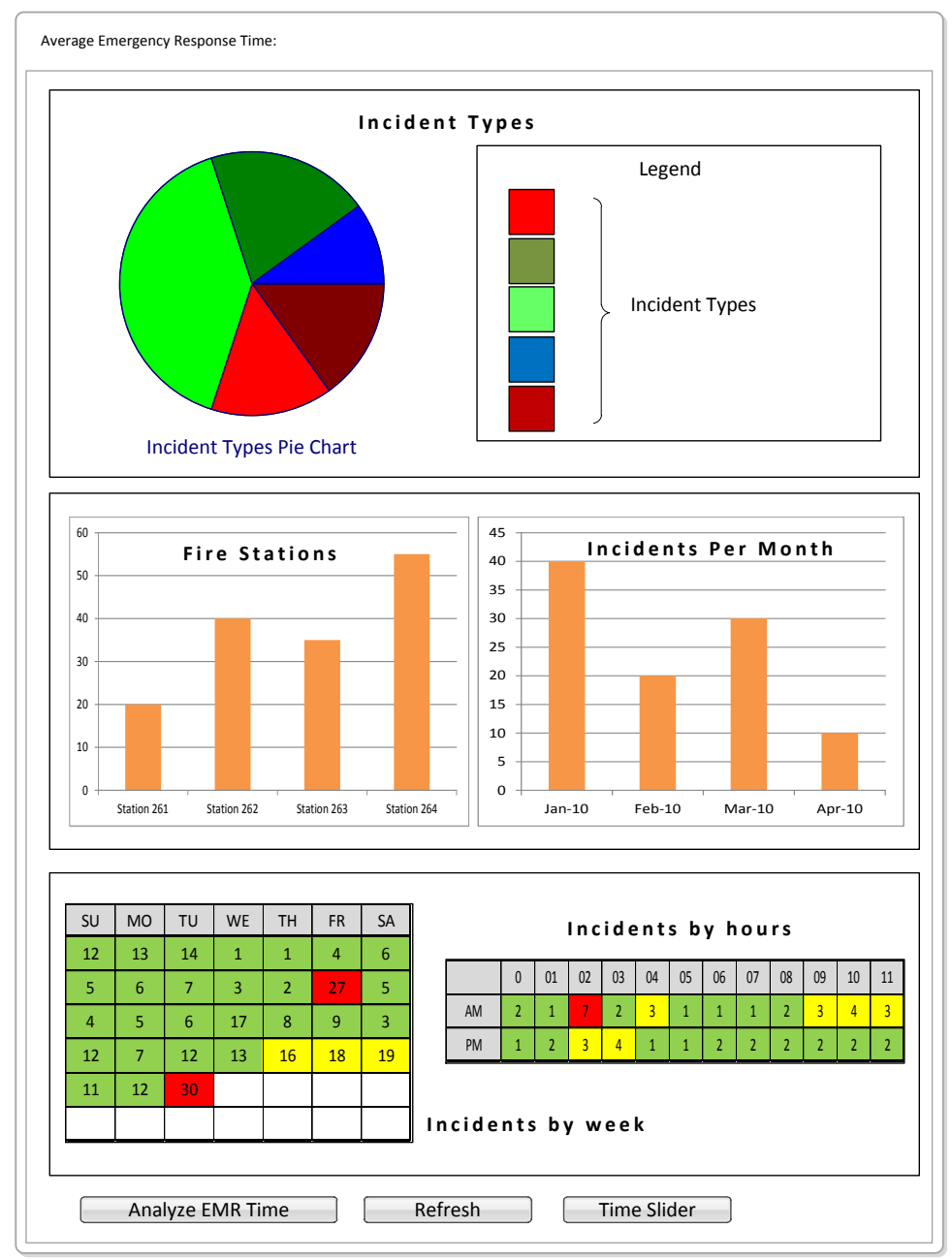

Figure 3-2 Show Statistics window

The Analyze Emergency Response Time window was designed to allow the user to search for the incidents that took more emergency response time than specified. Figure 33 shows the Analyze Emergency Response Time window. 


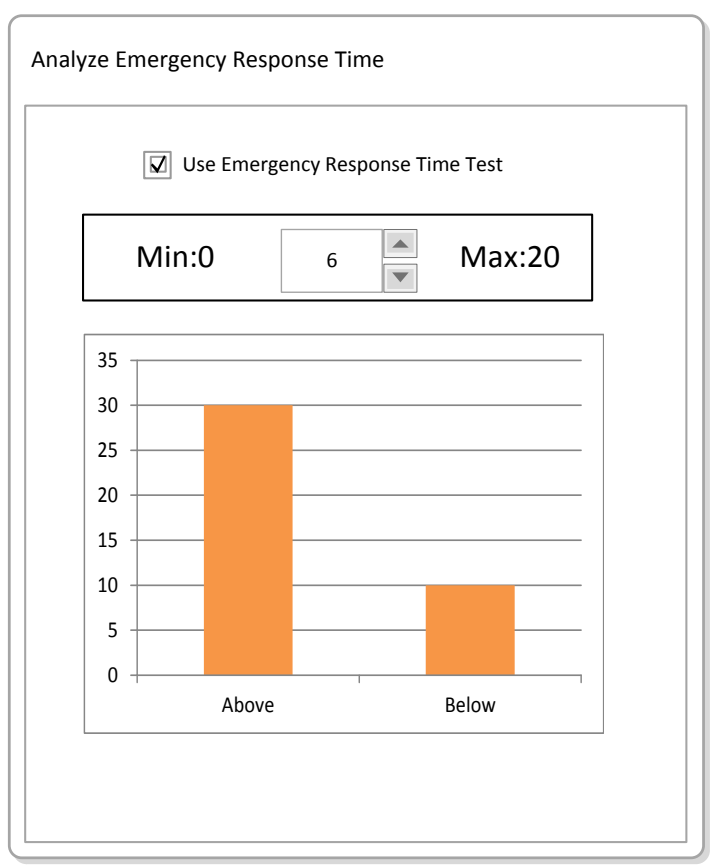

Figure 3-3 Analyze Emergency Response Time window

The Service Area window was designed to generate a service area for one or multiple fire stations based on the specified time intervals (in minutes). Figure 3-4 shows the Service Area window layout.

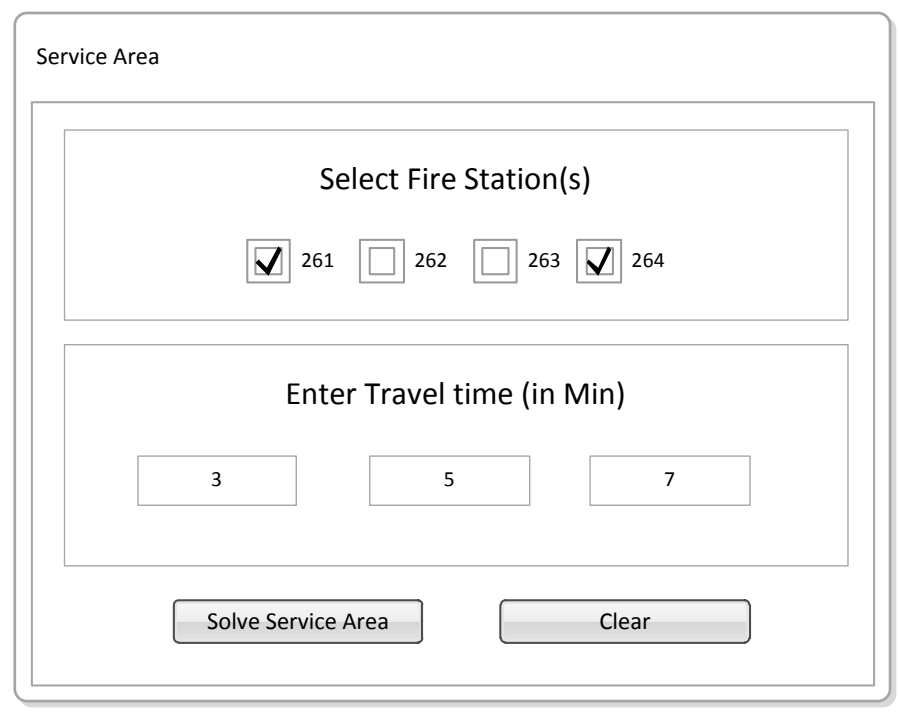

Figure 3-4 Service Area window

Figure 3-5 shows Closest Facility window layout, which helps the user to find the nearest fire stations to a selected point. Its interface allows the user to add point and barriers to the map. 


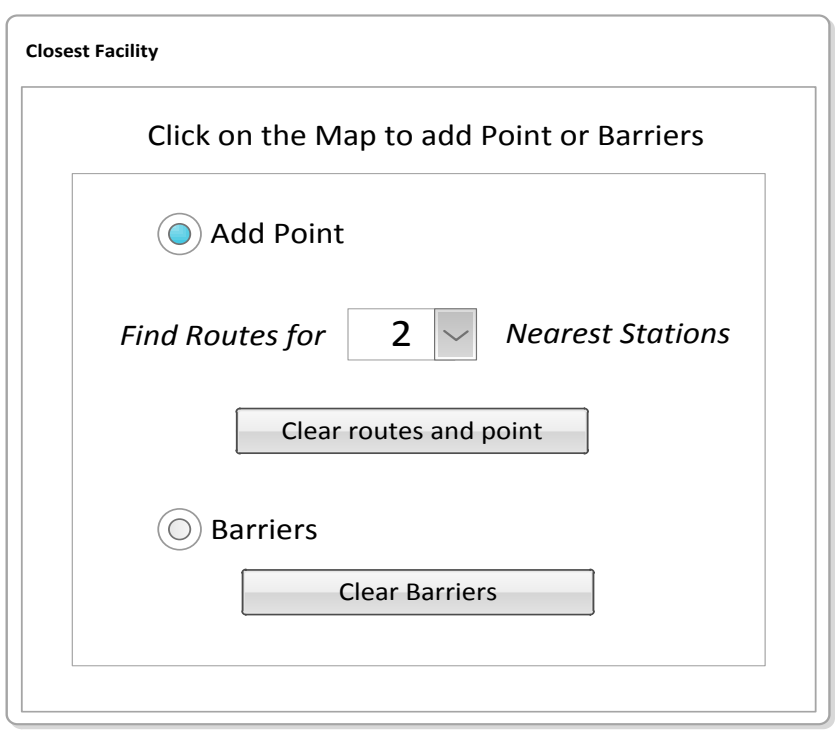

Figure 3-5 Closest Facility window

To analyze the temporal changes in incident distribution, a time slide bar was designed as shown in Figure 3-6. Once the user selects a timeframe, the incidents occurring within the timeframe will be animated by month. The total number of the incidents within selected timeframe will be displayed.

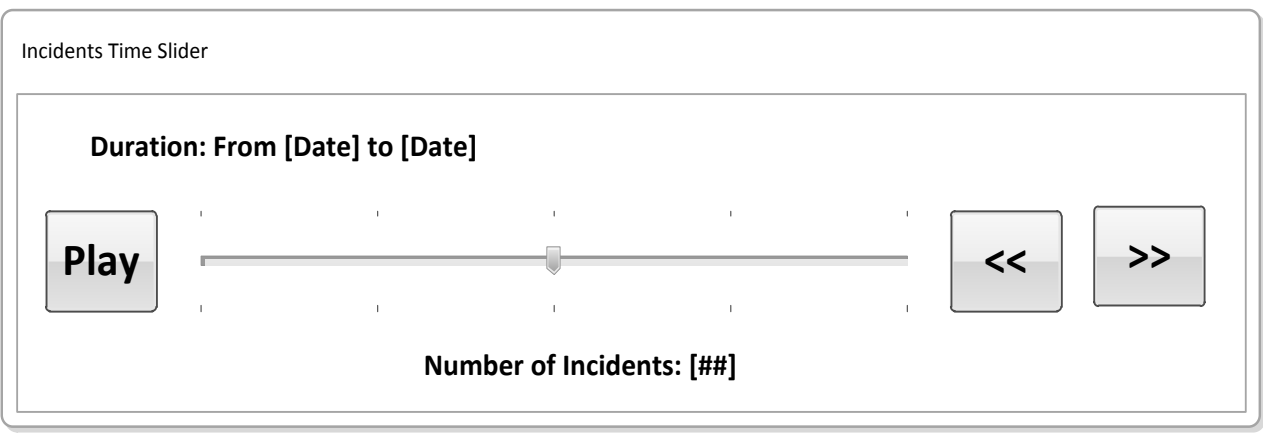

Figure 3-6 Incidents Time Slider window

The Options window (Figure 3-7) was designed to give the user more control on the application. The Option window allows the user to show or hide the all incidents layer, show or hide the selected incidents layer, auto zoom to selected incidents, and use or not use cluster option to view selected incidents. 


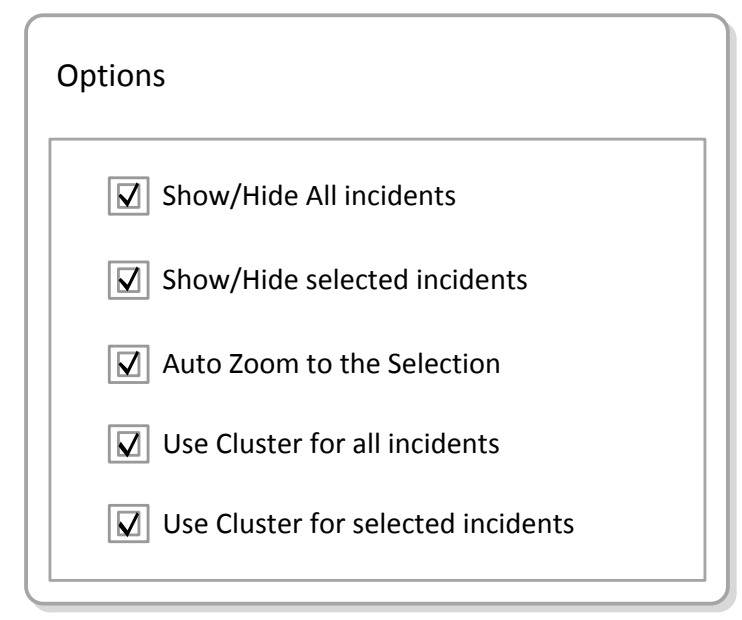

Figure 3-7 Options window

Finally, the Street View window was also included to the application to help the user better understand the local environment. Figure 3-8 shows the Street View window which allows the user to view contents from different sources, such as Bing maps, Google maps, street view, or a combination from these sources (Dual Viewer). This window was designed based on the Street View window which was created by Frank Roberts for Flex Viewer.

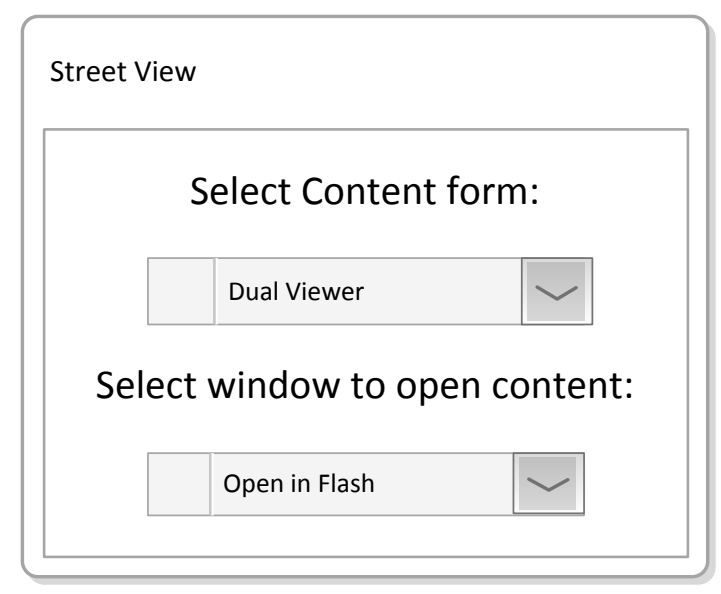

Figure 3-8 Street View window

The implementation of all these components/functions will be described in details in Chapter 5.

\subsection{Project Plan}

Time was a critical factor in the project development life cycle, because losing control of time would affect the project quality. To avoid this situation, the project plan identifying the major tasks and their required time was created. The plan of this project consisted of five major tasks. 
The first task was requirement analysis and design. The main objective of this task was to understand the client's needs and the scope of the project. Also, the functional non-functional requirements and system design were determined as the outcome of this task.

The second task was geodatabase development; during this task the client data were received. The goal of this task was creating the geodatabase and loading the client data. This task took longer than expected, because the data were received as a text file. To insure the data quality and integrity, a tool was developed to perform several validations and load valid data into the created geodatabase.

The third task was training. Learning the basics of the development using Flex and ArcGIS API for Flex was an essential task before starting the implementation task.

System implementation and testing, which was the fourth task, was based on the outcome of the requirements analysis and design tasks. The system was developed and several test cases were conducted to find the bugs and errors.

The final task was system delivery which included submitting the system and documentation to the client.

During the project development life cycle, some modifications in the plan were made. For example the ArcGIS API for Flex was chosen over ArcGIS Viewer for Flex because it provides more flexibility in customization. The project scope was also changed based on available data. For example, the usage of each fire truck was removed from the scope, because this information was not provided.

\subsection{Summary}

The output of the system analysis and design process was a blueprint for the project development. With good system analysis and design outcomes, many risks and problems that can influence projects development can be avoided. Moreover, identifying the required tasks that should be accomplished to deliver the system and put them within the appropriate time frame is important to insure implementing the system within the specified duration. This chapter focused on the system analysis and design and project plan. The next chapter will describe the system database design. 


\section{Chapter 4 - Database Design}

The purpose of a well-designed database is to determine and organize the required data for the project and to avoid data duplication. This reduces the database size and speeds up the search process. This chapter describes the steps that were performed to create the system database, starting from the conceptual data model and ending with data loading.

\subsection{Conceptual Data Model}

The conceptual data model was an effective way to determine the required data for the project. It was used to identify the necessary entities to solve the client's problem and shows how these entities are related.

Figure 4-1 shows the conceptual data model of the project. There are three main entities in this project: Fire_Stations, Incidents, and Fire_Trucks. The relationship between the Fire_Station and Incidents is "responds to" which is a one to many relationship. The Fire_Trucks and Fire_Stations are related by an "assigned to" relationship which is one to many. In addition to these main classes, Service_Area class is connected to the Fire_Stations via an aggregation relationship. The goal of this class is to store the service areas of each fire station on different times, to minimize the calculation time. Finally, the Fire_Trucks and Incidents are related by the association class "Dispatch." This class stores details about the dispatching action, such as the arrival time of the dispatched fire trucks.

Since the network analyses will be done based on the fire stations, two functions were added to the Fire_Stations class. The first function is ClosestFacility which is used to determine closest fire station to a selected location. The second function is ServiceArea which is used to calculate the service area for fire stations based on a given time.

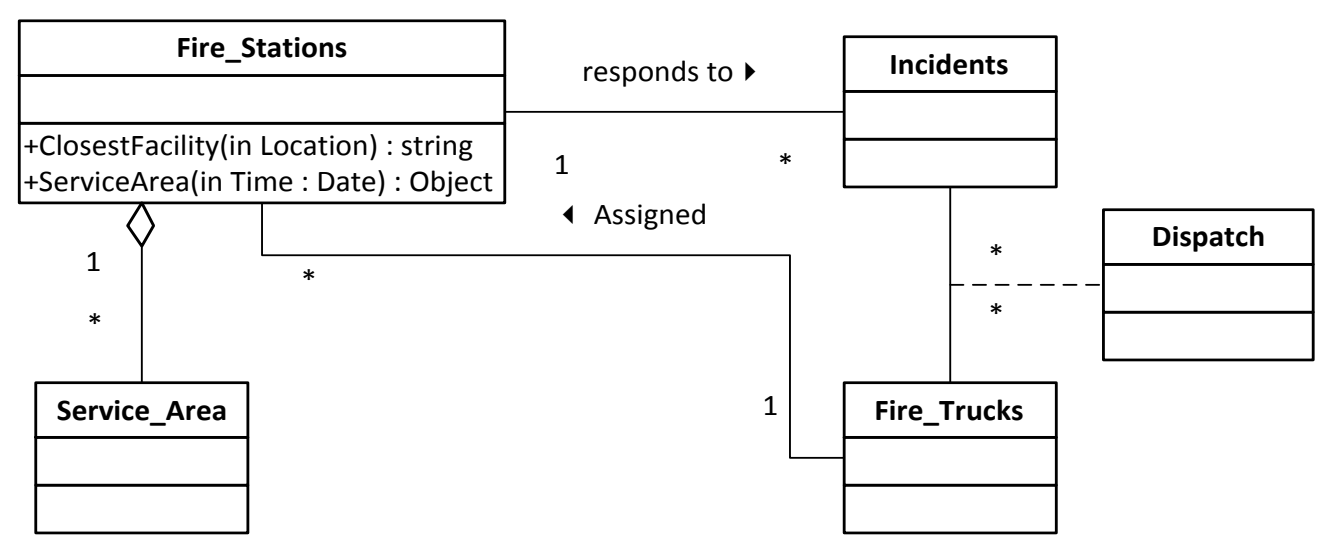

Figure 4-1 Conceptual Data Model of the project 


\subsection{Logical Data Model}

Unlike the conceptual data model, the logical data model shows more details about the identified entities. Thus, the required attributes and their data types are specified in that data model.

The database of this project has two feature classes — Incidents and Fire_Stations and two main tables, which are Incidents_Types and Fire_Trucks. In addition to these tables, standard table, which is based on the schema that was given from the client, is used in the loading incidents process.

Figure 4-2 shows the logical data model of the project database. Some modifications were made on the conceptual model based on the available data and the client's actual needs. Because client was interested in when the first fire truck arrives at the incident location, the information on this truck is stored in the incidents class instead of in the association class. In addition, a new class was created to store incidents type information. This class works as a lookup table for incidents types. Moreover, Service_Area class was removed, since there are no needs to store the service areas because the time is not critical since the application will not be used in the emergency response, but it will be used in the analysis process. In addition, storing the service area of each fire station will make difficult to handle the overlaps between the service areas in the application, because they should be clipped to remove the overlapped portions.

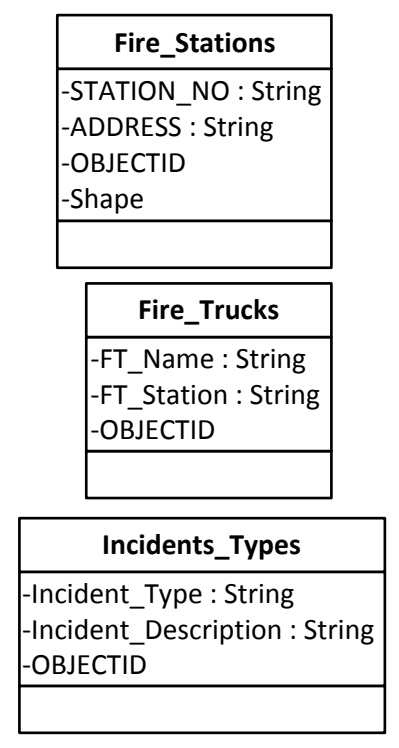

\begin{tabular}{|l|}
\hline \multicolumn{1}{|c|}{ Incidents } \\
\hline -Inc_key : String \\
-Inc_address : String \\
-Inc_city : String \\
-Inc_zipcode : String \\
-Inc_station : String \\
-Inc_AlarmTime : Date \\
-Inc_Type : String \\
-Inc_ArrivalTime : Date \\
-Inc_ClearTime : Date \\
-Inc_EmergencyResponseTime : Single \\
-Inc_TotalTime : Single \\
-Inc_HandleTime : Single \\
-Inc_1stFireTruck : String \\
-OBJECTID \\
-Shape \\
\hline
\end{tabular}

\begin{tabular}{|l|}
\hline \multicolumn{1}{|c|}{ standard } \\
\hline -INC_key : String \\
-INC_AlarmTime : String \\
-INC_1stCompany : String \\
-INC_GISAddress : String \\
-INC_City : String \\
-INC_Station : Date \\
-INC_IncType : String \\
-INC_IncDesc : Date \\
-INC_ArrivalTime : Date \\
-INC_ClearTime : Single \\
-INC_ZipCode : String \\
-OBJECTID \\
\hline
\end{tabular}

Figure 4-2 Logical Data Model of the project

The Fire_Stations feature class contains the fire station names and their addresses, and the primary key is STATION_NO. The Incidents_Types table stores incident type codes and their descriptions, and the primary key is Incident_Type. The Incidents feature class stores information about the incidents, such as Inc_Key, address, and clear time. The Inc_Key is the primary key of this feature class. The Inc_Station, Inc_Type, and Inc_1stFireTruck are foreign keys used to connect the incident with its related fire 
station, incident type and Fire_Trucks, respectively. Finally, the primary key of the Fire_Truck table which stores fire trucks information is FT_Name

\subsection{Data Sources}

A sample of incidents data was provided in a comma delimited text file, which was exported from the client's existing system. To understand the data and their structure, the file was converted to an Excel file. Table 4-1 shows the main fields in the provided text file. The file contained incidents records between 31 December 2009 and March 2011. In addition, the fire stations data were provided in a shapefile format.

Table 4-1 Main fields in the provided text file

\begin{tabular}{|c|c|}
\hline Field name & Description \\
\hline INC_Key & Incident ID \\
\hline INC_AlarmTime & Incident informed time \\
\hline INC_1stCompany & First fire truck arrived to the incident location \\
\hline INC_GISAddress & Incident address \\
\hline INC_City & City \\
\hline INC_ZipCode & Zip code \\
\hline INC_Station & Fire station \\
\hline INC_IncType & Incident type code \\
\hline INC_IncDesc & Incident Description \\
\hline INC_DispTime & Dispatch time \\
\hline INC_EnrouteTime & En route time \\
\hline INC_ArrivalTime & Arrival time \\
\hline INC_ClearTime & Finish time \\
\hline
\end{tabular}

The Redlands Fire Department follows the National Fire Incident Reporting System (NFIRS). Since the standard incidents types and their descriptions were not provided, the website of the NFIRS (http://nfirs.fema.gov/) was used to get this information, which was found in an Excel sheet named NFIRS_Spec_Tables_2009 that contains all codes that are used in NFIRS. After approval from the client, these data were used as the source for the Incidents_Types table.

Finally, The World Topographic map service was used as basemap of the application. 


\subsection{Data Scrubbing and Loading}

Before the beginning of the data loading process, the geodatabase schema was created based on the conceptual and logical data models. The fire stations data and the incidents data were tested before loading them to the geodatabase to ensure the integrity and the accuracy of the data. Several validations were performed, like testing if there were incidents records that had missing attributes. Some fields were calculated before data loading, such as emergency response time, arrival time, and total time. After all that, a geocoding process was done on the valid incidents.

Since the scrubbing and loading process for the incidents data will be done frequently based on the client needs for the future use of the application, a tool was implemented to handle this process. This tool is described in detail in Chapter 5. About $78.9 \%$ records from the total records were successfully added to the database, and the other data were removed due to various reasons that will be further discussed in Chapter 5. These records added to the geodatabase were used for testing and building the application.

All tables and feature classes were exported into the ArcSDE geodatabase, since the client has ArcSDE geodatabase in their environment. ArcSDE geodatabase can store a large amount of data without affecting the performance of data manipulation.

\subsection{Summary}

This chapter discussed how the project database schema was generated using the conceptual data model and the logical data model. Both data models were used to identify the necessary entities and their attributes to meet the client's needs. The second part of this chapter focused on the database implementation. 


\section{Chapter 5 - Implementation}

Two components were developed to meet the client's requirements: an Import Incidents tool which was implemented using ModelBuilder and Python scripts; and a web-based application, which was used to analyze the fire incidents. This chapter discusses the implementation of these components.

\subsection{Import Incidents Tool}

The Import Incidents tool was developed in the project to import the data provided by the client to the system. Moreover, it will be used frequently on a large number of new incident data in the future when the client needs to update the system database. This tool consists of multiple processes to check data integrity, and ModelBuilder and Python scripts were used to implement this tool.

Figure 5-1 shows the workflow of importing incident data using the Import Incidents tool. In this project, data were exported from the existing system as a text file, and then converted to an Excel file before using the tool. The tool uses the converted file as input and its output is an Excel file that contains the status of each incident. The user can view which items were inserted successfully, and which could not be inserted. For the items that were not inserted successfully, a reason will be given. The user can then fix any errors and repeat the process using the output file.

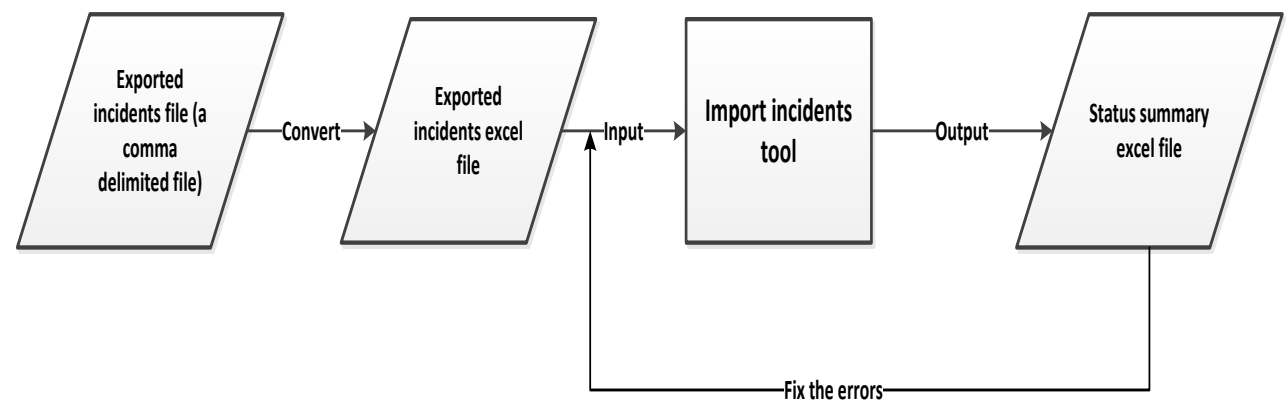

Figure 5-1 Import incidents data workflow

Figure 5-2 shows the interface of the Import Incidents tool. This tool allows the user to set the input table; match the fields; specify the output file format, which is either comma separated values (CSV) or Microsoft excel file format (XLS); and set the location of the output file. 


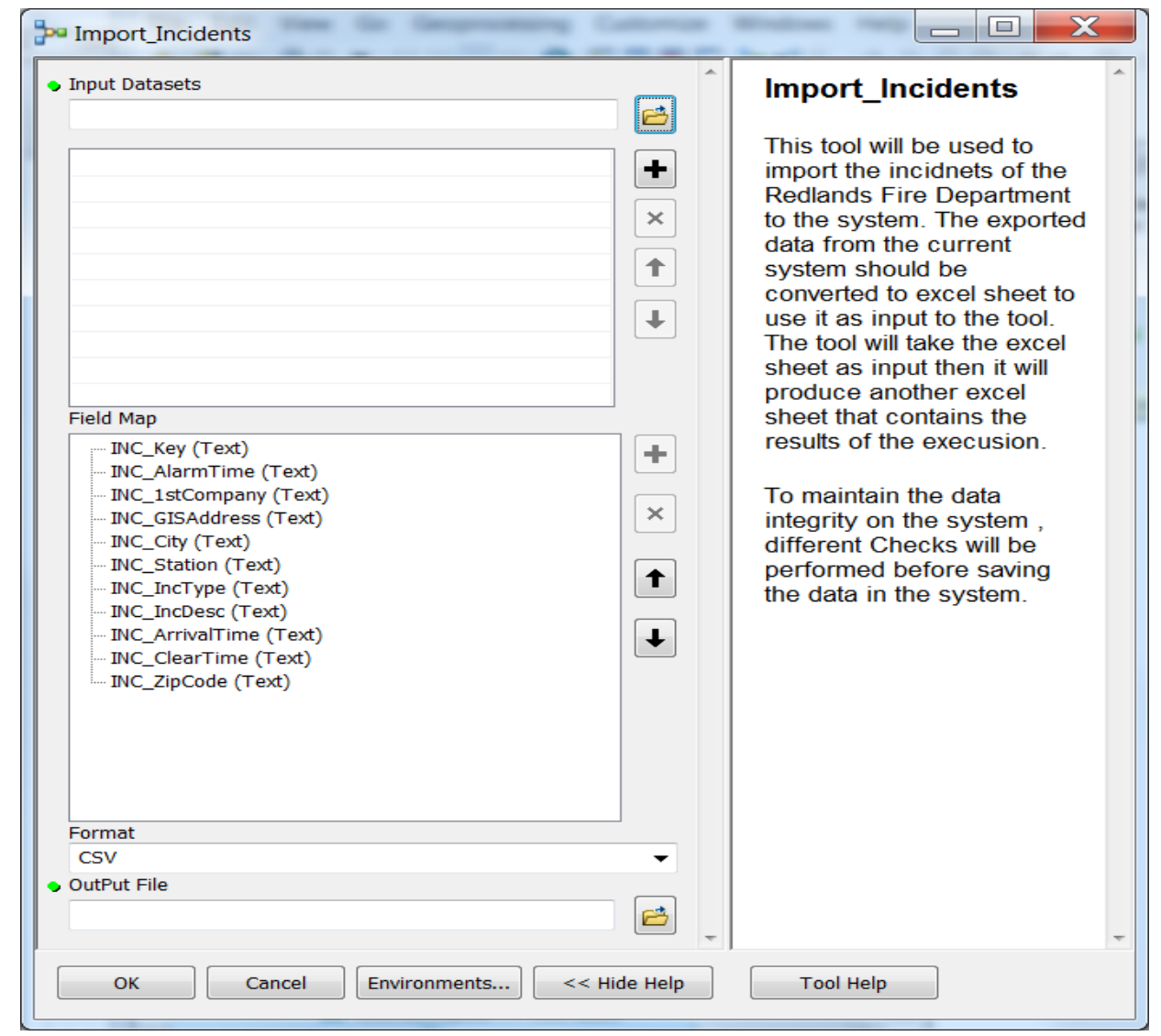

Figure 5-2 Import incident tool interface

The tool performs several tasks, including copying incident data, validating records, geocoding, performing field calculations, and exporting the results into an Excel file or CSV file. The following sections describe how these tasks were accomplished in this project. The tool model is provided in Appendix 1.

\subsubsection{Copy incident data}

The data import process started by creating a test table based on the standard table schema that was used in the client's existing database. The Append tool was used to copy the data from the input Excel sheet to the test table based on the field matching that was specified using the field map section in the tool interface. Subsequently, status and description fields were added to the test table to store the status of each incident record.

\subsubsection{Validations}

Many validations were performed on the imported data to avoid data inconsistency and to ensure the data integrity and quality. Because most fields were used in the application, these fields (such as Inc_key, Inc_address, and Inc_AlarmTime) should not be empty.

The first step in the validation process was to check if there were empty fields. The second step was to check if the Inc_key followed the standard format. The Inc_key should consist of 25 characters; it must start with "CA", and the rest of the characters 
should be numbers. The third step was to check if the incident ID already exists in order to avoid the duplication of incidents.

To maintain the relationship between the incident and its incident type, the fire station, and the fire truck that dealt with it, the existence of these attributes were checked across other related tables.

Finally, the time fields, which are incident time, incident arrival, and incident clear time, were checked to verify their sequence and their date and time format.

\subsubsection{Geocoding}

Once validated, the incidents records were geocoded. The Import Incidents tool uses an online address locator: the North American Address Locator. After this process, the tool selected the matched records with a score of 90 and inserted them into the incidents feature class using InsertCursor. On the other hand, the tool wrote the status of unmatched records in the status and description fields in the test table.

\subsubsection{Fields Calculation}

Several fields that were used in the web application were calculated: the emergency response time, which is the difference between the arrival time and the incident time; the handle time, which is the difference between the clear time and arrival time; and the total time, which is the difference between the clear time and the incident time. This process was accomplished by selecting the inserted records from incidents feature class using MakeFeatureLayer, and using Calculate Field to calculate the value. This process was repeated to calculate each value separately, since Calculate Field tool is used to calculate one value at a time. Table 5-1 shows the equations that were used to calculate the emergency response time, handle time, and total time. These times are measured in minutes.

\section{Table 5-1 The Field Calculations Equations}

\begin{tabular}{|l|l|}
\hline \multicolumn{1}{|c|}{ Field } & \multicolumn{1}{c|}{ Equation } \\
\hline Emergency Response Time & ( [Inc_ArrivalTime]- [Inc_AlarmTime] $* 24 * 60$ \\
\hline Handle Time & ( [Inc_ClearTime]-[Inc_ArrivalTime] $* 24 * 60$ \\
\hline Total Time & ( [Inc_ClearTime]-[Inc_AlarmTime] $* 24 * 60$ \\
\hline
\end{tabular}

\subsubsection{Results Exporting}

Finally, the test table was exported to an Excel file by using a Table to Excel script that was downloaded from ArcGIS Resource Center. The exported file contains the status codes and the description of each record. The status code of each record indicates whether the record was successfully added into the system database and what problems had occurred if it was not. Each record will have only one status. Table 5-2 provides the 
descriptions of these status codes. The codes were designed in that way to allow the user to group the results based on their category. Also, several new codes can be added in the future without affecting the sequence of the current codes. After exporting the results, all intermediate tables like test table will be deleted. 
Table 5-2 Status Code and Description

\begin{tabular}{|c|l|}
\hline Code & \multicolumn{1}{|c|}{ Description } \\
\hline $\mathbf{9}$ & Incident was added successfully \\
\hline $\mathbf{1}$ & Checking if one of the mandatory fields is empty \\
\hline 1.1 & Incident ID is empty \\
\hline 1.2 & Incident Time is empty \\
\hline 1.3 & Arrival Time is empty \\
\hline 1.4 & Clear Time is empty \\
\hline 1.5 & Incident Address is empty \\
\hline 1.6 & Fire Station is empty \\
\hline 1.7 & Incident Type is empty \\
\hline 1.8 & City is empty \\
\hline 1.9 & Zip Code is empty \\
\hline $\mathbf{2}$ & Checking if the Incident ID follows the standard \\
\hline 2.1 & The Incident ID is more than or less than 25 characters \\
\hline 2.2 & The Incident ID does not follow the standard 'Not start with CA' \\
\hline 2.3 & The Incident ID does not follow the standard 'it has letters other than CA' \\
\hline $\mathbf{3}$ & Checking if the incident ID already exists \\
\hline 3.1 & The Incident ID exists in the incidents \\
\hline 3.2 & The incident ID exists in the imported file more than once \\
\hline $\mathbf{4}$ & Checking the relations with other tables \\
\hline 4.1 & The Fire Truck is not in the FireTrucks Table \\
\hline 4.2 & The Fire Station is not in the FireStations Table \\
\hline 4.3 & The Incident Type is not in the IncidentType Table \\
\hline 4.4 & $\begin{array}{l}\text { Incident Description not matched with existing incident descriptions for the } \\
\text { incident ID }\end{array}$ \\
\hline $\mathbf{5}$ & Checking the date and time fields \\
\hline 5.1 & Problems in time sequence \\
\hline 5.2 & The Incident Time is not in the standard format '\%m/\%d/\%Y \%I:\%M:\%S \%p' \\
\hline 5.3 & The Arrival Time is not in the standard format '\%m/\%d/\%Y \%I:\%M:\% \%p' \\
\hline 5.4 & The Clear Time is not in the standard format '\%m/\%d/\%Y \%I:\%M:\%S \%p' \\
\hline $\mathbf{6}$ & Checking the geocoding results \\
\hline 6.1 & Address Unmatched \\
\hline 6.2 & Score Below 90 \\
\hline 6.3 & Zip Code or City not in the matched address \\
\hline
\end{tabular}


This tool was used to load the incident data that were received from the client. The data were grouped based on the month, and then the tool was used to import the incidents data. Table 5-3 summarizes the results of this process. Since the main problem in the data was the inaccuracy of the addresses in most of the incidents records, the client was notified about the problem to avoid it in the future. The total incidents number of records was 10408 , the total number of successfully saved records was 8211, and the total number of unsaved records was 2197.

Table 5-3 Results of Data Loading

\begin{tabular}{|c|c|c|}
\hline Code & Type & Total \\
\hline 1.1 & Incident time is empty & 6 \\
\hline 1.3 & Arrival time is empty & 1 \\
\hline 1.4 & Clear time is empty & 1 \\
\hline 1.5 & Incident address is empty & 2 \\
\hline 4.1 & The Fire Truck is not in the FireTrucks Table & 10 \\
\hline 6.1 & Address Unmatched & 10 \\
\hline 6.2 & Score Below 90 & 1507 \\
\hline 6.3 & Zip Code or City not in the matched address & 660 \\
\hline
\end{tabular}

\subsection{The Web Application Development}

Developing the web application to meet the client requirements was the main focus of this project. In order to develop an interactive Rich Internet Application (RIA), a Flex framework was chosen for the development process. This section focuses on how the web application was developed.

\subsubsection{Publishing the Map Services}

Map services are one of the major components in web GIS applications because the application communicates with the database through them. In this project, three map services were published: incidents that included all incidents' locations details like occurrence times and fire stations that were dealt with these incidents, incident types that was a table that stores incident codes and their description, and fire stations containing all fire station locations and names.

The first step in publishing map services is authoring the map documents. In this step, three map documents were prepared. Each map document had a layer that points to the required data. The symbology was set for both incidents layer and fire stations layer. 
Because temporal analysis function was one of the client requirements, temporal animation was enabled in the incidents layer property and the time attribute that indicated when the incidents occurred was specified (Figure 5-3). So after selecting the analysis duration, the user can use the Time Slider window to visualize the incidents by months. When the Time Slide window opens, start and end dates are generated. The user can then select the time slider stops. When the user changes the time extent, the time definition property of the feature layer that is used to display incidents changes to the new extent.

Unlike the incidents and fire stations map documents, the incident type did not have symbology, because it only points to the incidents types table.

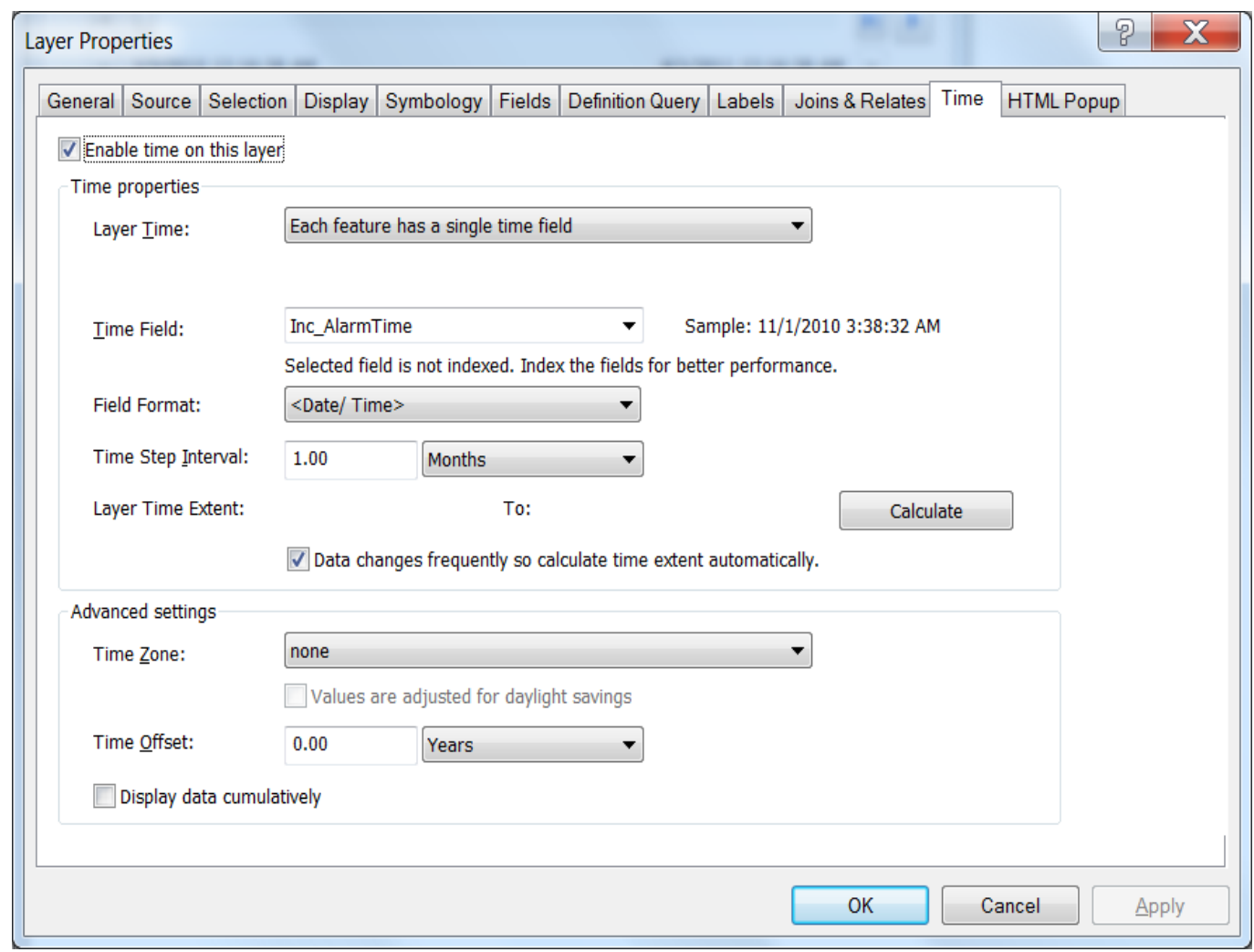

Figure 5-3 Time properties of the incidents layer

After authoring the map documents, the second step was to use the Map Service Publishing toolbar to analyze the map documents. This step was to fix any errors or to avoid warnings that could affect the performance of the map services. This step was completed using ArcMap 10.

The final step was to publish the map documents to ArcGIS Server 10 using ArcCatalog 10. The default maximum number of records returned by the server was 1,000 for each service. This number was changed to " $1,000,000,000$ " for the incidents map service, to accommodate the large number of incidents that can be selected by the user. This change was done by stopping the service, changing the value from service properties, and then restarting the service. 


\subsubsection{Building the Web Application}

The proposed application was developed using the Flex environment because it has extensive libraries of components, such as charts and data grids, that were used to meet the project goals. Flex SDK 4.6 was used with ArcGIS API for Flex version 2.5. Flash Builder 4.6 was also used as the IDE for the application development. The first step was to install the latest version of Flash Builder, and then imported the Shockwave Flash Component (SWC) file of the ArcGIS API for Flex to the created Flex project. Generally, SWC files are used to store classes, components, and assets to distribute and reuse them in other applications (Ahmed, Hirschi, \& Abid, 2009). This section details how the main functions and components were developed in this environment.

\subsubsection{Map Component}

The map component is very important in the web GIS applications, because it holds the layers that are used to show map features.

Because the application is focused on the city of Redlands, the initial extent property of the Map component was set as follows: $x \max ="-13043827.765 "$, ymax="4036937.772", xmin="-13045738.691", and ymin="4035504.578". These settings ensure that the map component shows the City of Redlands when the application is opened.

Three types of map service layers were used in the project: Graphic Layer, Feature Layer, and ArcGISTiledMapServiceLayer. The first type (ArcGISTiledMapServiceLayer) was used to view the basemap, because it is used to display the cached map services. The second type (Graphic Layer) was used to show the results of the analyses (such as service area analysis), and the parameters of some functions (such as the barrier points for closest facility analysis). The symbology of the graphic layers should be set manually, so the renderer property was used. There are two types of renderers. A simple renderer was used to set the same symbology for all features, such as barriers graphic layer so all barriers will have the same symbol. A unique value renderer was used to set different symbologies for different features; an example of this would be setting different colors for the results of closest facility analysis. Table 5-4 shows all graphic layers that were used in the application. 
Table 5-4 Applications' Graphic Layers

\begin{tabular}{|c|c|c|c|}
\hline $\begin{array}{c}\text { Graphic Layer } \\
\text { Name }\end{array}$ & Usage & Renderer Type & Image \\
\hline $\begin{array}{l}\text { resultsGraphics_ } \\
\text { Layer }\end{array}$ & $\begin{array}{l}\text { Show the results of } \\
\text { the service area } \\
\text { analysis }\end{array}$ & Uniquevaluerenderer & \\
\hline glFindAddress & $\begin{array}{l}\text { The results of the } \\
\text { geocoding process }\end{array}$ & Simple & \\
\hline $\begin{array}{l}\text { routeGraphics_ } \\
\text { Layer }\end{array}$ & $\begin{array}{l}\text { The results of } \\
\text { closest facility } \\
\text { analysis }\end{array}$ & Uniquevaluerenderer & \\
\hline $\begin{array}{l}\text { barriersGraphics_ } \\
\text { Layer }\end{array}$ & $\begin{array}{l}\text { Show barriers for } \\
\text { closest facility } \\
\text { analysis }\end{array}$ & Simple & \\
\hline graphicsLayer & $\begin{array}{l}\text { Show the selected } \\
\text { location for using } \\
\text { street view }\end{array}$ & Simple & \\
\hline $\begin{array}{l}\text { incidentsGraphics_ } \\
\text { Layer }\end{array}$ & $\begin{array}{l}\text { Show the selected } \\
\text { location for closest } \\
\text { facility analysis }\end{array}$ & Simple & \\
\hline
\end{tabular}

Unlike graphic layers, feature layers use the symbology of the original map document, so there is no need to specify the symbology. Since the feature layers have a definition query property, the queries can be done directly. In addition, feature layers come in three modes: Snapshot mode, On demand mode, and Selection mode. Snapshot mode is used to retrieve all features at once, On demand mode is used to retrieve features that are within the viewing extent, and Selection mode is used to retrieve the selected features. Table 5-5 shows all feature layers that were used in the application. 
Table 5-5 Applications' Feature Layers

\begin{tabular}{|l|l|c|c|}
\hline Feature Layer Name & \multicolumn{1}{|c|}{ Usage } & Mode & Image \\
\hline fireStations & Show fire stations & snapshot \\
\hline flAllIncidents & Show all incidents & selection \\
\hline flselectedIncidents & $\begin{array}{l}\text { Show the selected } \\
\text { incidents }\end{array}$ & $\begin{array}{l}\text { Show the incidents } \\
\text { which are within the } \\
\text { timeframe of the } \\
\text { timeslider }\end{array}$ & snapshot \\
\hline
\end{tabular}

Because there are more than 200 potential incident types, using different colors to symbolize the incidents by types could potentially confuse the user. Thus, a tooltip was set for each incident to show the incident type. The tooltips were set in "add graphic event" which is one of the feature layer events.

The popup menus were used to provide the user with more information about the incidents. The information shown in the popup menus are: Incident ID, Alarm Time, Arrival Time, Clear Time, emergency response time, Handle Time, Total Time, Fire Station, and Address. The popup menus were configured using the InfoWindowRenderer property of the feature layers.

\subsubsection{Data representation}

When the selected duration contains a high number of incidents, the map will be unreadable because these incidents overlap. A clustering process, provided by ArcGIS API, was used to solve this problem. The clustering process groups the nearby points into a single point. The grouping distance is dynamic depending on the map scale. Figure 5-4 shows the difference clustering makes in the map display. In the map on the left, clustering has not been used. In the map on the right, clustering has been used. 


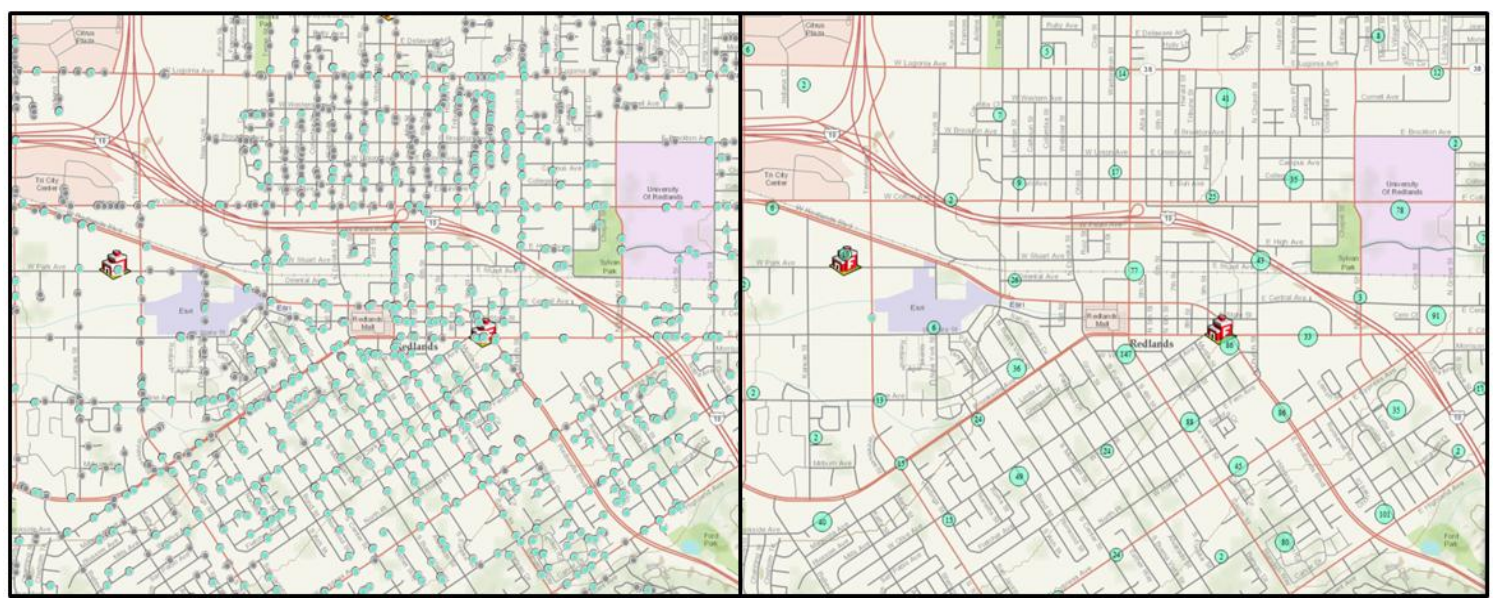

Figure 5-4 Map without Clustering and Map with Clustering

A WeightedClusterer component was used to implement the cluster process by assigning it to the Feature Layer using clusterer property of the Feature Layer. To remove cluster, a null value should be assigned to the clusterer property of the Feature Layer. Cluster is used in selected Incidents Feature Layer and all Incidents Feature Layer. The FlareSymbol component was used with WeightedClusterer. Figure 5-5 shows the effect of using FlareSymbol with the WeightedClusterer component. The FlareSymbol component was assigned to the WeightedClusterer component using the symbol property of the component. Several properties were used to configure FlareSymbol. backgroundAlpha, was set to 0.6. backgroundColor was set to 0x66FFCC.

flareMaxCount, was set to 30; this means that the maximum cluster size that can be flared is 30. flareSizeIncOnRollOver was set to 3. Weights was set to [30, 60]; this was used to set breaks and the size for each break was set using size property [20, 30, 60]. Therefore, the size of the cluster from 2 to 30 will be 20, the size of the cluster from 31 to 60 will be 30 , and the size for a cluster whose value is greater than 60 will be 60 . This feature helps the user imagine the amount of the incidents in the cluster.

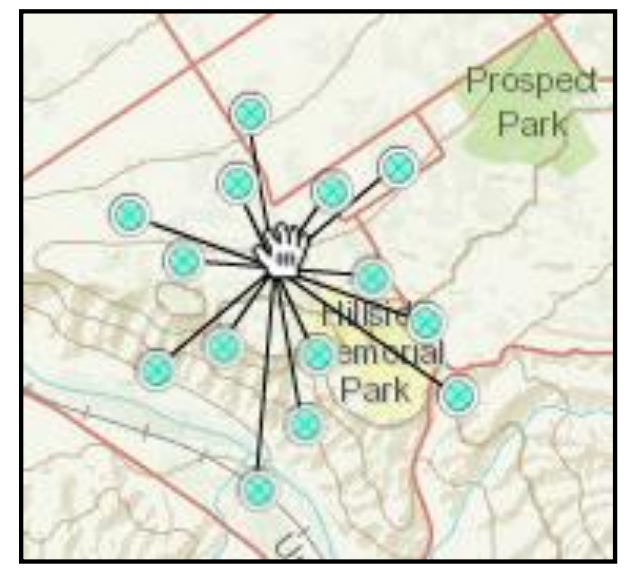

Figure 5-5 Flare Cluster 


\subsubsection{Find Address}

The find address function was based on an online address locater, provided by Esri that can be changed using the application configuration file. The function accepts three parameters: the address, an array of values that are needed in the output (for example, loc_name), and AsyncResponder (which is used to define the onresult and onfault functions).

If the address is successfully returned, a new graphic will be created and added to the glFindAddress graphic layer. Based on the results of the geocoding (Table 5-6), the map scale will be changed correspondingly.

Table 5-6 Map Scales for the Geocoding results

\begin{tabular}{|c|c|}
\hline Result Type & Scale \\
\hline Street Number & 10000 \\
\hline Street & 15000 \\
\hline Zip code & 20000 \\
\hline City & 150000 \\
\hline
\end{tabular}

\subsubsection{Street View}

Visiting the sites that have a high concentration of incidents is an important task that needs to be completed by the incident analyst in order to understand the causes of the concentration. In order to assist the incident analyst in performing this task, a window that provides a connection to the Google Street view was included in the application. Using this window, the user can select a point on the map and view panoramic images of the selected point. This was created based on the Street View widget that was created for Flex Viewer by Frank Roberts. The source code was downloaded from the code gallery of ArcGIS API for Flex in the ArcGIS Resource Center. The widget views the data from different sources, such as Google maps, Street View, and Bing. The data is displayed using mapchannels.com which defines the interface and the arrangement of display. The Street View window allows the user to select different views, such as Dual Viewer, Bing Maps, Google Map, and Street View. Figure 5-6 shows examples of different interfaces that are provided by mapchannels.com. 

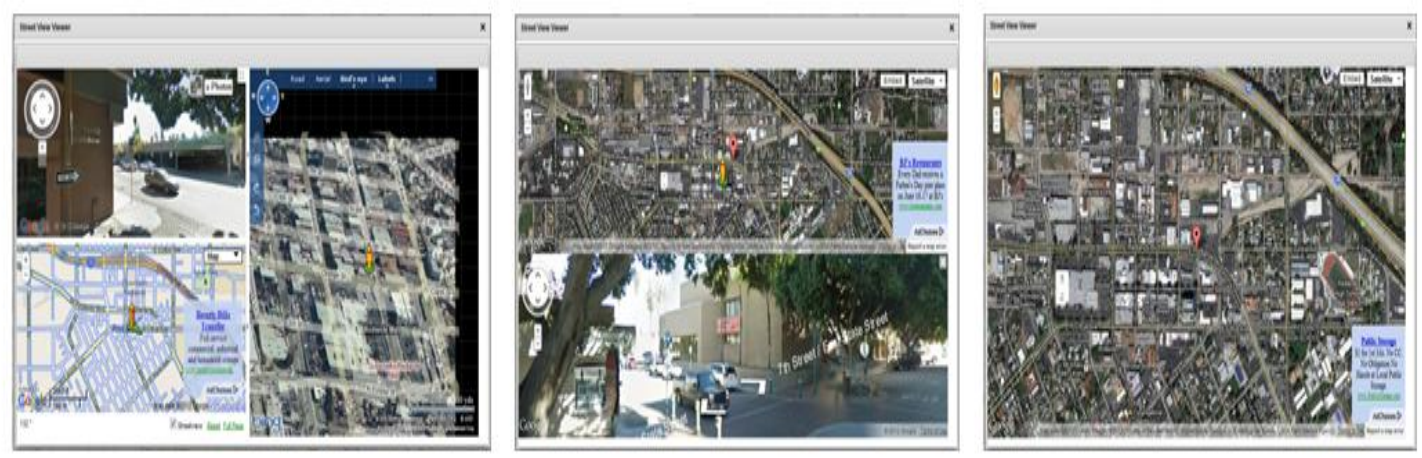

Figure 5-6 Different Interfaces for Street View

These interfaces were determined using the URL, so there is URL provided for each interface. The coordinates of the selected point were included in the specified URL based on the selected interface.

In order for the code to work on the standalone application outside of Flex Viewer, some modifications were made to replace the parts related to the Flex Viewer. The WebForm.mxml component that is used to display the images and interfaces was imported to the project. Also, flex-iframe-1.4.6.swc library was downloaded from Google Code and imported to the application library.

\subsubsection{ActionScript Classes}

ActionScript is an object-oriented programming language that is used to develop applications in Flex platforms with MXML. MXML is based on XML and is used to implement the application interface. ActionScript is the main language in that platform, so all MXML tags will be converted to ActionScript statements in the process of compiling the code of the application (Labriola, Tapper, \& Boles, 2011).

Displaying incident statistics using charts, tables, and map was one of the most important requirements of the project. This was implemented by developing ActionScript Classes. The idea was to create basic classes that store essential information about the objects and methods, such as increment and reset count values, to access the stored data. Instead of dealing with each object individually, collection classes were created to store the created objects in ArrayCollections, which contain methods to access all stored objects. At the end, all collections classes were stored in a parent class named ChartsDataCollection to manage the requests for collection classes (Figure 5-7). 


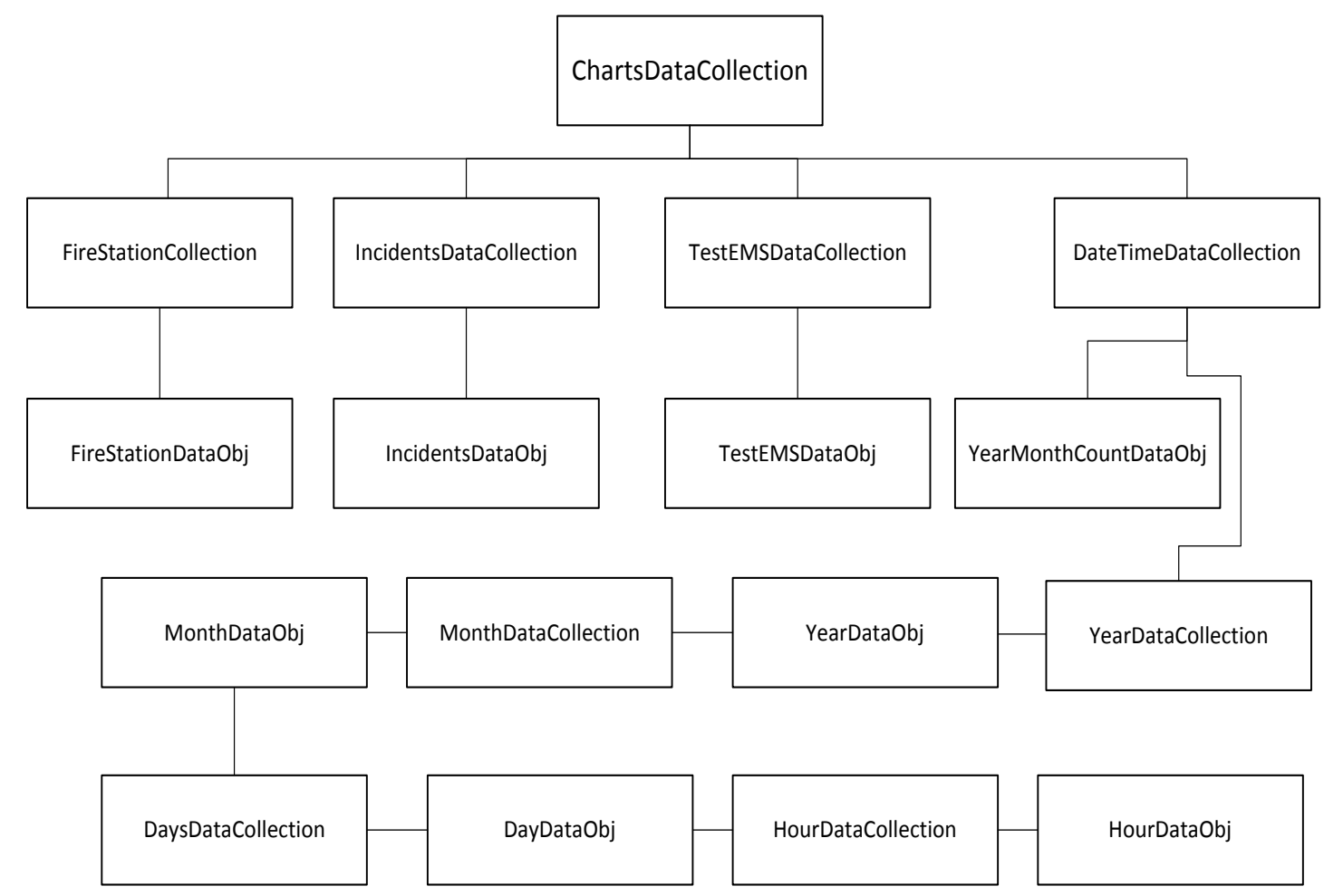

Figure 5-7 ActionScript Classes

FireStationDataObj class was used to create fire station object that has the fire station name and the number of the incidents that were dealt with by this fire station. Because the Redlands Fire Department has four fire stations, four objects from this class were created. IncidentsDataObj class was implemented to create incidents objects which contain incident code, incident type, code level, and total number of the incidents of this type. One object from this class was created for each incident type. The TestEMSDataObj class was used to store the number of incidents that had an emergency response time above and below the specified value in the Analyze Emergency Response Time window. So when the user uses the Analyze Emergency Response Time window, two objects will be created, based on this class, in order to store above and below counts.

All objects are stored in ArrayCollections. Thus, the objects of FireStationDataObj are stored in the FireStationCollection, IncidentsDataObj objects are stored in IncidentsDataCollection, and TestEMSDataObj objects are stored in TestEMSDataCollection. These collection classes contain methods that are used to determine the value of the object that should be incremented. Also, they contain methods to reset the count of all objects.

The same concept was applied on DateTimeDataCollection, except the data needed to be stored in a different time and date level. Thus, different DataObj and DataCollection classes were created. For example, YearDataCollection has an ArrayCollection to store YearDataObj objects. Each YearDataObj has an ArrayCollection to store the year's months, which are stored in MonthsDataCollection and so on. YearMonthCountDataObj 
is a special class that is used to connect to the distribution of the incidents over months, so it contains the year, month, and count.

ChartsDataCollection is a parent class that stores the objects of collection classes. Also, it serves as data provider for the charts and tables that are used in the Show Statistics window. The ChartsDataCollection methods receive the data, and then it calls the appropriate functions in the Collection Classes.

This data structure was useful in the development of the Show Statistics window, because handling and managing all the data with different user actions separately is very difficult. Moreover, this structure is reusable, so the functions can be used multiple times in different events. The code can also be extended easily by adding more functions without affecting the other functions or classes. Finally, managing and tracing the errors is simple because of the encapsulation feature of the object-oriented programming language, so the changes are done on the functions but not on the entire code.

The fire stations and the incident types data are retrieved when the system is being initialized. On the other hand, the incident data are retrieved after specifying duration. The calculations and the user selections are handled using ChartDataCollection methods.

\subsubsection{Show Statistics and Analyze Emergency Response Time windows}

In order to retrieve data from the map services, two query components were used: Query and QueryTask. The Query component was used to specify the parameters for QueryTask, such as the where statement and returned fields. The QueryTask component was used to execute queries based on the Query components and handle the queries results.

Because incident types and fire stations are static, their queries are executed at the beginning of the session, and their results are handled using ActionScript classes as described in Section 5.2.2.5. Unlike incident types and fire stations, incidents are dynamic, and different types of queries will be executed based on the user selection. All incident queries should be within a specified duration, so a time extent property of Query component was used for this purpose.

The Show Statistics window consists of several visual elements, such as a pie chart, column bars, and tables. The pie chart was used to show the percentage of the selected incidents based on the incident types. Since the incident types have three levels of detail, this was implemented by allowing the user to click on the chart to navigate from one level to the next level. Figure 5-8 shows the navigation from fire incident to the details of structure fire incident type. Figure 5-8a shows the first level, which contains the main incident types. Figure 5-8b shows the details of fire incident type, which was displayed after clicking on fire segment. Figure 5-8c shows the sub categories of the structure fire incident type, which was viewed after clicking on the structure fire incident type. 
a.

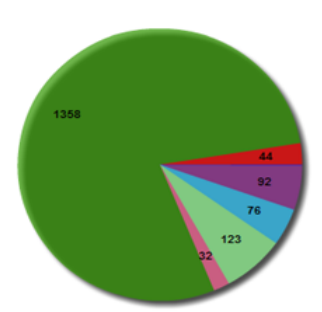

Incidents Categories

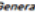

Fine

V Rescue 8 Emergency Medical Service Incident

III. Hasardous Condition (Mo Fire)

service Call

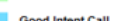

II False Alarm \& False Call

Severe Weather \& Hatural Disaster.

b.

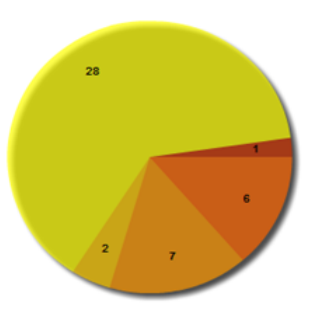

Incidents Categories

II Fire, other

Structure Fire

Gre in mobilie property used

Mobile property (vehicle) fire
Outside rubbish fire

Ir Outside rubbish fire

c.

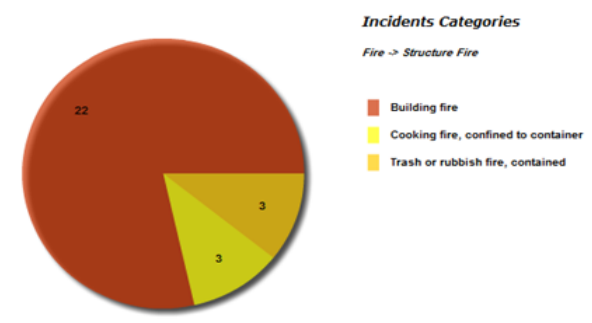

\section{Figure 5-8 Navigation between Incident Types Levels}

This process was implemented by using the structure of the incident code. The incident code consists of three digits. The leftmost digit represents the first level; for example, 1 is used for fire. The leftmost digit and the middle digit represent the second level; for example, 11 is used for structure fire incident type. The whole code represents the detail level; for example, 111 represent a building fire.

In addition to the navigation between the different levels of the incident types, the user can focus his analysis on one incident type. This is done by double clicking on the incident type (Figure 5-9), which will refresh all components based on the selected incident type.

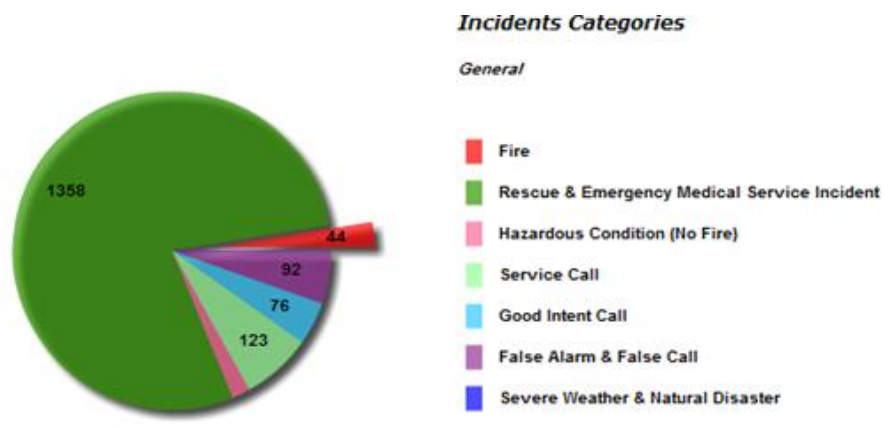

Figure 5-9 Selecting Incident Type 
The fire stations column bar chart (Figure 5-10) shows the distribution of the incidents over the fire stations based on the selected incidents and duration. The user can focus on one fire station by clicking on that particular fire station, and the values of all charts and other components will be recalculated based on the selected fire station.

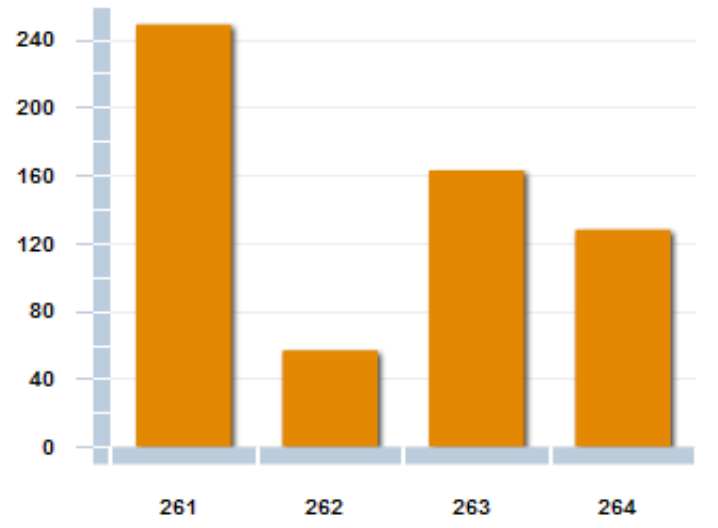

Figure 5-10 Fire Stations Column Bar Chart

The Months Column Bar Chart (Figure 5-11) shows the number of incidents in each month within the selected duration. This was accomplished by determining the months within the selected duration, then calculating the amount of incidents within each determined month using ActionScript Classes. This component will be populated with the data when the user specifies the duration, selects the incident type, or selects the fire station.

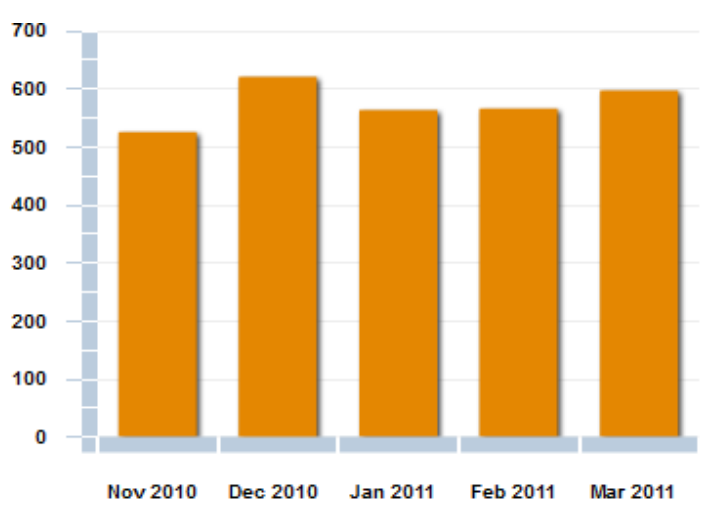

Figure 5-11 Months Column Bar Chart

The user can select a month from Months Column Chart, to show the distribution of incidents by each week in that month. Figure 5-12 shows the calendar for December of 2010. The number of incidents is classified into three groups. The first group is green. This group includes days in which there were 1-14 incidents. The second group is yellow. This group includes days in which there were 15-24 incidents. The third group is red. This group includes days in which the number of incidents was greater than 24 . These ranges were determined after the discussion with the client. 


\begin{tabular}{|l|l|l|l|l|l|l|}
\hline SU & MO & TU & WE & TH & FR & SA \\
\hline & & & 19 & 19 & 22 & 23 \\
\hline 20 & 14 & 13 & 22 & 17 & 19 & 26 \\
\hline 13 & 19 & 22 & 15 & 20 & 20 & 17 \\
\hline 15 & 22 & 46 & 34 & 26 & 18 & 18 \\
\hline 11 & 16 & 20 & 18 & 24 & 13 & \\
\hline & & & & & \\
\hline
\end{tabular}

Figure 5-12 Distribution of the Incidents by Weeks

Figure 5-13 shows an example the distribution of the incidents by hours. This component shows the number of incidents in each hour for the selected day from incident week's calendar. The hour cells are colored based on the values of the incidents, so the range of the green color is from 1 to 2 , the range of the yellow color 3 to 5 , and the cells with incident value greater than 5 . These ranges were specified by the client.

\begin{tabular}{|c|c|c|c|c|c|c|c|c|c|c|c|c|}
\hline & 00 & 01 & 02 & 03 & 04 & 05 & 06 & 07 & 08 & 09 & 10 & 11 \\
\hline AM & 0 & 1 & 0 & 3 & 0 & 2 & 2 & 1 & 1 & 2 & 1 & 3 \\
\hline PM & 1 & 0 & 1 & 1 & 1 & 0 & 0 & 2 & 1 & 3 & 5 & 15 \\
\hline
\end{tabular}

Figure 5-13 Distribution of the Incidents by Hours

The other window is Analyze Emergency Response Time which is used to determine the incidents that had emergency response time greater or smaller than the specified time. The minimum and maximum emergency response time will first be calculated for the incidents under consideration. The system will not accept values greater than or less than the calculated minimum and maximum ranges. Figure 5-14 shows an example of the range, so the user cannot enter value smaller than zero or greater than 729 minutes.

\section{Min: 0

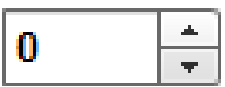 \\ Max: 729}

\section{Figure 5-14 Minimum and Maximum Emergency Response Time}

The user can specify the test value and the system will calculate how many incidents were above and below this value using ActionScript Classes. Figure 5-15 shows an example of the incidents that had emergency response time above and below seven minutes. This tool can facilitate the user to study the incidents that had emergency response time greater than the specified value, figure out what problems may have occurred, and finds ways to avoid those problems in the future. The details of those particular incidents will be displayed in the Show Statistics window, and those incidents will also be selected on the map. 


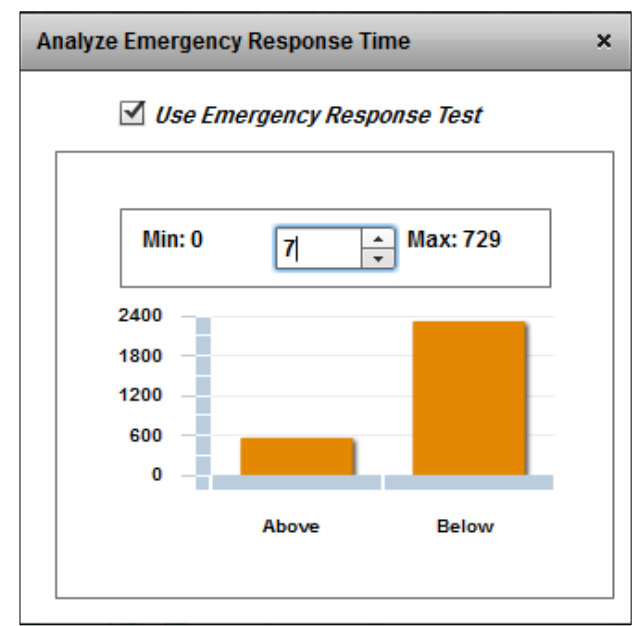

Figure 5-15 Analyze Emergency Response Time Window

\subsubsection{Closest Facility}

One of the client's requirements was to show the fire stations closest to a selected point. This was achieved by using closest facility analysis. An online closest facility solver, which is provided by Esri, was used to meet this requirement, but the client can change this solver by changing the service URL in the configuration file. Two components were declared to implement the closest facility analysis: closest facility task and closest facility parameters. The closest facility task was used to specify the request properties, such as request time out and the URL of the published closest facility solver. Table 5-7 shows the configuration of the Closest Facility Task. The concurrency determines how multiple requests will be handled; the "Last" value means to solve the last request only.

Table 5-7 Closest Facility Task Configuration

\begin{tabular}{|c|c|}
\hline Property & Value \\
\hline Concurrency & Last \\
\hline Requesttimeout & 60 second \\
\hline Showbusycursor & True \\
\hline URL & Specified in the configuration file \\
\hline
\end{tabular}

The closest facility parameters component was used to specify the required parameters for the solver, such as target facility count, barriers, incidents, and facilities. All these values are determined by the user using the Closest Facility window.

The process starts when the user selects a point so the closest facility task will be executed based on the specified parameters. When the results are received, another process is executed to display the results and show tooltips for the results. 
The routes drawing effect was implemented using a SWC library file called "Extended Polyline Effects" that was downloaded from the code gallery of the ArcGIS Resource Center.

\subsubsection{Service Area}

Service area analysis is very important to emergency response services, since it shows the coverage area for the selected facilities within the specified times. This information helps the fire department assess the locations of their facilities, and determining the areas that are out of coverage.

Two components were defined to implement the service area function in the project. The first component was service area task, which was used to specify request properties, (such as the URL of the published service area solver, which can be changed using the application configuration file), concurrency, and request time out. Table 5-8 shows the configurations of service area task component.

Table 5-8 Service Area Task Configuration

\begin{tabular}{|c|c|}
\hline Property & Value \\
\hline Concurrency & Last \\
\hline Requesttimeout & 120 second \\
\hline Showbusycursor & True \\
\hline URL & $\begin{array}{c}\text { Specify in the configuration } \\
\text { file }\end{array}$ \\
\hline
\end{tabular}

The second component was a service area parameters component, which was used to specify the required parameters for the solver, such as facilities and default breaks (travel intervals).

The user can use a Service Area window to generate the service area. This is achieved by specifying the travel time intervals and selecting one or multiple fire stations. The tooltips are specified, after receiving the results.

\subsubsection{Configuration File}

A configuration file was created to increase the flexibility and usability of the application. This file is an XML file that was used to define the URLs of the services that were included in the application. The administrator can change the solvers, like closest facility and service area, without changing the code. This can be achieved by changing the URLs in the configuration file. Like solvers, the map services can also be changed. An HTTPService was used to read the URLs from the configuration file and set the services at the application initialization. As shown in Figure 5-16, the configuration file contains three sections, which are basemap, operationallayers, and services. 


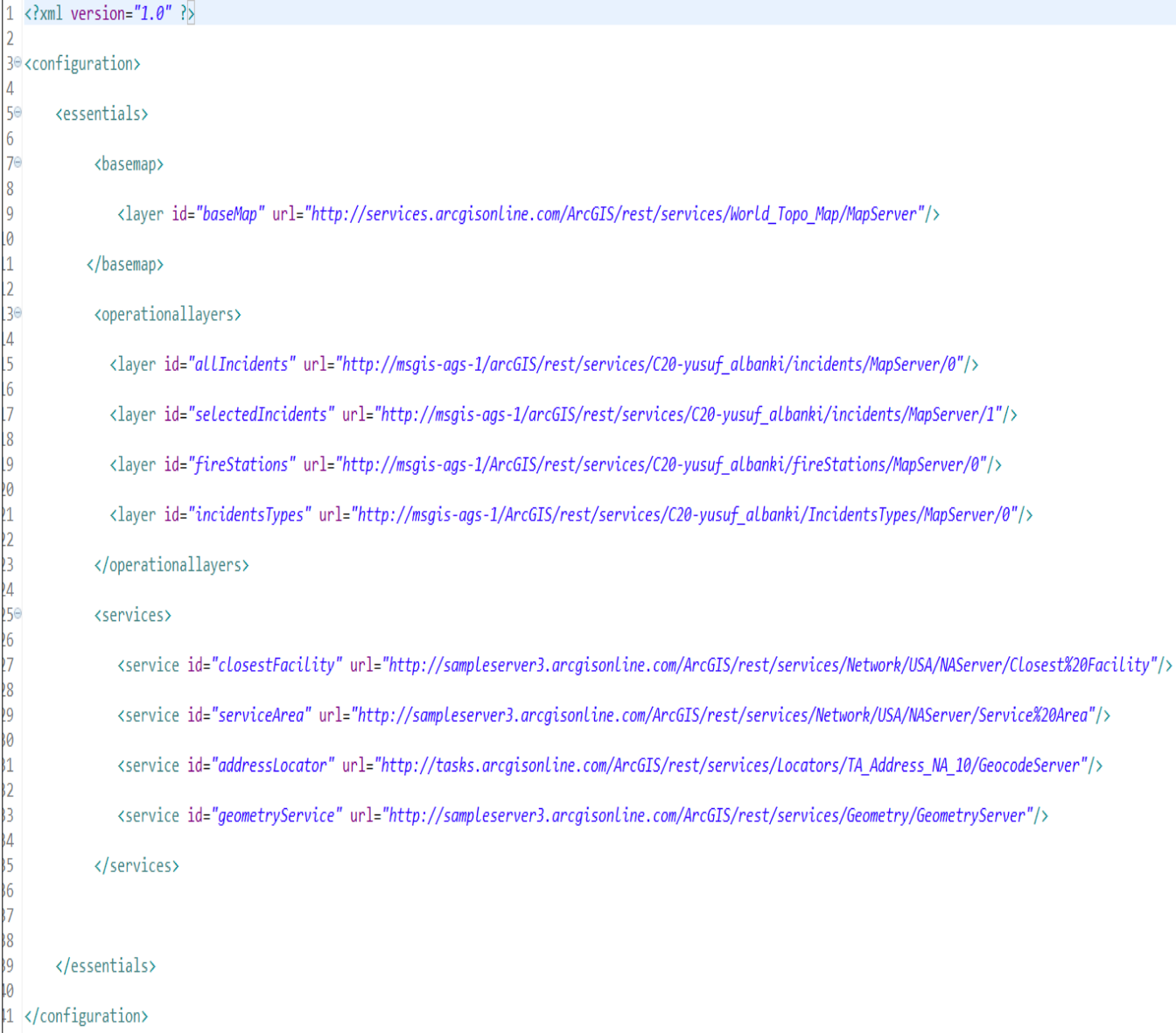

Figure 5-16 Configuration File

\subsection{Summary}

The main objective of this chapter was to shed light on the implementation process. The importance and the steps of developing the Import Incidents tool were discussed in section 1. Section 2 described the main components of the web-based application. The next chapter provides scenarios and use cases of the application. 



\section{Chapter 6 - Use Cases}

The main purpose of the application is to provide different analysis tools to the incidents analysts of the Redlands Fire Department, and to help them in analyzing the fire incidents. This chapter demonstrates different use cases in using the system.

\subsection{Exploring Incidents within a Specific Duration}

Suppose an incidents analyst wants to study the fire incidents that happened between October 2010 and March 2011. After selecting this duration, all incidents falling in this period are retrieved and displayed on the map (Figure 6-1). Each incident has a tooltip that shows its type and information window that can be displayed by clicking on the incident.

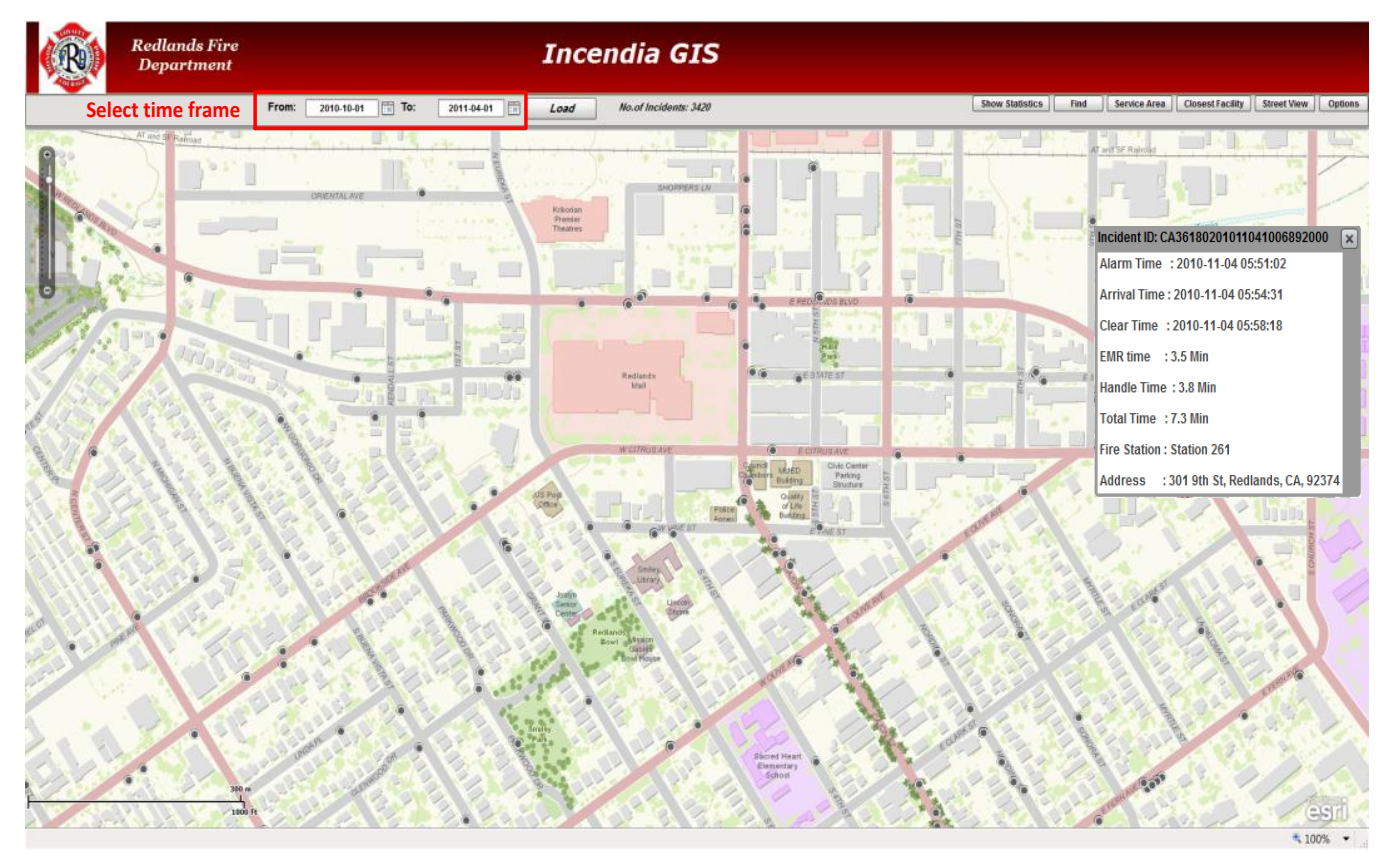

Figure 6-1 Incidents between October 2010 to March 2011

To help the incidents analyst in understanding these incidents, a Show Statistics window, which contains dynamically linked graphs and maps, is used (Figure 6-2). The pie chart on the top of the window displays the types of incidents given a period specified by the user. Underneath the pie chart are two bar charts displaying the number of incidents for each fire station and the distribution of incidents by months respectively. A more detailed distribution of the incidents by days and by hours is also provided at the bottom the window. 


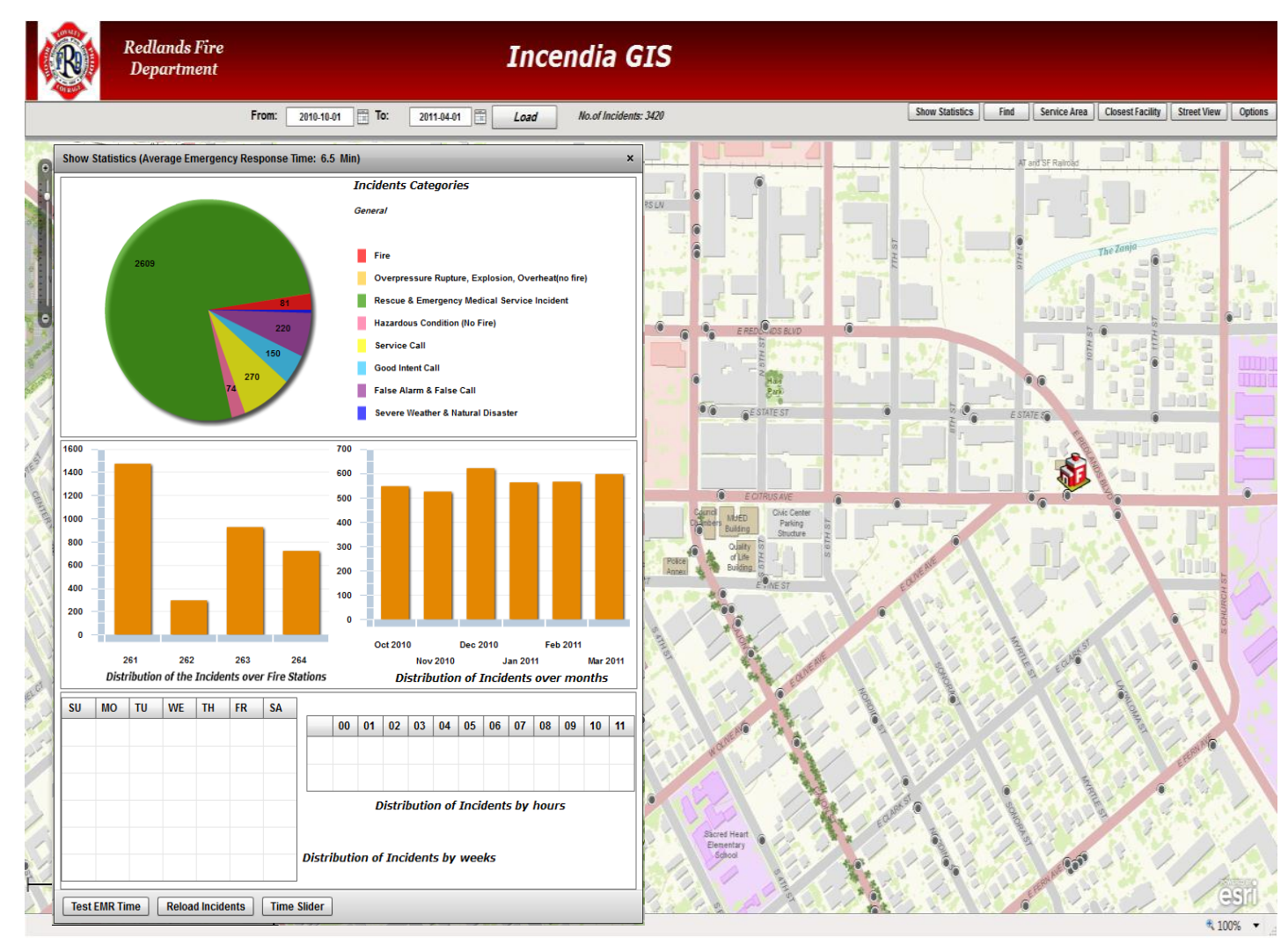

Figure 6-2 Show Statistics Window

During October 2010 and March 2011, there were a total number of 3420 calls received by the Redland Fire Department and these incidents fall into 8 categories as indicated by the pie chart. Rescue and Emergency Medical Service Incident, Service Call, and False Alarm and False Call are the top three categories of incidents during that period of time. The average response time to these incidents is 6.5 minutes (shown on the top of the window). To help the incidents analyst better interpret the pie chart, the colors associated with different categories of incidents are fixed. 
Since the types of incidents contained in the data are organized in a 3-level hierarchical structure, they are displayed hierarchically as well. The pie chart shown in Figure 6-2 only displays the top level of the incidents types. If the analyst wants to explore more refined incidents types, he/she can click on a particular type and the nested incident types in that type will show up in a pie chart as well. On the pie chart at any level, the analyst can double click on it to select all incidents of a specified type. For example, the user can double click on the fire, the red part of the chart, and all the fire incidents are updated in the map and other charts (Figure 6-3).

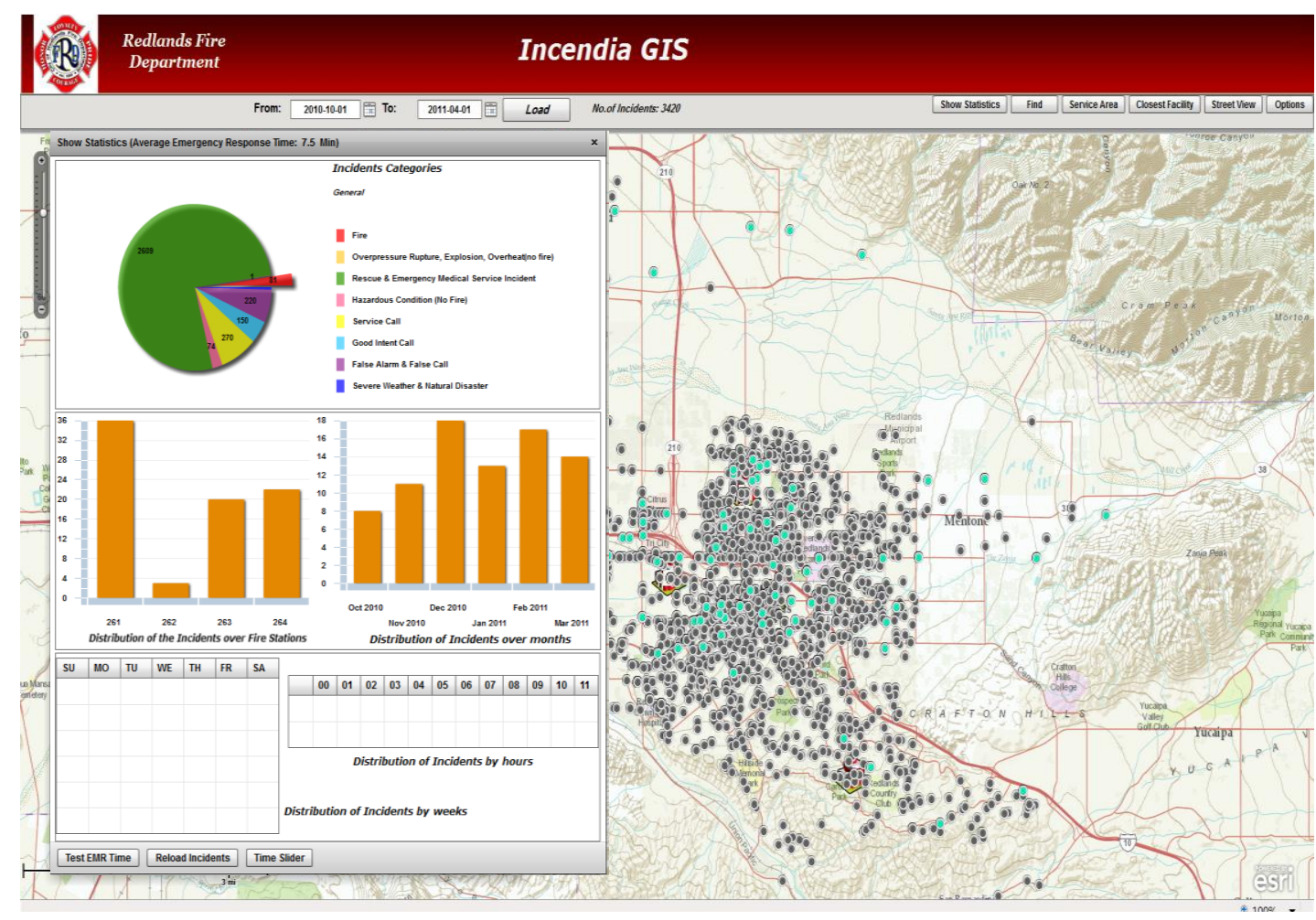

Figure 6-3 Select Fire Incidents

In addition to viewing the incidents by their types, the incidents analyst can also explore the incidents by months and by fire stations. For example, when the analyst clicks on Fire Station 263 on the fire station chart, all the incidents handled by this fire station are highlighted in the map and updated in all rest of graphs (Figure 6-4). 


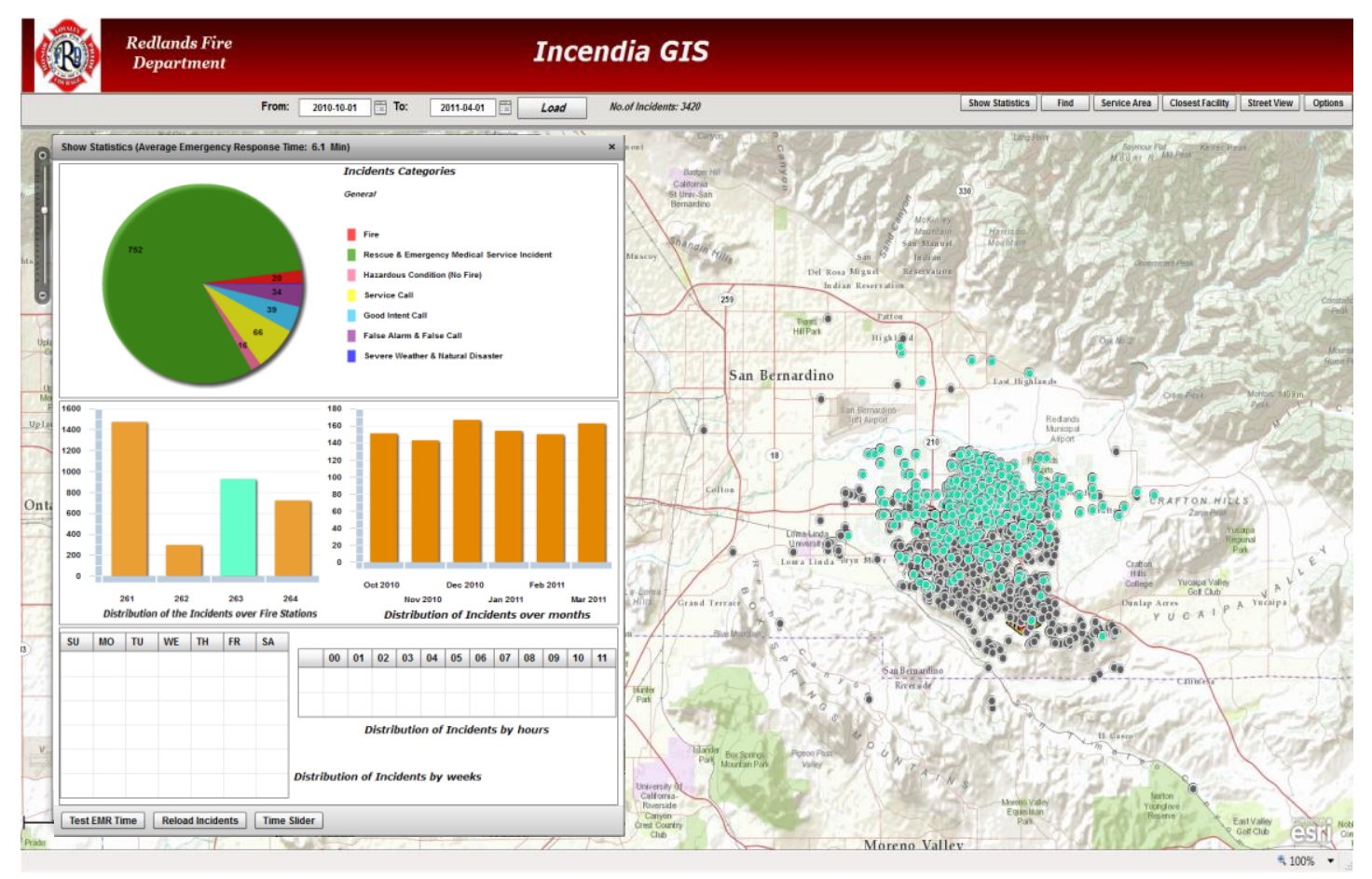

Figure 6-4 Select 263 Fire Station

Detailed information like the distribution of incidents over weeks and hours for each month can also be displayed using the interactive feature of this window. For example, the incidents analyst may want to examine how the incidents were distributed over October 2010. By clicking on the Oct 2010 in the month chart, the number of incidents on each day is shown in the bottom left chart. Apparently, Monday and Tuesday had the highest number of incidents in the month. . To view the hourly distribution of the incidents on Oct $1^{\text {st }} 2010$, the incident analyst can click on that day (Figure 6-5). 


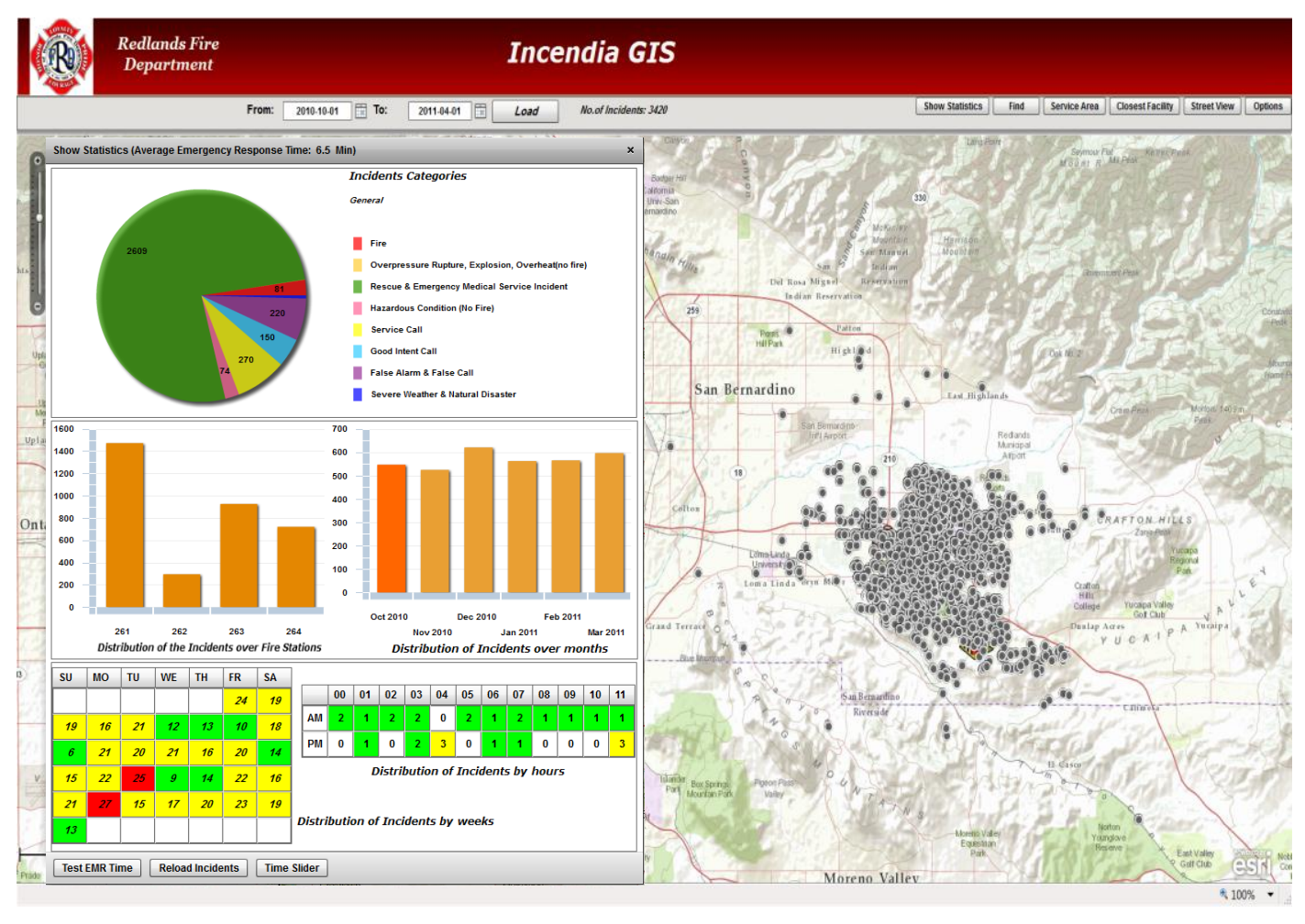

Figure 6-5 Distribution of the Incidents over Days and Hours

Besides getting some statistics about the incidents for a specified period, the analyst can also use the Find an Address to find a location. For example, if the analyst is interested in exploring the incidents in the neighborhood of 1111 East Central Avenue, Redlands, he/she can quickly identify the target location by entering the address (Figure 6-6). 


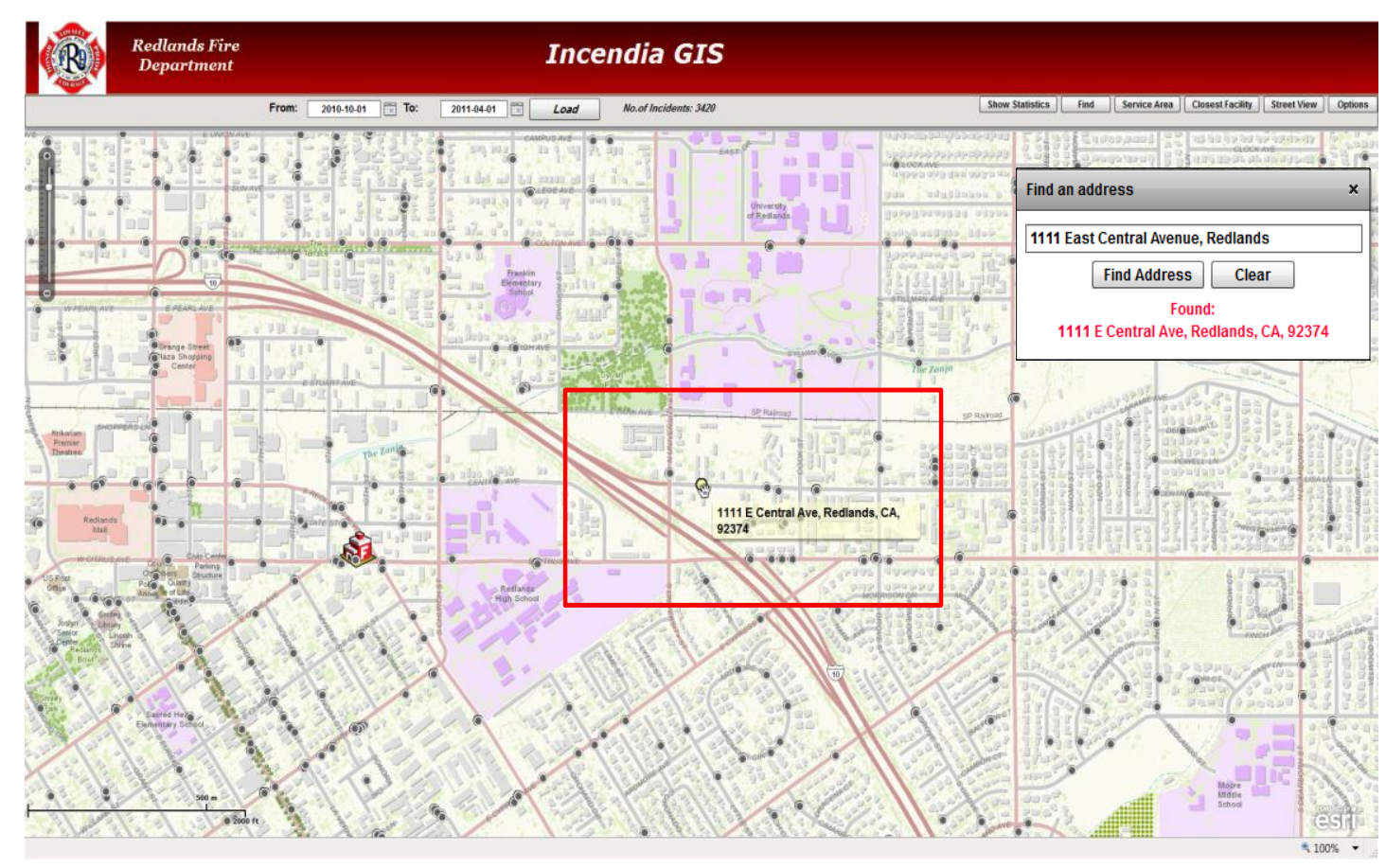

Figure 6-6 Find an Address Window

The analyst can also use the Street View to know more about the nature of the target location. Figure 6-7 shows that the analyst can explore 360 degree pictures of the specified location.

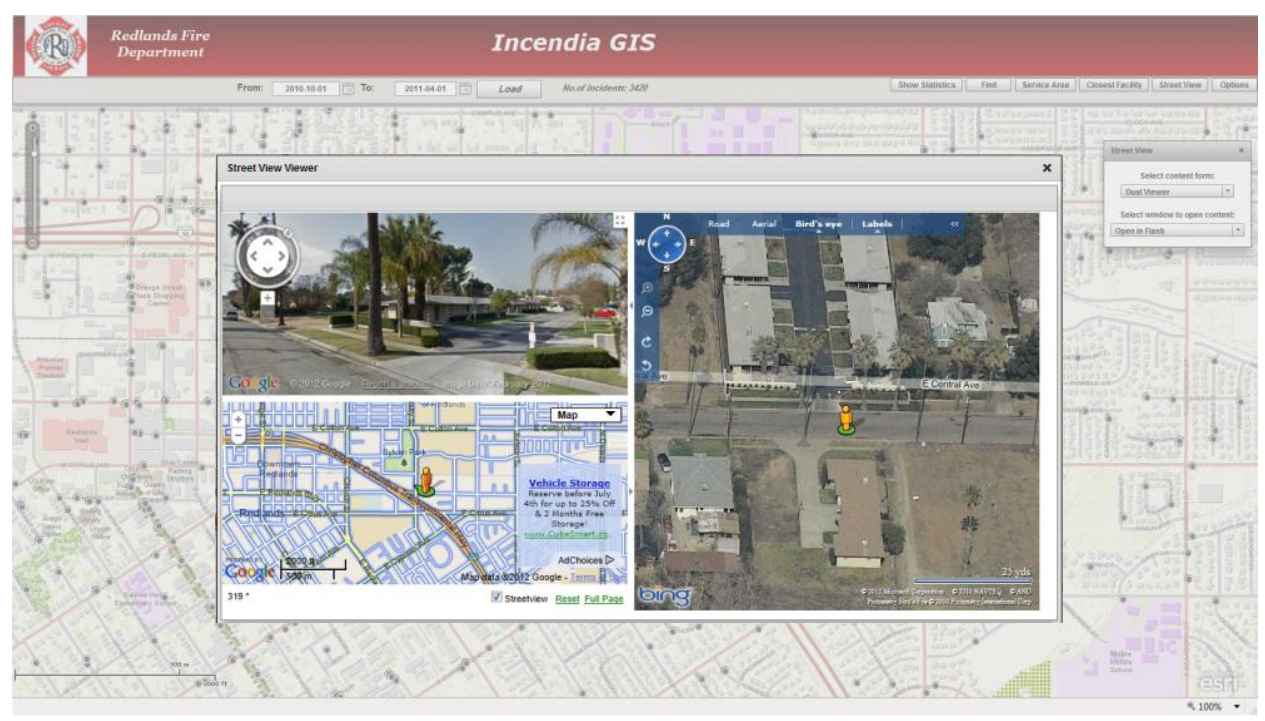

Figure 6-7 Street View Window

Sometime, the study area may contain a large number of incidents that may overlap each other. This will confuse the incidents analyst, so he/she cannot figure out the exact number of incidents or identify the incidents pattern. This problem can be solved using cluster option for the selected incidents. Thus, the incidents analyst can select an incident 
type or fire station and select cluster option from Options window (Figure 6-8). The cluster process groups nearby incidents into one symbol. The size of the symbol indicates the number of incidents that it contains. The cluster process is dynamic, so the cluster process will activate when the map scale is changed.

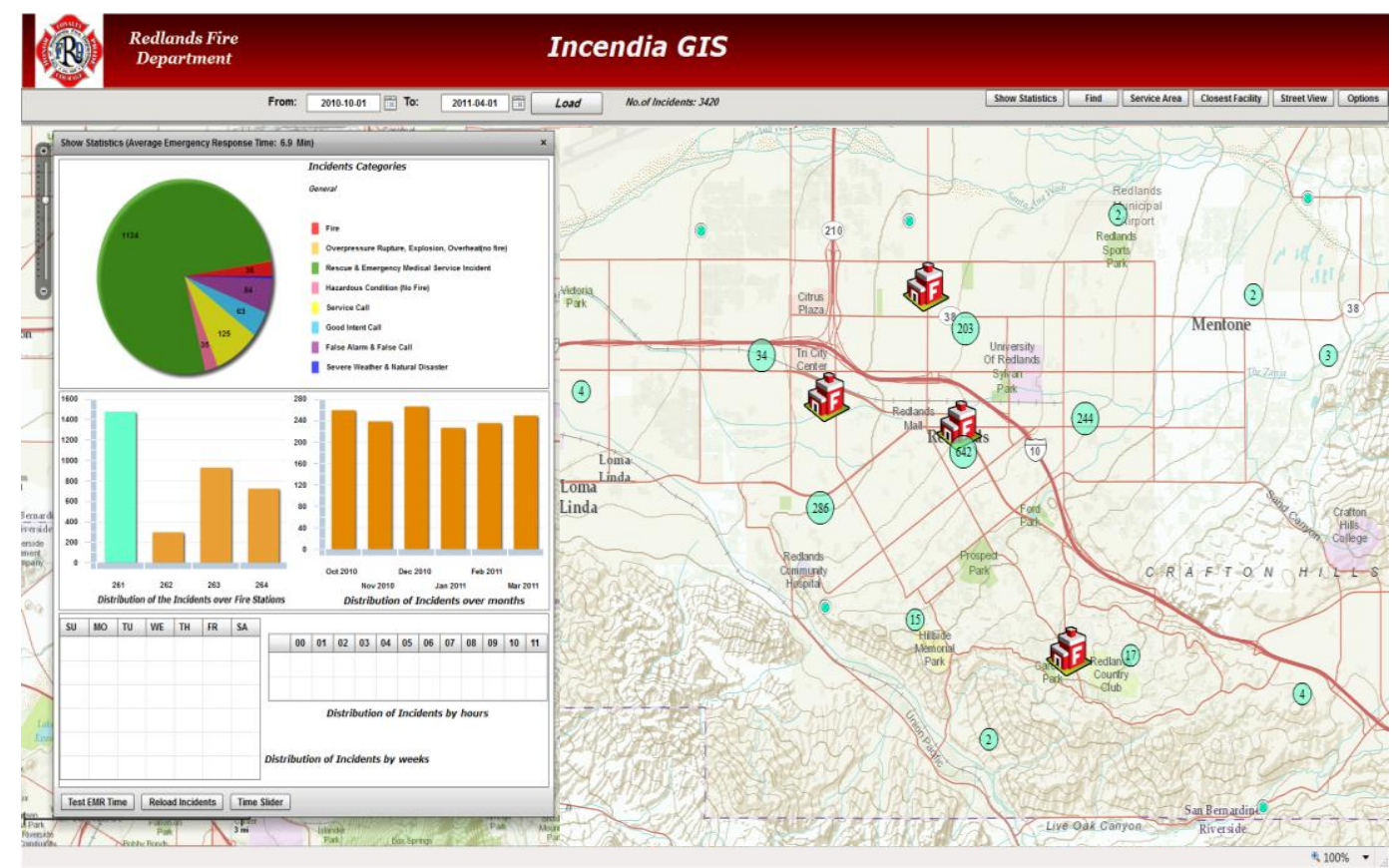

Figure 6-8 Using Cluster Option

The individual incidents within cluster symbol can be accessed by hovering the mouse over that symbol. In addition to use cluster for selected incidents, the Options window allows the incidents analyst to control the visibility of all incidents layer and the layer of the selected incidents.

Finally, the Incidents Time Slider window can be used by the incidents analyst to see the distribution of the incidents in each month (Figure 6-9). The time slider is flexible, so the incidents analyst can specify start month and end month. 


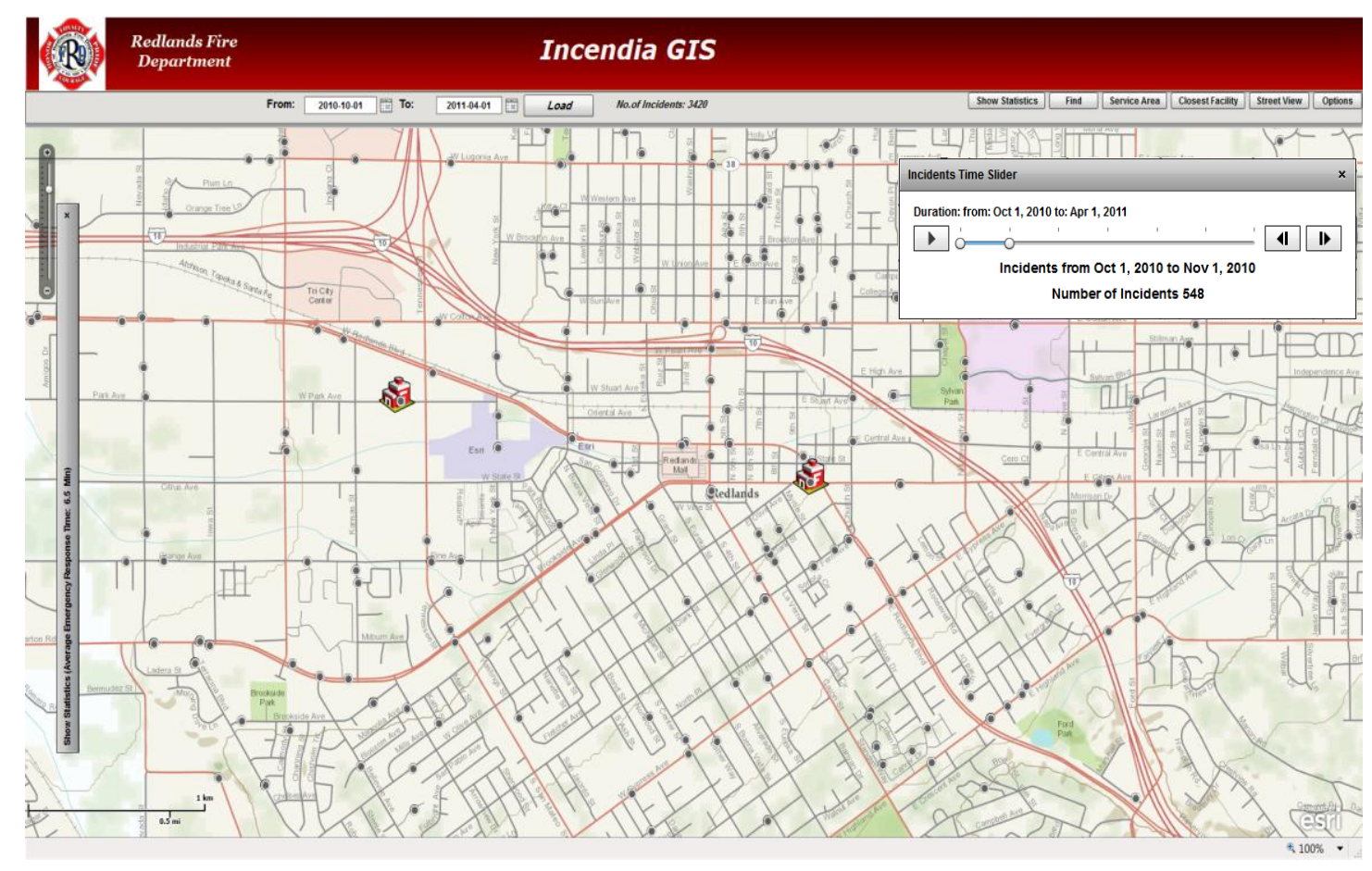

Figure 6-9 Distribution of the Incidents by Months

\subsection{Analyzing Emergency Response Time}

In addition to viewing and exploring the incidents, another important function provided by the application is to analyze emergency response time, as it is critical for fire departments to improve their services. Suppose the incidents analyst wants to analyze incidents that had emergency response times greater than 10 minutes. This analysis can be done using the Analyze Emergency Response window (Figure 6-10). After the analyst enters 10 minutes, all incidents that had an emergency response time greater than the specified time are displayed on the map. The incidents analyst can then further explore the statistics of these incidents using the Show Statistics window. 


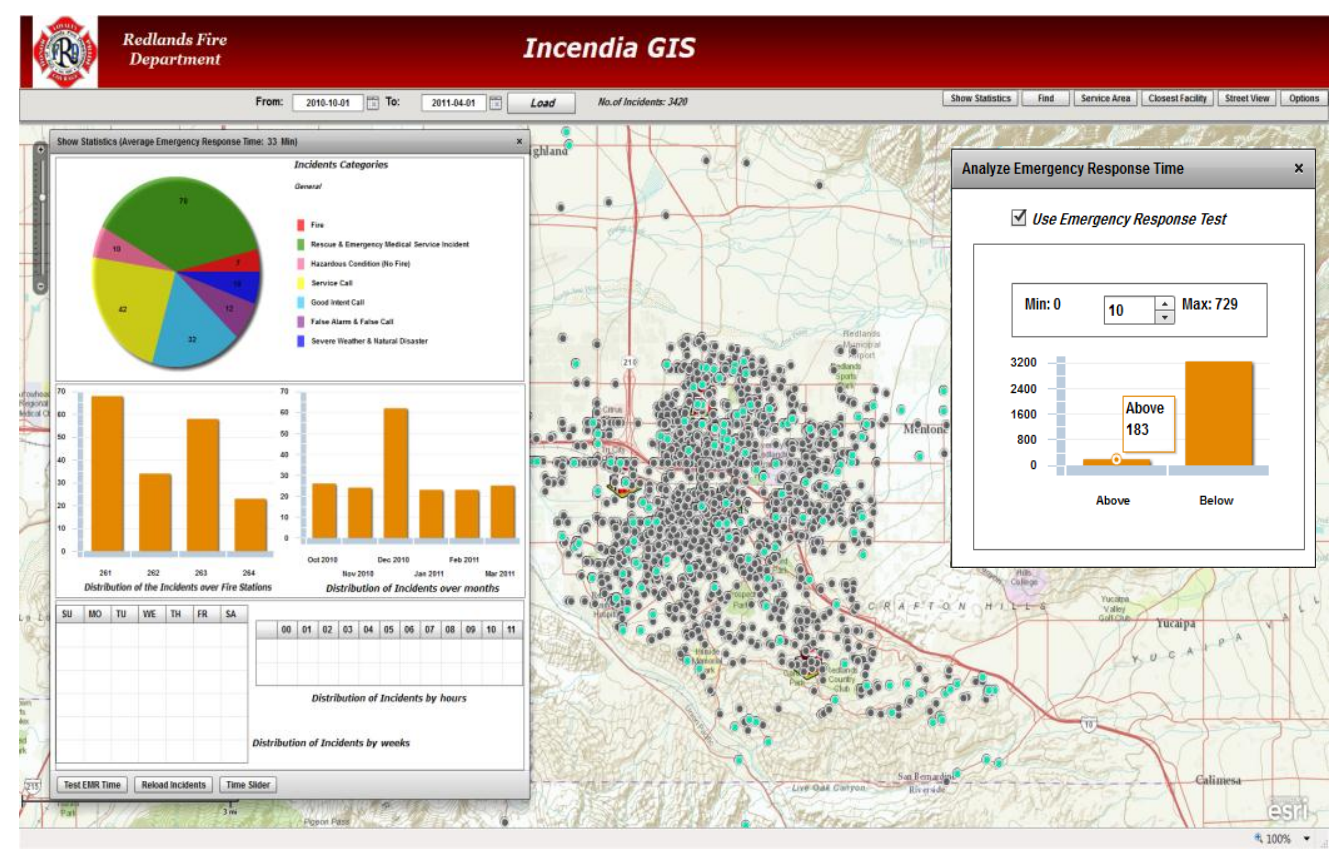

Figure 6-10 Analyze Emergency Response Time Window

\subsection{Finding Service Areas and Closest Fire Station}

The service area of a facility is often represented by a specified travel zone and people living within the zone are taken as the potential demand for the service provided by the facility. This analysis is commonly conducted to analyze the customers' profiles. Suppose the incidents analyst wants to find the service areas of Fire Station 261 and 262 for 3, 5, and 7 minutes. In this case, the analyst chooses all the fire stations under consideration, and enters the time parameters. The application then calculates the requested service areas for the specified fire stations as shown in Figure 6-11. 


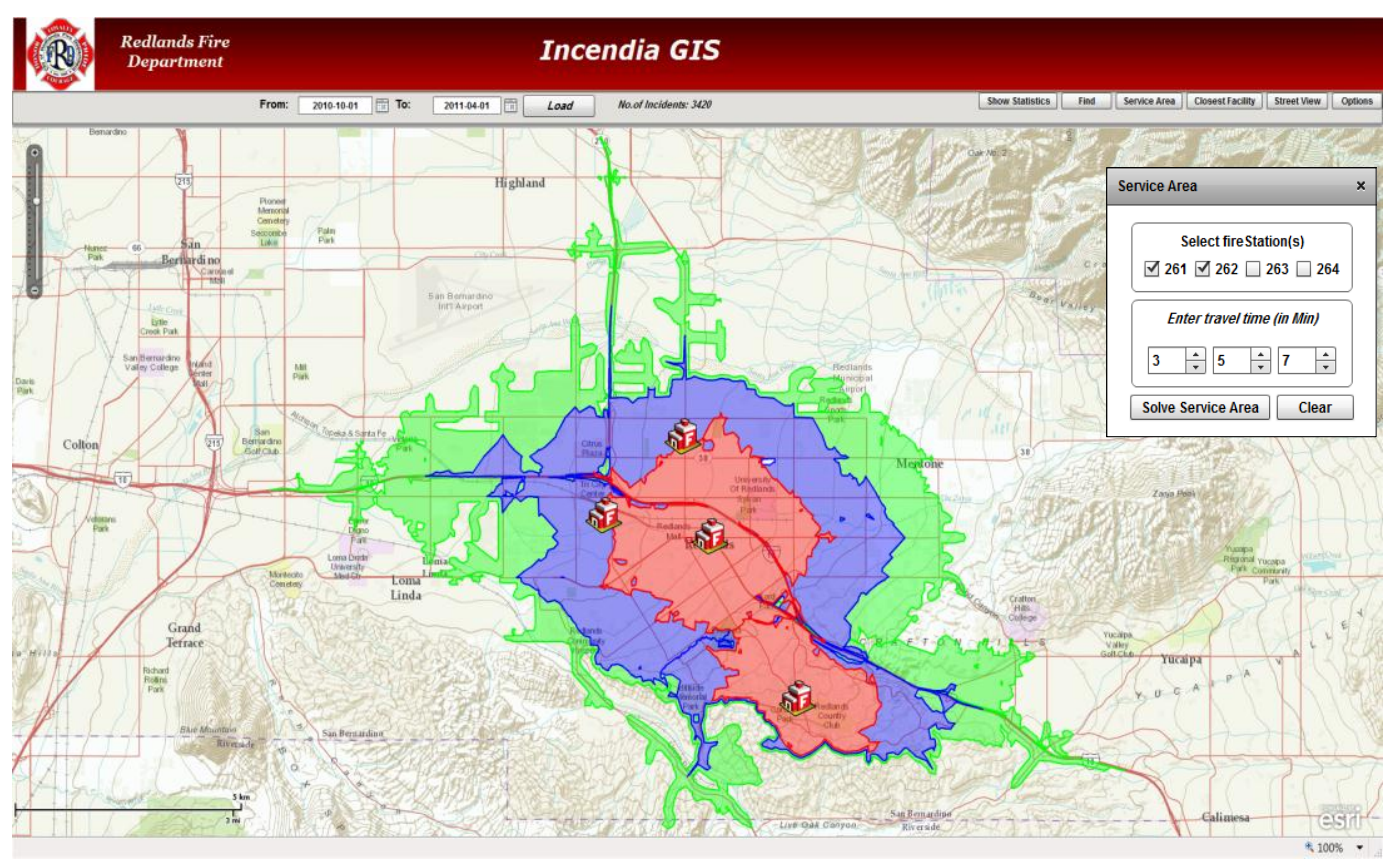

Figure 6-11 Service Area Analysis

Another popular analysis that is often conducted in facility management is to find the closet facility, which will be very important for dispatching fire trucks. The Closest Facility window can be used to display the closest fire stations to a selected point. This window can also be used to add road barriers to represent closed roads, which should be avoided by closest facility solver. Suppose incidents analyst wants to find the nearest fire stations to the Redlands Mall if there are road constructions around the mall. Figure 6-12 shows the results of using closest facility analysis with barriers; each route has a distinct color and a tooltip that shows the required time to reach to the specified location. Based on that result, 261station can reach to the mall within 1 minute. This type of analysis help the incidents analyst to study the impact of closing roads, so he/she can put plans to avoid having a high emergency response. 


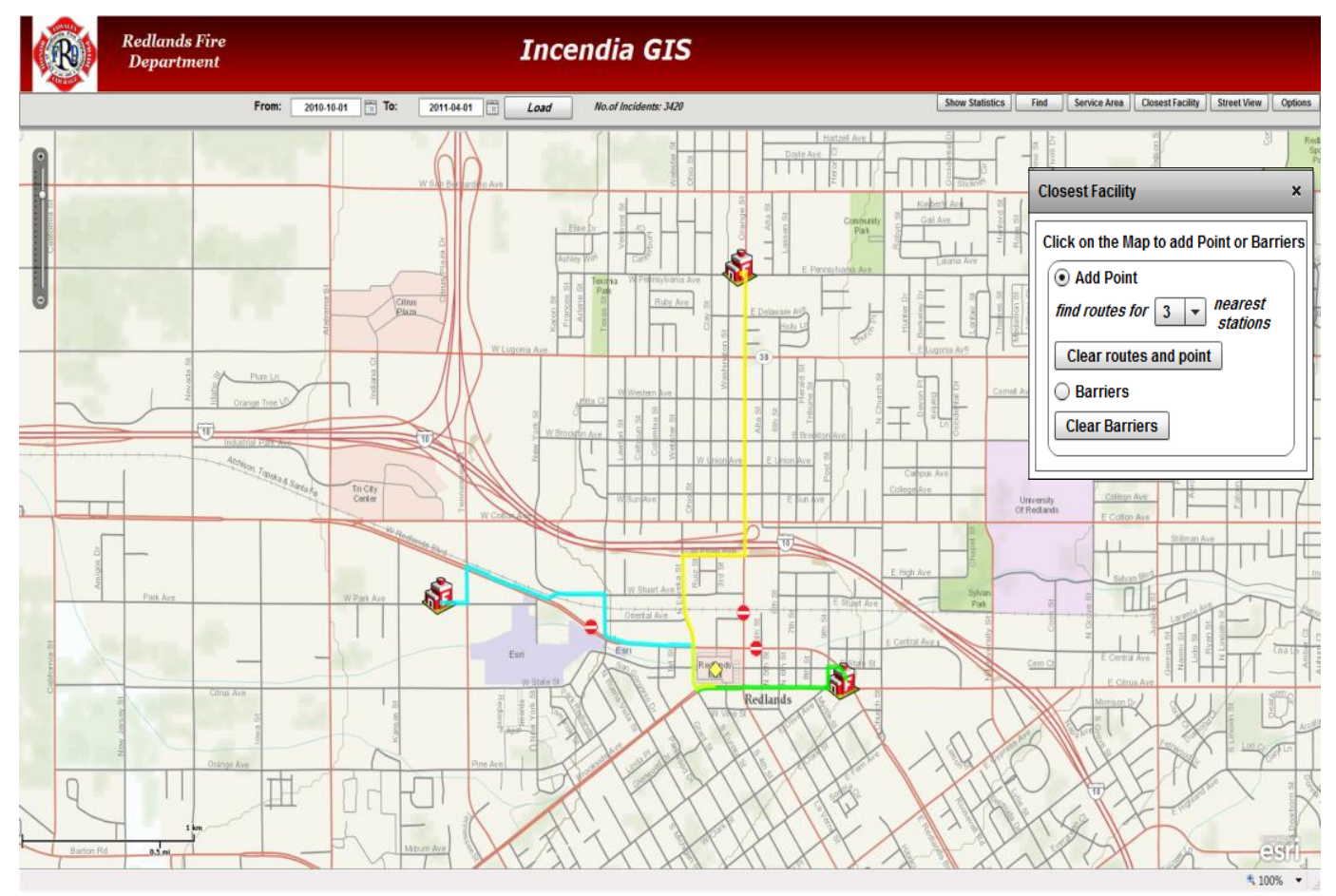

Figure 6-12 Closest Facility Analysis

\subsection{Summary}

The process of incidents analysis is very important, since it allows the fire department to discover any weak points or problems that can affect their critical services. This strategy helps in reducing the impact of the incidents on people and property. To make analysis process effective, several functions and statistics should be used and studied.

This application provides the incidents analyst with the necessary functions to help them in the analysis process. The closest facility and service area analyses can be used to evaluate the coverage of the fire stations, and identified the effects of closing roads on their services. Moreover, Show Statistics window provides a dynamic statistics about the incidents. Since graphics and maps are used to show statistics, the incidents analyst can quickly figure out the variations and identified the incidents patterns. In addition, Analyze Emergency Response Time window can be used to help the incidents analyst to study the causes of high emergency response for some incidents. Different supportive tools were added to the application to increase the accuracy of analysis process, such as Street View window and Incidents Time Slider window. Several use cases was discussed in this chapter to show how to use these tools and functions. 



\section{Chapter 7 - Conclusions and Future Work}

The primary goal of this project was to provide a web application for the Redlands Fire Department in order to help them analyze fire incidents and make decisions for enhancing their services. The application was developed based on their requirements that were analyzed in the early stages of the project. Their main problem was that they do not have a GIS-based system, although the nature of their work is highly dependent on determining and analyzing locations of incidents, like studying the distribution of the incidents throughout the city, in order to take appropriate actions.

After studying the requirements and similar systems, several analysis functions were added to the developed application to allow them to evaluate the performance of their fire stations and identify the causes for having a high emergency response for some incidents. Service area and closest facility network analyses were added to the application to help study the coverage area for the fire stations within specified time intervals, and identify the closest fire stations for selected incidents. Using these functions can help the Redlands Fire Department management make important decisions, such as building new fire stations or using specific routes when responding to incidents in specific locations. Generally, closed roads have a great impact on the fire department's response time. Using the closest facility function in the application can minimize this problem. The user can add barriers, and the application will find the best alternative routes.

By studying previous incidents, the fire department can work to avoid mistakes and identify the needs and shortages in order to enhance the services they provide. There are a huge number of recorded incidents, which makes the analysis process very difficult. An interactive dashboard window was developed to solve this problem. It displays the incident statistics using dynamic charts, tables, and maps. This feature helps the user identify the incident patterns by examining incident locations, types, and times. It also helps the user evaluate the performance of each fire station. Critical decisions can be made by studying the incidents. The fire department may discover that they need to increase the number of firemen for a specific fire station, buy new fire trucks, or redistribute resources among fire stations.

Most fire departments have a standard emergency response time for responding to incidents. A tool was added to the application to allow the Redlands Fire Department to determine the incidents that had a high emergency response time. Studying these incidents can help them discover the causes of the delay in response time, and put a plan into place to solve them.

Although the available functions cover the project scope, additional functions can be added to the application to maximize its benefits. First of all, there are different types of fire trucks, such as tower ladder, hydraulic platform, and turntable ladder. Each type has a specific task and role in firefighting. Statistics about the usage of the current fire station's fire trucks can be added to appear in the Show Statistics window. This information helps management recognize the shortages of each fire station; this could also explain why services need to be made by one station in another station's area.

Second, kernel density and hotspot analyses can be added to the project analysis functions. With this, the user can weigh the incidents based on several factors, such as the loss in lives and property, the number of the resources that were used to deal with the 
incidents, and the time that was spent to handle the incident. This function would help the user assess incidents based on their real impacts.

Third, the overlay analysis can be done between fire stations' service areas, and an incidents layer can be used to determine the incidents that had an emergency response time that was greater than the expected time. This feature would help the user discover if there are locations that should be assigned to different fire stations to decrease the emergency response time, or if there is a shortcoming at a fire station.

Fourth, a function to study the distribution of the incident types with demographic data could be added to the application to identify a relationship between the occurrence of certain incidents and a specific category of the population, such as age and education. This analysis could help the fire department provide appropriate awareness and training.

Fifth, integration between the fire department's existing system and the new application could be implemented to exchange the incident data directly between these systems. This would ensure that the system geodatabase is always updated. This would mean that the analysis process could be done at any time, without needing to load incidents every time analysis needs to be done.

In summary, this project successfully met the client's functional and non-functional requirements. Also, several improvements and functions were identified and could be added in the future. Finally, this project shows how GIS technology can be used in the public safety field. 


\section{Works Cited}

Ahmed, T., Hirschi, J., \& Abid, F. (2009). Flex 3 in Action. Greenwich: Manning Publications Co.

Alesheikh, A., Helali, H., \& Behroz, H. (2002). Web GIS: Technologies and Its Applications. Symposium on Geospatial Theory, Processing and Applications. Ottawa.

Caplan, J. M. (2010). GIS for Public Safety: An Annotated Guide to ArcGIS Tools and Procedures. Rutgers Center on Public Security.

Chang, k. (2011). Introduction to Geographic Information Systems. New York: McGrawHill.

Cova. (1999). GIS in Emergency Management. In P. Longley, M. Goodchild, D. Maguire, \& D. Rhind, Geographical Information Systems: Principles, Techniques, Applications, and Management (pp. 845-858). New York: John Wiley \& Sons.

Dragićević, S. (2004). The potential of Web-based GIS. Journal of Geographical Systems, 79-81.

Eckerson, W. W. (2011). PERFORMANCE DASHBOARDS : MEASURING, MONITORING. New Jersey: John Wiley \& Sons, Inc.

Esri. (2007). GIS Integration with Public Safety Applications. Redlands: Esri Press.

Esri. (2008). Public Safety Enterprise : GIS Solutions for Community Protection and Response. Redlands: Esri Press.

EsriNeA. (n.d.). Geographic Security System Suites. Retrieved May 5, 2012, from ESRI Northeast Africa: http://www.esrinea.com/index.aspx?id=120

Ewald, K. (2004). Integrating workflows of a Municipality into a Web GIS using Geo Media WebMap Publisher. Stuttgart.

Few, S. (2006). INFORMATION DASHBOARD DESIGN. California: O'Reilly Media, Inc.

Fu, P., \& Sun, J. (2010). Web GIS: PRINCIPLES AND APPLICATIONS. Redlands: ESRI Press.

Labriola, M., Tapper, J., \& Boles, M. (2011). Adobe Flex 4.5 Fundamentals: Training from the Source. Berkeley: Adobe Press.

Leitinger, S. H. (2004). COMPARISION OF GIS-BASED PUBLIC SAFETY SYSTEMS FOR EMERGENCY. Proc 24th Urban Data Management Symposium.

Penev, P. T. (2006). INTERNET GIS and INTERNET MAPPING. International Conference on Cartography and GIS. Borovets.

Peng. (1999). An assessment framework for the development of Internet GIS. Environment and Planning B: Planning and Design, 117 - 132.

Stachowicz, S. (2004). GEOGRAPHICAL DATA SHARING - ADVANTAGES OF WEB BASED TECHNOLOGY TO LOCAL GOVERNMENT. 10th EC GI \& GIS Workshop Proceedings, ESDI: State of the Art. Warsaw,Poland.

Stasko, J., \& Pousman, Z. (2006). A taxonomy of ambient information systems: Four patterns of design. Proceedings of the working conference on Advanced visual interfaces (pp. 67-74). New York: ACM Press. 
The Omega Group. (n.d.). Fire Analysis. Retrieved May 5, 2012, from THE OMEGA GROUP: http://www.theomegagroup.com/fire/omega_dashboard_fire.html

Waters, N. M. (1999). Transportation GIS: GIS-T. In P. A. Longley, m. f. Goodchild, D. J. Maguire, \& D. W. Rhind, Geographical Information Systems: Principles, Techniques, Applications and Management (pp. 832-833). New York: John Wiley $\&$ Sons, Inc. 


\section{Appendix A. Import Incidents Tool Model}
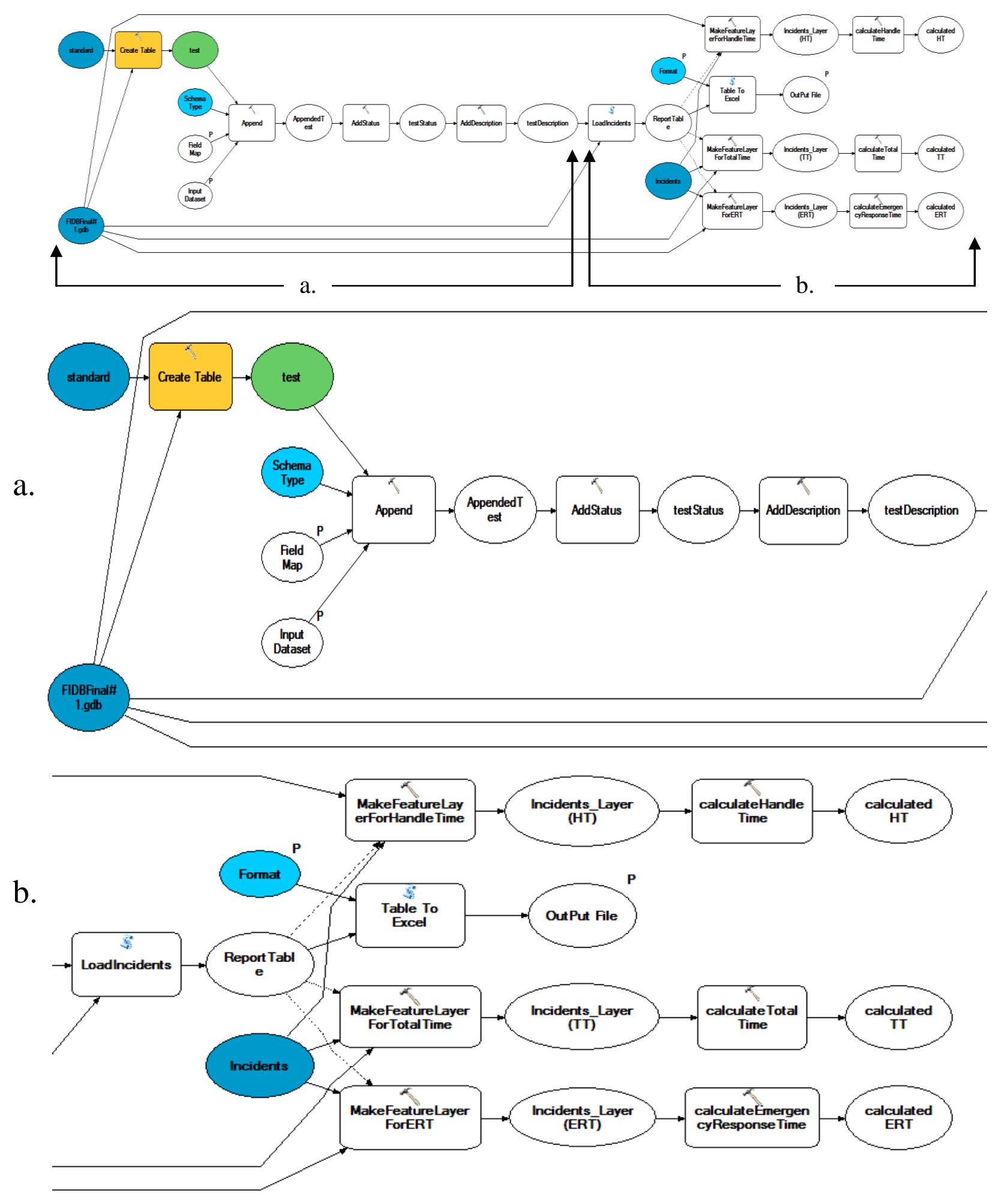


\section{Appendix B. Incidents Types based on NFIRS}

\begin{tabular}{|c|c|c|}
\hline No. & Incident Code & Description \\
\hline 1 & 1 & Fire \\
\hline 2 & 10 & Fire, other \\
\hline 3 & 100 & Fire, other \\
\hline 4 & 11 & Structure Fire \\
\hline 5 & 110 & Structure fire, other (conversion only) \\
\hline 6 & 111 & Building fire \\
\hline 7 & 112 & Fires in structure other than in a building \\
\hline 8 & 113 & Cooking fire, confined to container \\
\hline 9 & 114 & Chimney or flue fire, confined to chimney or flue \\
\hline 10 & 115 & Incinerator overload or malfunction, fire confined \\
\hline 11 & 116 & Fuel burner/boiler malfunction, fire confined \\
\hline 12 & 117 & Commercial Compactor fire, confined to rubbish \\
\hline 13 & 118 & Trash or rubbish fire, contained \\
\hline 14 & 12 & Fire in mobile property used as a fixed structure \\
\hline 15 & 120 & Fire in mobile prop. used as a fixed struc., other \\
\hline 16 & 121 & Fire in mobile home used as fixed residence \\
\hline 17 & 122 & Fire in motor home, camper, recreational vehicle \\
\hline 18 & 123 & Fire in portable building, fixed location \\
\hline 19 & 13 & Mobile property (vehicle) fire \\
\hline 20 & 130 & Mobile property (vehicle) fire, other \\
\hline 21 & 131 & Passenger vehicle fire \\
\hline 22 & 132 & Road freight or transport vehicle fire \\
\hline 23 & 133 & Rail vehicle fire \\
\hline 24 & 134 & Water vehicle fire \\
\hline 25 & 135 & Aircraft fire \\
\hline 26 & 136 & Self-propelled motor home or recreational vehicle \\
\hline 27 & 137 & Camper or recreational vehicle $(\mathrm{RV})$ fire \\
\hline 28 & 138 & Off-road vehicle or heavy equipment fire \\
\hline 29 & 14 & Natural vegetation fire \\
\hline 30 & 140 & Natural vegetation fire, other \\
\hline 31 & 141 & Forest, woods or wildland fire \\
\hline 32 & 142 & Brush or brush-and-grass mixture fire \\
\hline 33 & 143 & Grass fire \\
\hline 34 & 15 & Outside rubbish fire \\
\hline 35 & 150 & Outside rubbish fire, other \\
\hline 36 & 151 & Outside rubbish, trash or waste fire \\
\hline 37 & 152 & Garbage dump or sanitary landfill fire \\
\hline 38 & 153 & Construction or demolition landfill fire \\
\hline 39 & 154 & Dumpster or other outside trash receptacle fire \\
\hline
\end{tabular}




\begin{tabular}{|c|c|c|}
\hline 40 & 155 & Outside stationary compactor/compacted trash fire \\
\hline 41 & 16 & Special outside fire \\
\hline 42 & 160 & Special outside fire, other \\
\hline 43 & 161 & Outside storage fire \\
\hline 44 & 162 & Outside equipment fire \\
\hline 45 & 163 & Outside gas or vapor combustion explosion \\
\hline 46 & 164 & Outside mailbox fire \\
\hline 47 & 17 & Cultivated vegetation, crop fire \\
\hline 48 & 170 & Cultivated vegetation, crop fire, other \\
\hline 49 & 171 & Cultivated grain or crop fire \\
\hline 50 & 172 & Cultivated orchard or vineyard fire \\
\hline 51 & 173 & Cultivated trees or nursery stock fire \\
\hline 52 & 2 & Overpressure Rupture, Explosion, Overheat(no fire) \\
\hline 53 & 20 & Overpressure rupture, explosion, overheat, other \\
\hline 54 & 200 & Overpressure rupture, explosion, overheat other \\
\hline 55 & 21 & Overpressure rupture from steam (no ensuing fire) \\
\hline 56 & 210 & Overpressure rupture from steam, other \\
\hline 57 & 211 & Overpressure rupture of steam pipe or pipeline \\
\hline 58 & 212 & Overpressure rupture of steam boiler \\
\hline 59 & 213 & Steam rupture of pressure or process vessel \\
\hline 60 & 22 & Overpressure rupture from air or gas (no fire) \\
\hline 61 & 220 & Overpressure rupture from air or gas, other \\
\hline 62 & 221 & Overpressure rupture of air or gas pipe/pipeline \\
\hline 63 & 222 & Overpressure rupture of boiler from air or gas \\
\hline 64 & 223 & Air or gas rupture of pressure or process vessel \\
\hline 65 & 23 & Overpressure rupture, chemical reaction (no fire) \\
\hline 66 & 231 & Chemical reaction rupture of process vessel \\
\hline 67 & 24 & Explosion (no fire) \\
\hline 68 & 240 & Explosion (no fire), other \\
\hline 69 & 241 & Munitions or bomb explosion (no fire) \\
\hline 70 & 242 & Blasting agent explosion (no fire) \\
\hline 71 & 243 & Fireworks explosion (no fire) \\
\hline 72 & 25 & Excessive heat, scorch burns with no ignition \\
\hline 73 & 251 & Excessive heat, scorch burns with no ignition \\
\hline 74 & 3 & Rescue \& Emergency Medical Service Incident \\
\hline 75 & 30 & Rescue, emergency medical call (EMS), other \\
\hline 76 & 300 & Rescue, EMS incident, other \\
\hline 77 & 31 & Medical assist \\
\hline 78 & 311 & Medical assist, assist EMS crew \\
\hline 79 & 32 & Emergency medical service (EMS) Incident \\
\hline 80 & 320 & Emergency medical service, other (conversion only) \\
\hline 81 & 321 & EMS call, excluding vehicle accident with injury \\
\hline 82 & 322 & Motor vehicle accident with injuries \\
\hline
\end{tabular}




\begin{tabular}{|c|c|c|}
\hline 83 & 323 & Motor vehicle/pedestrian accident (MV Ped) \\
\hline 84 & 324 & Motor vehicle accident with no injuries. \\
\hline 85 & 33 & Lock-In \\
\hline 86 & 331 & Lock-in (if lock out, use 511 ) \\
\hline 87 & 34 & Search for lost person \\
\hline 88 & 340 & Search for lost person, other \\
\hline 89 & 341 & Search for person on land \\
\hline 90 & 342 & Search for person in water \\
\hline 91 & 343 & Search for person underground \\
\hline 92 & 35 & Extrication, rescue \\
\hline 93 & 350 & Extrication, rescue, other \\
\hline 94 & 351 & Extrication of victim(s) from building/structure \\
\hline 95 & 352 & Extrication of victim(s) from vehicle \\
\hline 96 & 353 & Removal of victim(s) from stalled elevator \\
\hline 97 & 354 & Trench/below-grade rescue \\
\hline 98 & 355 & Confined space rescue \\
\hline 99 & 356 & High-angle rescue \\
\hline 100 & 357 & Extrication of victim(s) from machinery \\
\hline 101 & 36 & Water or ice-related rescue \\
\hline 102 & 360 & Water \& ice-related rescue, other \\
\hline 103 & 361 & Swimming/recreational water areas rescue \\
\hline 104 & 362 & Ice rescue \\
\hline 105 & 363 & Swift water rescue \\
\hline 106 & 364 & Surf rescue \\
\hline 107 & 365 & Watercraft rescue \\
\hline 108 & 37 & Electrical rescue \\
\hline 109 & 370 & Electrical rescue, other \\
\hline 110 & 371 & Electrocution or potential electrocution \\
\hline 111 & 372 & Trapped by power lines \\
\hline 112 & 38 & Rescue or EMS standby \\
\hline 113 & 381 & Rescue or EMS standby \\
\hline 114 & 4 & Hazardous Condition (No Fire) \\
\hline 115 & 40 & Flammable gas or liquid condition, other \\
\hline 116 & 400 & Hazardous condition, other \\
\hline 117 & 41 & Combustible/flammable spills \& leaks \\
\hline 118 & 410 & Combustible/flammable gas/liquid condition, other \\
\hline 119 & 411 & Gasoline or other flammable liquid spill \\
\hline 120 & 412 & Gas leak (natural gas or LPG) \\
\hline 121 & 413 & Oil or other combustible liquid spill \\
\hline 122 & 42 & Chemical release, reaction, or toxic condition \\
\hline 123 & 420 & Toxic condition, other \\
\hline 124 & 421 & Chemical hazard (no spill or leak) \\
\hline 125 & 422 & Chemical spill or leak \\
\hline
\end{tabular}




\begin{tabular}{|c|c|c|}
\hline 126 & 423 & Refrigeration leak \\
\hline 127 & 424 & Carbon monoxide incident \\
\hline 128 & 43 & Radioactive condition \\
\hline 129 & 430 & Radioactive condition, other \\
\hline 130 & 431 & Radiation leak, radioactive material \\
\hline 131 & 44 & Electrical wiring/equipment problem \\
\hline 132 & 440 & Electrical wiring/equipment problem, other \\
\hline 133 & 441 & Heat from short circuit (wiring), defective/worn \\
\hline 134 & 442 & Overheated motor \\
\hline 135 & 443 & Breakdown of light ballast \\
\hline 136 & 444 & Power line down \\
\hline 137 & 445 & Arcing, shorted electrical equipment \\
\hline 138 & 45 & Biological hazard \\
\hline 139 & 451 & Biological hazard, confirmed or suspected \\
\hline 140 & 46 & Accident, potential accident \\
\hline 141 & 460 & Accident, potential accident, other \\
\hline 142 & 461 & Building or structure weakened or collapsed \\
\hline 143 & 462 & Aircraft standby \\
\hline 144 & 463 & Vehicle accident, general cleanup \\
\hline 145 & 47 & Explosive, bomb removal \\
\hline 146 & 471 & Explosive, bomb removal (for bomb scare, use 721) \\
\hline 147 & 48 & Attempted burning, illegal action \\
\hline 148 & 480 & Attempted burning, illegal action, other \\
\hline 149 & 481 & Attempt to burn \\
\hline 150 & 482 & Threat to burn \\
\hline 151 & 5 & Service Call \\
\hline 152 & 50 & Service call, other \\
\hline 153 & 500 & Service Call, other \\
\hline 154 & 51 & Person in distress \\
\hline 155 & 510 & Person in distress, other \\
\hline 156 & 511 & Lock-out \\
\hline 157 & 512 & Ring or jewelry removal \\
\hline 158 & 52 & Water problem \\
\hline 159 & 520 & Water problem, other \\
\hline 160 & 521 & Water evacuation \\
\hline 161 & 522 & Water or steam leak \\
\hline 162 & 53 & Smoke, odor problem \\
\hline 163 & 531 & Smoke or odor removal \\
\hline 164 & 54 & Animal problem or rescue \\
\hline 165 & 540 & Animal problem, other \\
\hline 166 & 541 & Animal problem \\
\hline 167 & 542 & Animal rescue \\
\hline 168 & 55 & Public service assistance \\
\hline
\end{tabular}




\begin{tabular}{|c|c|c|}
\hline 169 & 550 & Public service assistance, other \\
\hline 170 & 551 & Assist police or other governmental agency \\
\hline 171 & 552 & $\begin{array}{l}\text { Police matter } \\
\end{array}$ \\
\hline 172 & 553 & Public service \\
\hline 173 & 554 & Assist invalid \\
\hline 174 & 555 & Defective elevator, no occupants \\
\hline 175 & 56 & Unauthorized burning \\
\hline 176 & 561 & Unauthorized burning \\
\hline 177 & 57 & Cover assignment, standby at fire station, move-up \\
\hline 178 & 571 & Cover assignment, standby, moveup \\
\hline 179 & 6 & Good Intent Call \\
\hline 180 & 60 & Good intent call, other \\
\hline 181 & 600 & Good intent call, other \\
\hline 182 & 61 & Dispatched and canceled en route \\
\hline 183 & 611 & Dispatched \& canceled en route \\
\hline 184 & 62 & Wrong location, no emergency found \\
\hline 185 & 621 & Wrong location \\
\hline 186 & 622 & No incident found on arrival at dispatch address \\
\hline 187 & 63 & Controlled burning \\
\hline 188 & 631 & Authorized controlled burning \\
\hline 189 & 632 & Prescribed fire \\
\hline 190 & 64 & Vicinity alarm \\
\hline 191 & 641 & Vicinity alarm (incident in other location) \\
\hline 192 & 65 & Steam, other gas mistaken for smoke \\
\hline 193 & 650 & Steam, other gas mistaken for smoke, other \\
\hline 194 & 651 & Smoke scare, odor of smoke \\
\hline 195 & 652 & Steam, vapor, fog or dust thought to be smoke \\
\hline 196 & 653 & Smoke from barbecue, tar kettle \\
\hline 197 & 66 & EMS call where party has been transported \\
\hline 198 & 661 & EMS call, party transported by non-fire agency \\
\hline 199 & 67 & HazMat release investigation w/no HazMat \\
\hline 200 & 671 & HazMat release investigation w/no HazMat \\
\hline 201 & 672 & Biological hazard investigation, none found \\
\hline 202 & 7 & False Alarm \& False Call \\
\hline 203 & 70 & False alarm and false call, other \\
\hline 204 & 700 & False alarm or false call, other \\
\hline 205 & 71 & Malicious, mischievous false alarm \\
\hline 206 & 710 & Malicious, mischievous false call, other \\
\hline 207 & 711 & Municipal alarm system, malicious false alarm \\
\hline 208 & 712 & Direct tie to FD, malicious false alarm \\
\hline 209 & 713 & Telephone, malicious false alarm \\
\hline 210 & 714 & Central station, malicious false alarm \\
\hline 211 & 715 & Local alarm system, malicious false alarm \\
\hline
\end{tabular}




\begin{tabular}{|c|c|c|}
\hline 212 & 72 & Bomb scare \\
\hline 213 & 721 & Bomb scare - no bomb \\
\hline 214 & 73 & System or detector malfunction \\
\hline 215 & 730 & System malfunction, other \\
\hline 216 & 731 & Sprinkler activation due to malfunction \\
\hline 217 & 732 & Extinguishing system activation due to malfunction \\
\hline 218 & 733 & Smoke detector activation due to malfunction \\
\hline 219 & 734 & Heat detector activation due to malfunction \\
\hline 220 & 735 & Alarm system sounded due to malfunction \\
\hline 221 & 736 & $\mathrm{CO}$ detector activation due to malfunction \\
\hline 222 & 74 & Unintentional system/detector operation (no fire) \\
\hline 223 & 740 & Unintentional transmission of alarm, other \\
\hline 224 & 741 & Sprinkler activation, no fire - unintentional \\
\hline 225 & 742 & Extinguishing system activation \\
\hline 226 & 743 & Smoke detector activation, no fire - unintentional \\
\hline 227 & 744 & Detector activation, no fire - unintentional \\
\hline 228 & 745 & Alarm system activation, no fire - unintentional \\
\hline 229 & 746 & Carbon monoxide detector activation, no CO \\
\hline 230 & 75 & Biohazard scare \\
\hline 231 & 751 & Biological hazard, malicious false report \\
\hline 232 & 8 & Severe Weather \& Natural Disaster \\
\hline 233 & 800 & Severe weather or natural disaster, other \\
\hline 234 & 811 & Earthquake assessment \\
\hline 235 & 812 & Flood assessment \\
\hline 236 & 813 & Wind storm, tornado/hurricane assessment \\
\hline 237 & 814 & Lightning strike (no fire) \\
\hline 238 & 815 & Severe weather or natural disaster standby \\
\hline 239 & 9 & Special Incident Type \\
\hline 240 & 90 & Special type of incident, other \\
\hline 241 & 900 & Special type of incident, other \\
\hline 242 & 91 & Citizen complaint \\
\hline 243 & 911 & Citizen complaint \\
\hline 244 & UUU & Undetermined incident type (conversion only) \\
\hline
\end{tabular}




\section{Appendix C. ActionScript Classes Code}

\section{CalendarWeeksDataObj .as}

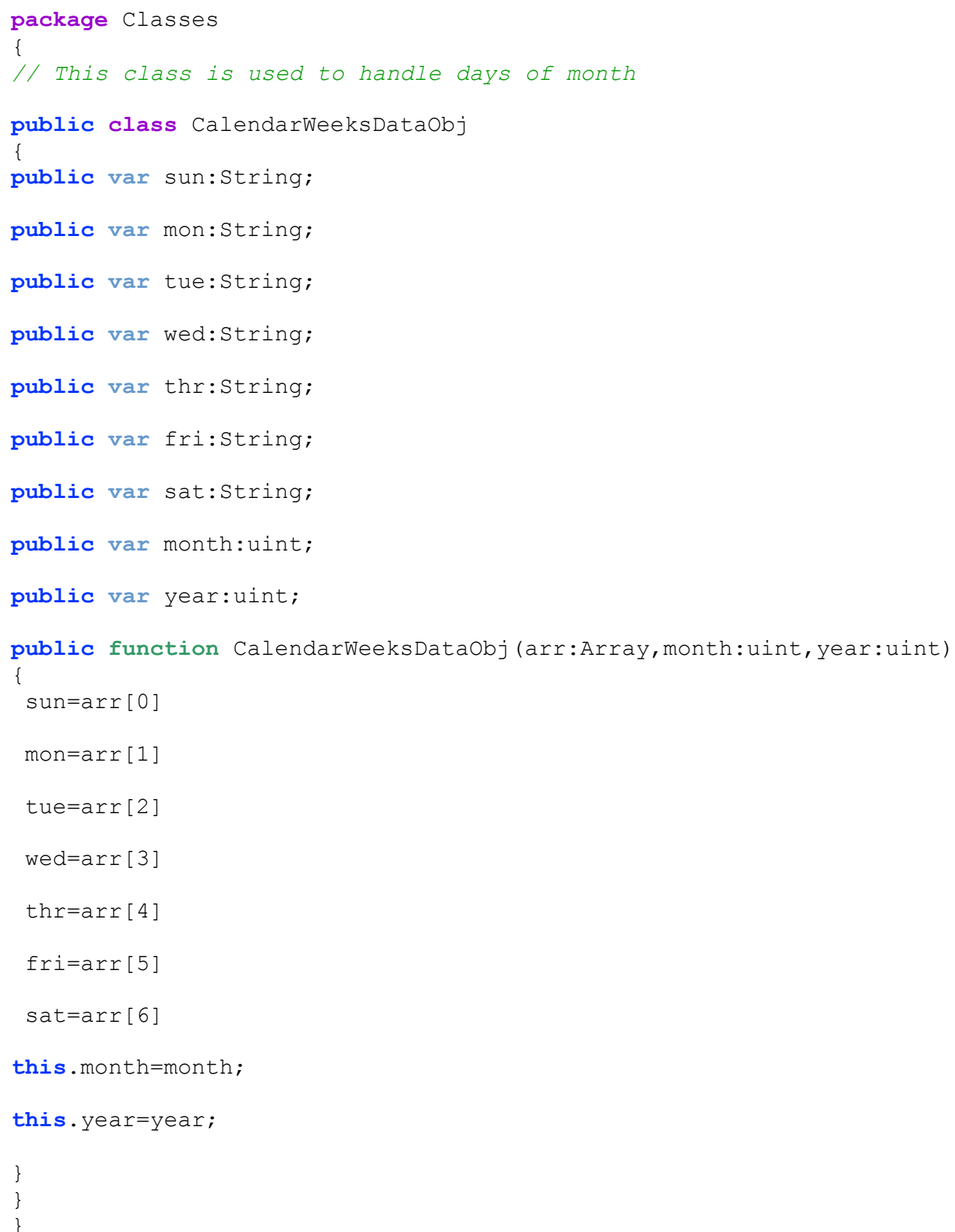




\section{ChartsDataCollection.as}

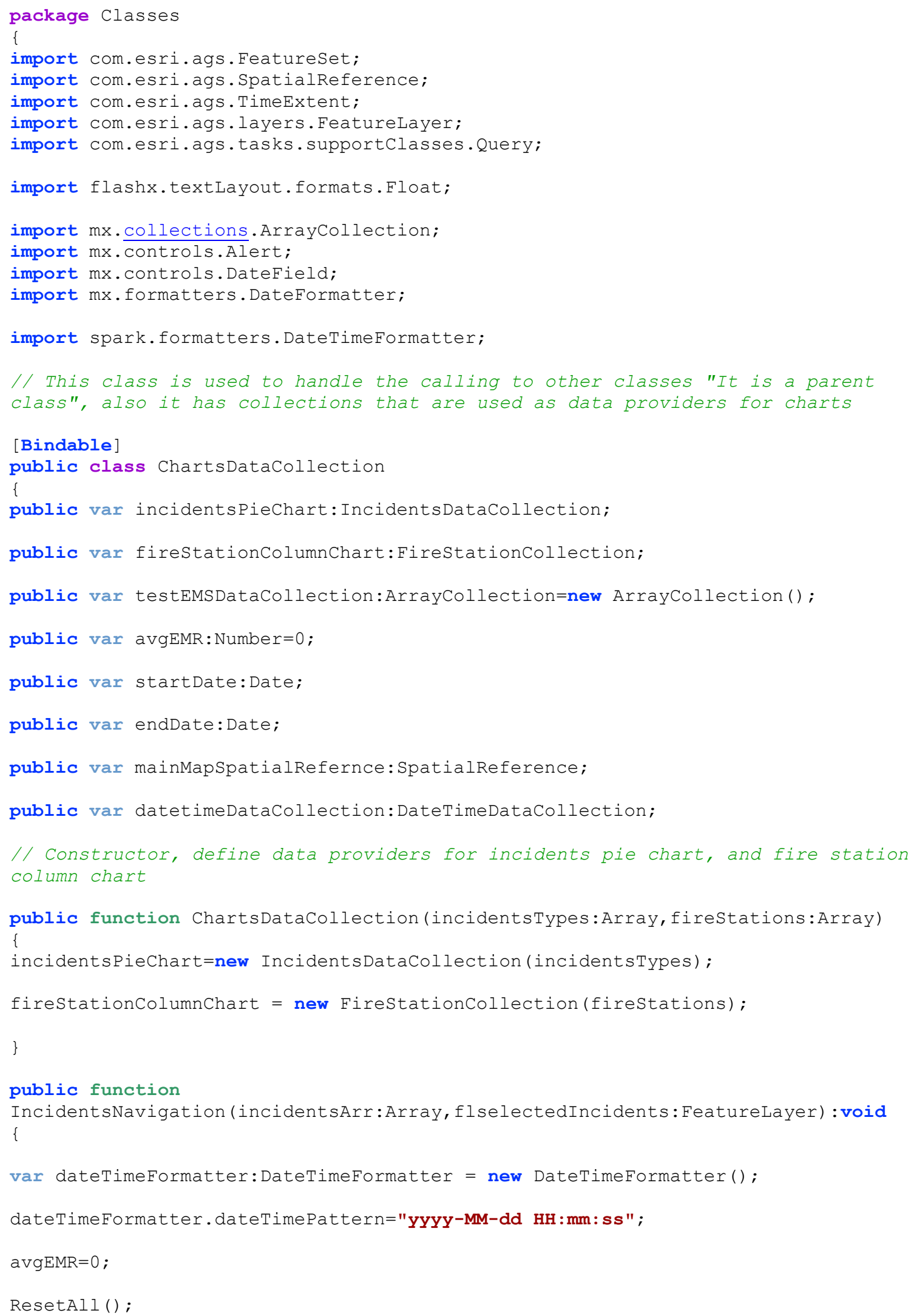




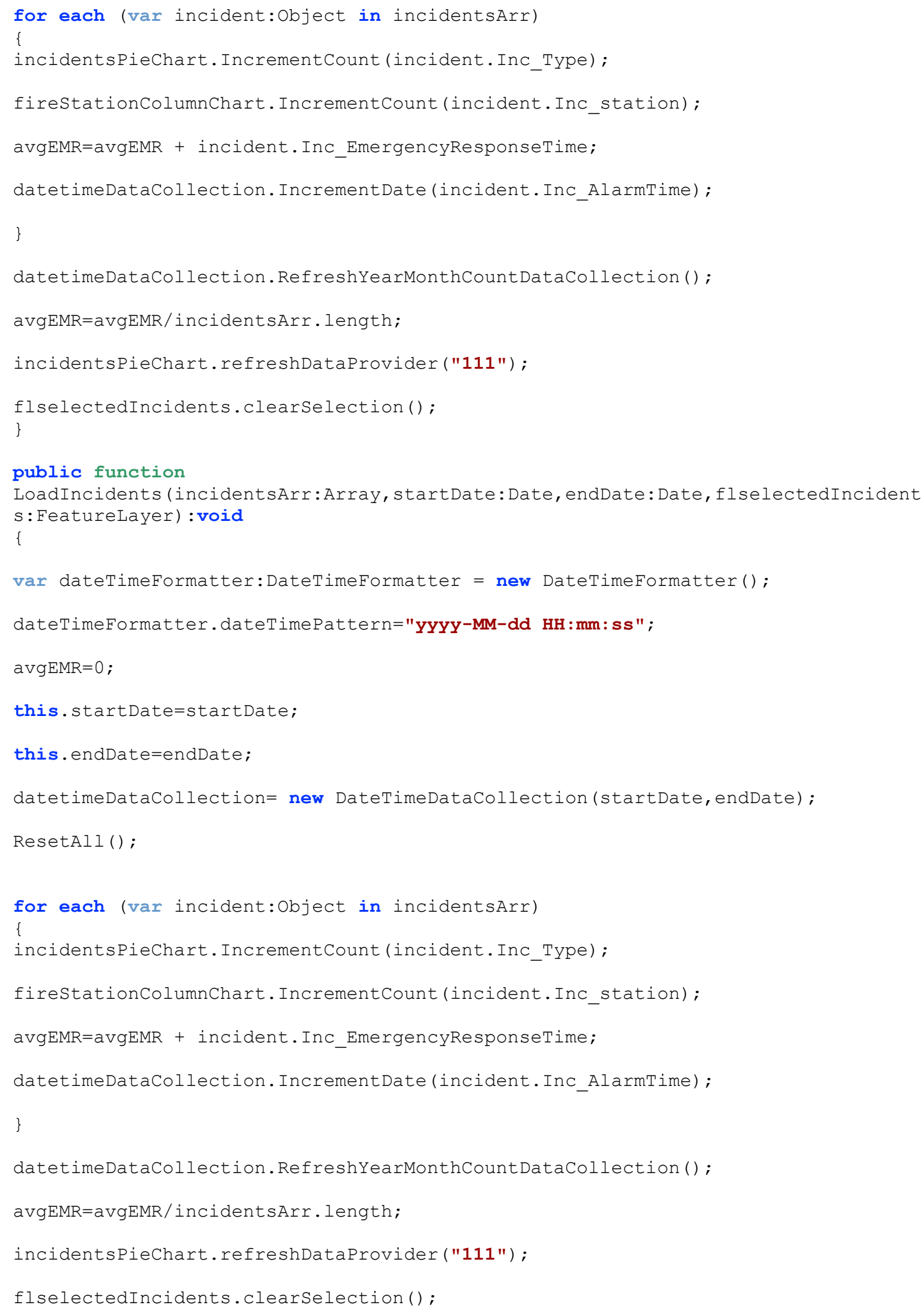




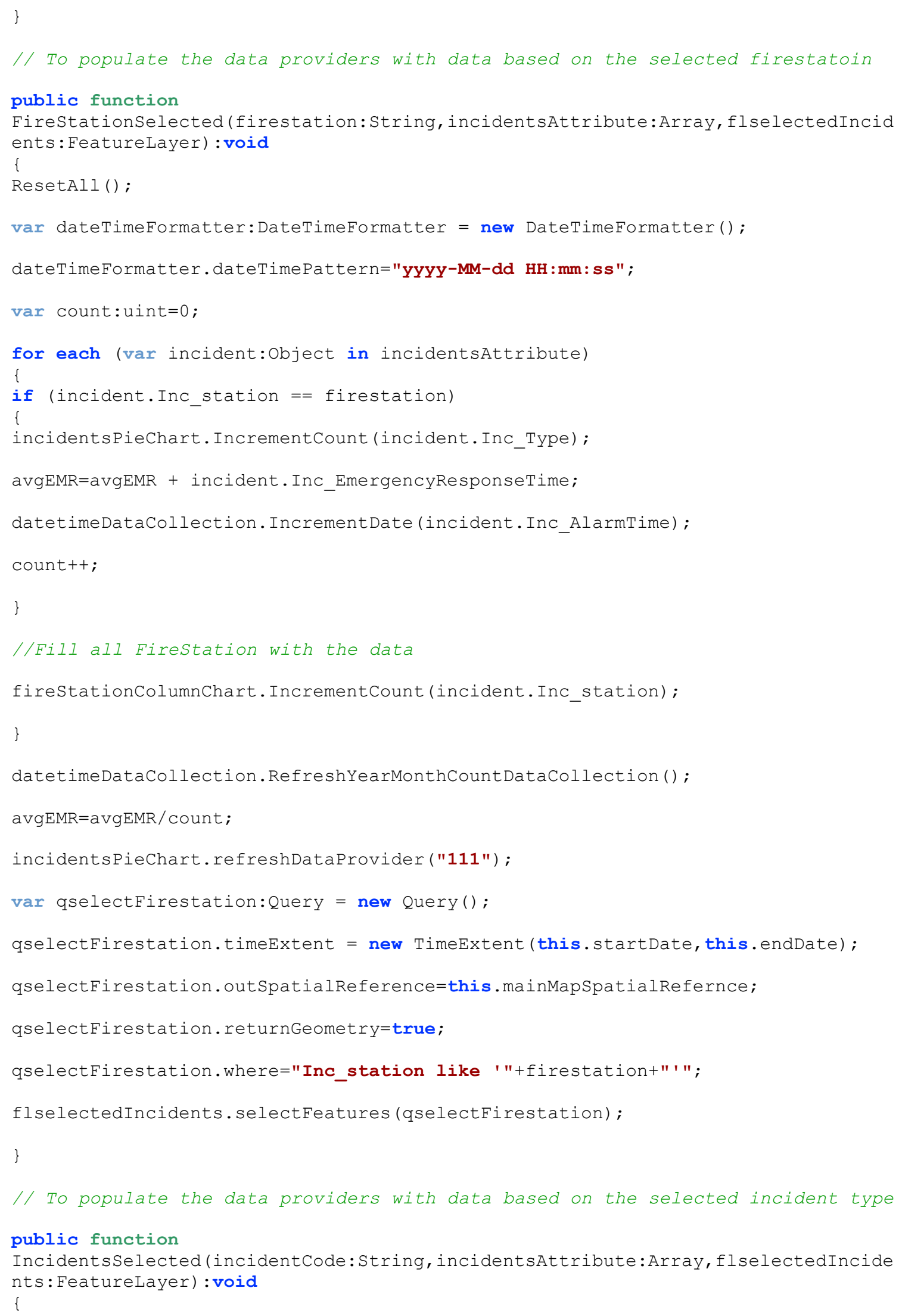




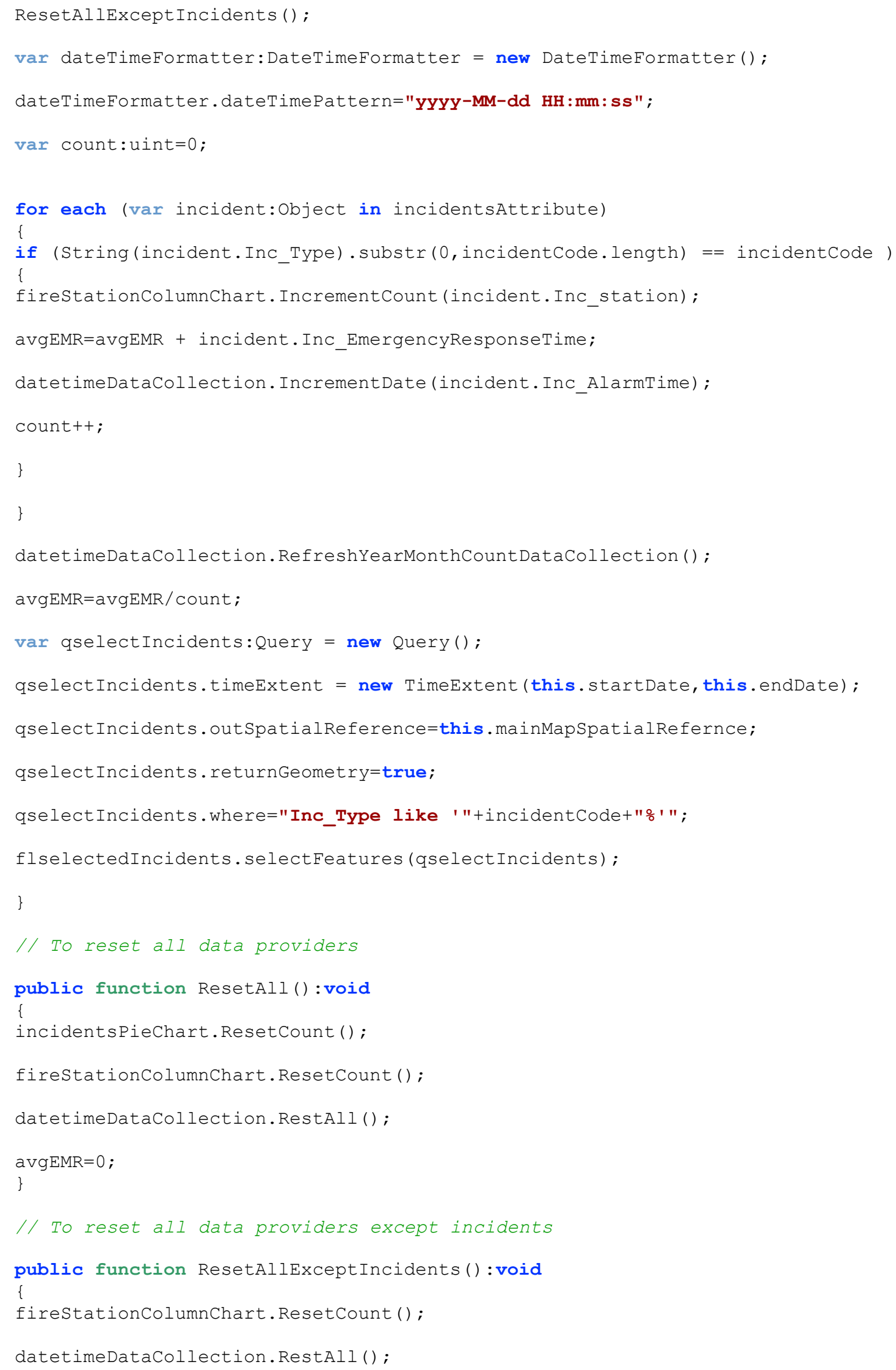




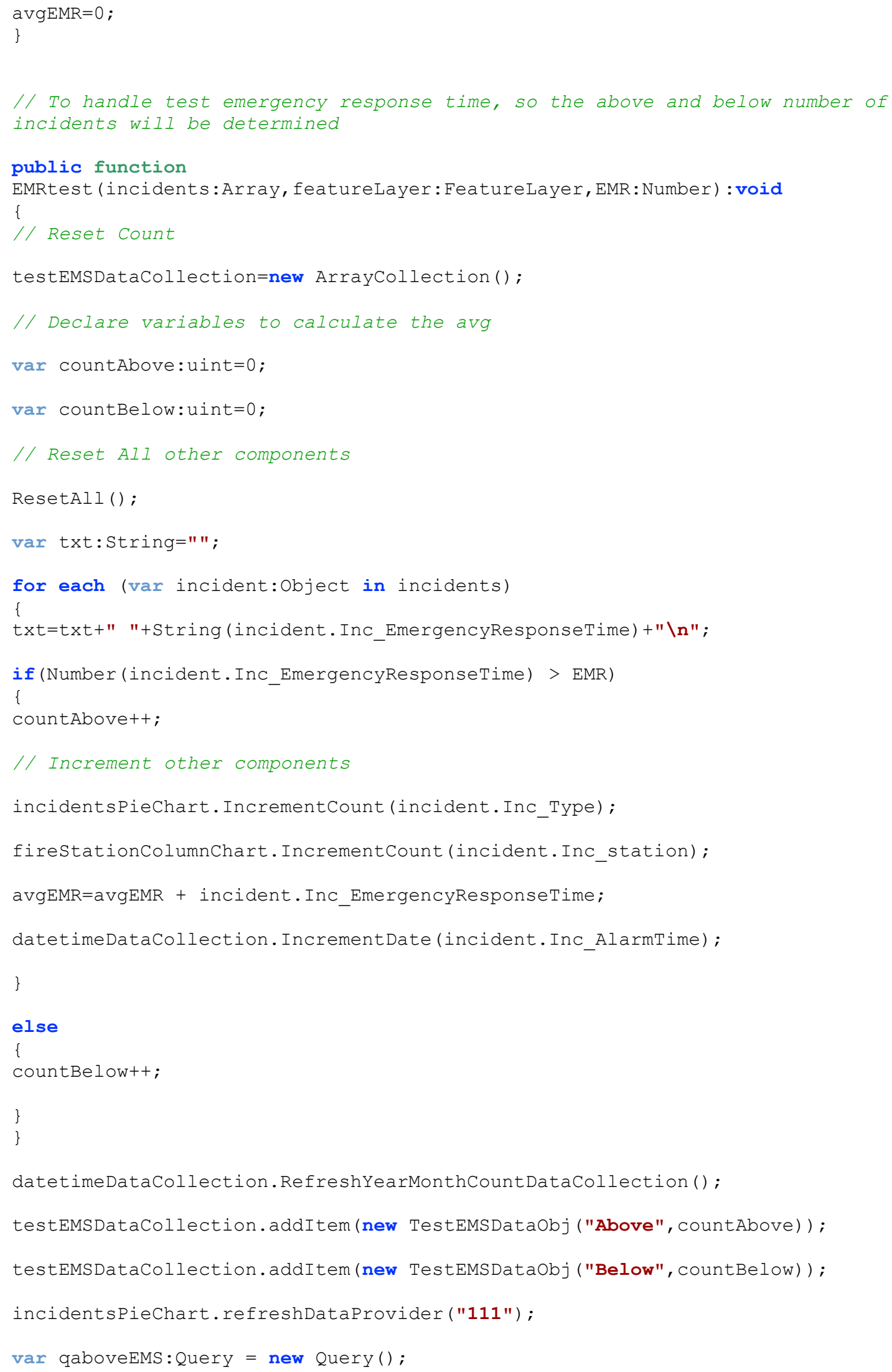




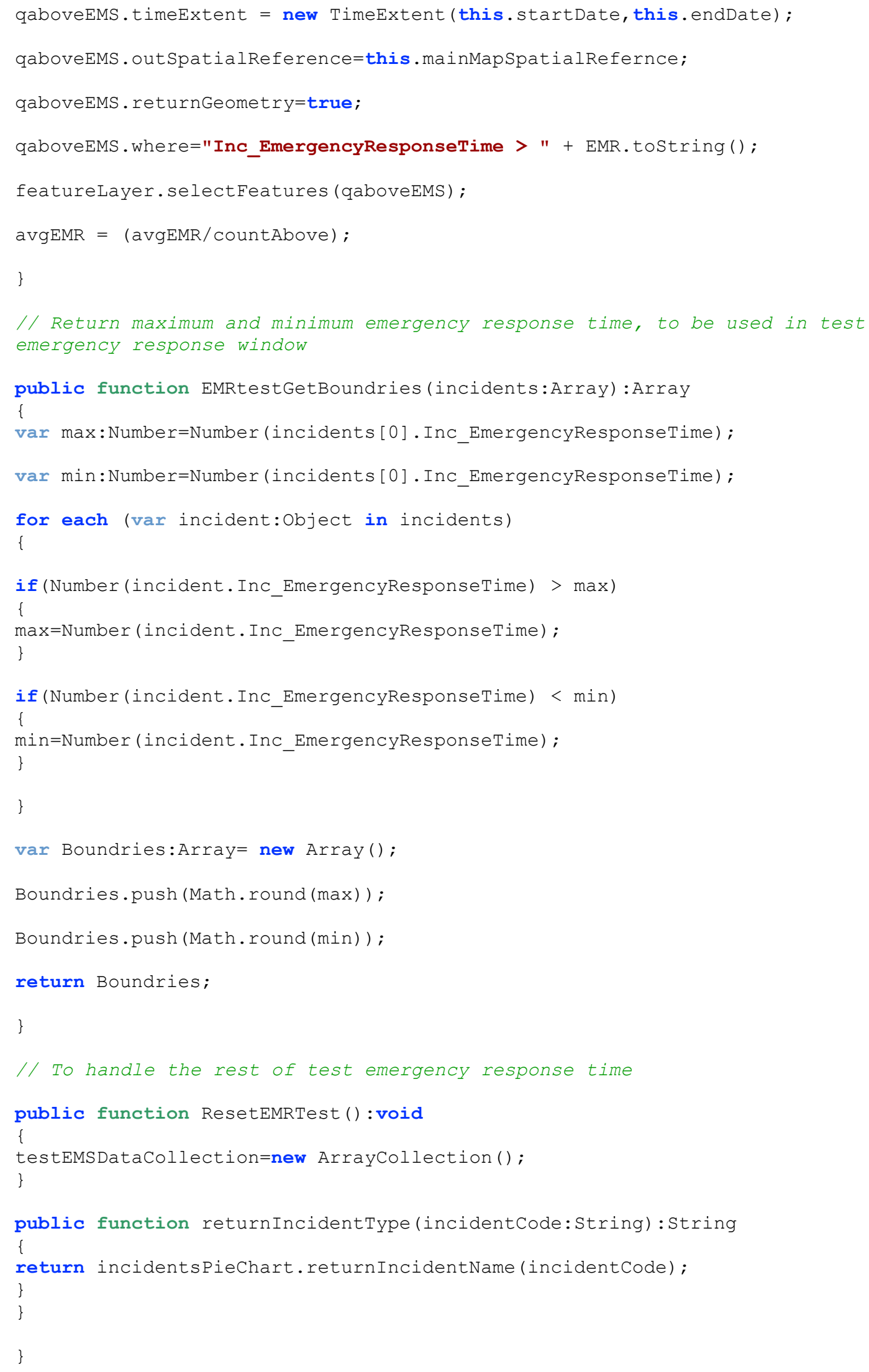




\section{DateTimeDataCollection.as}

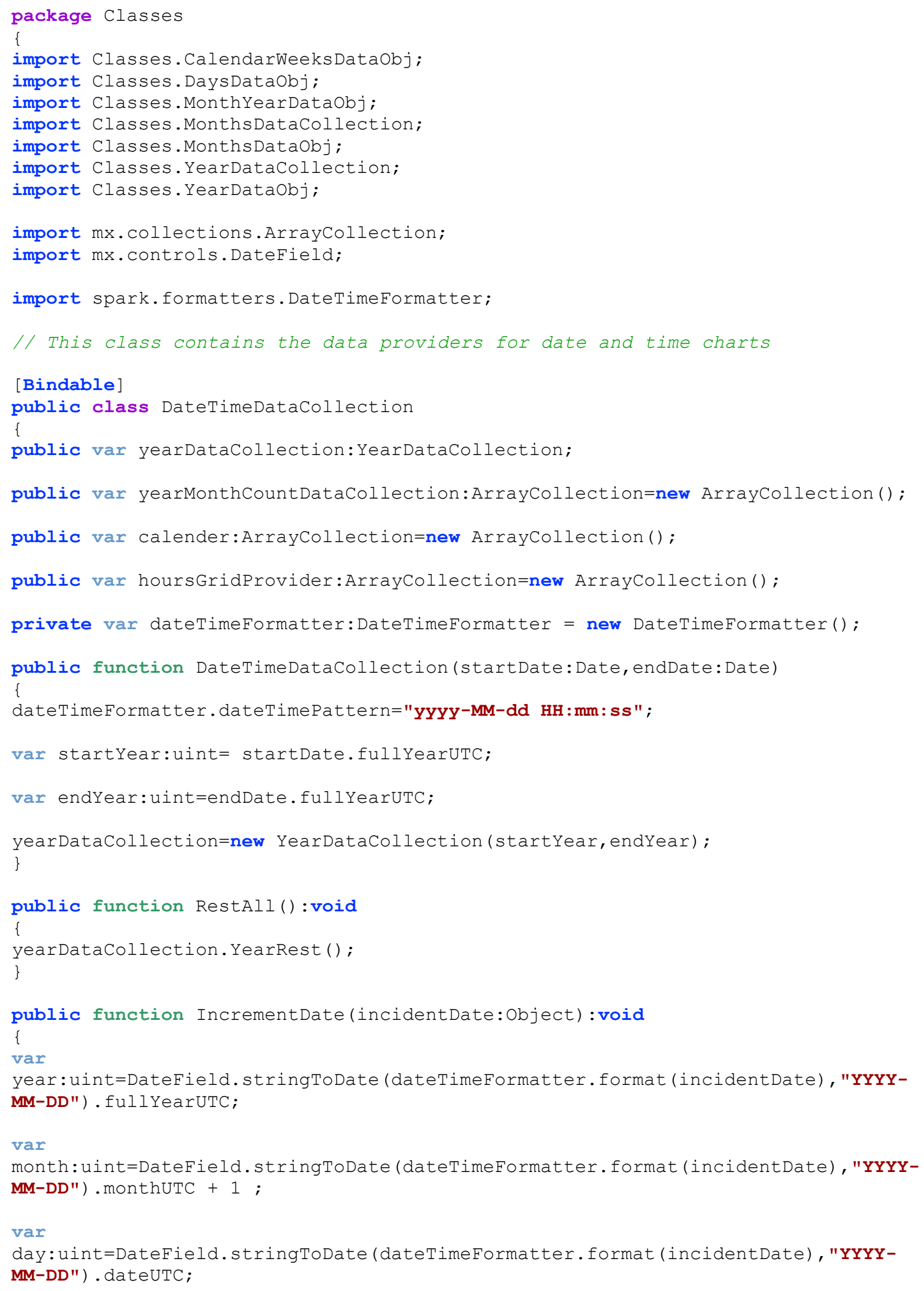




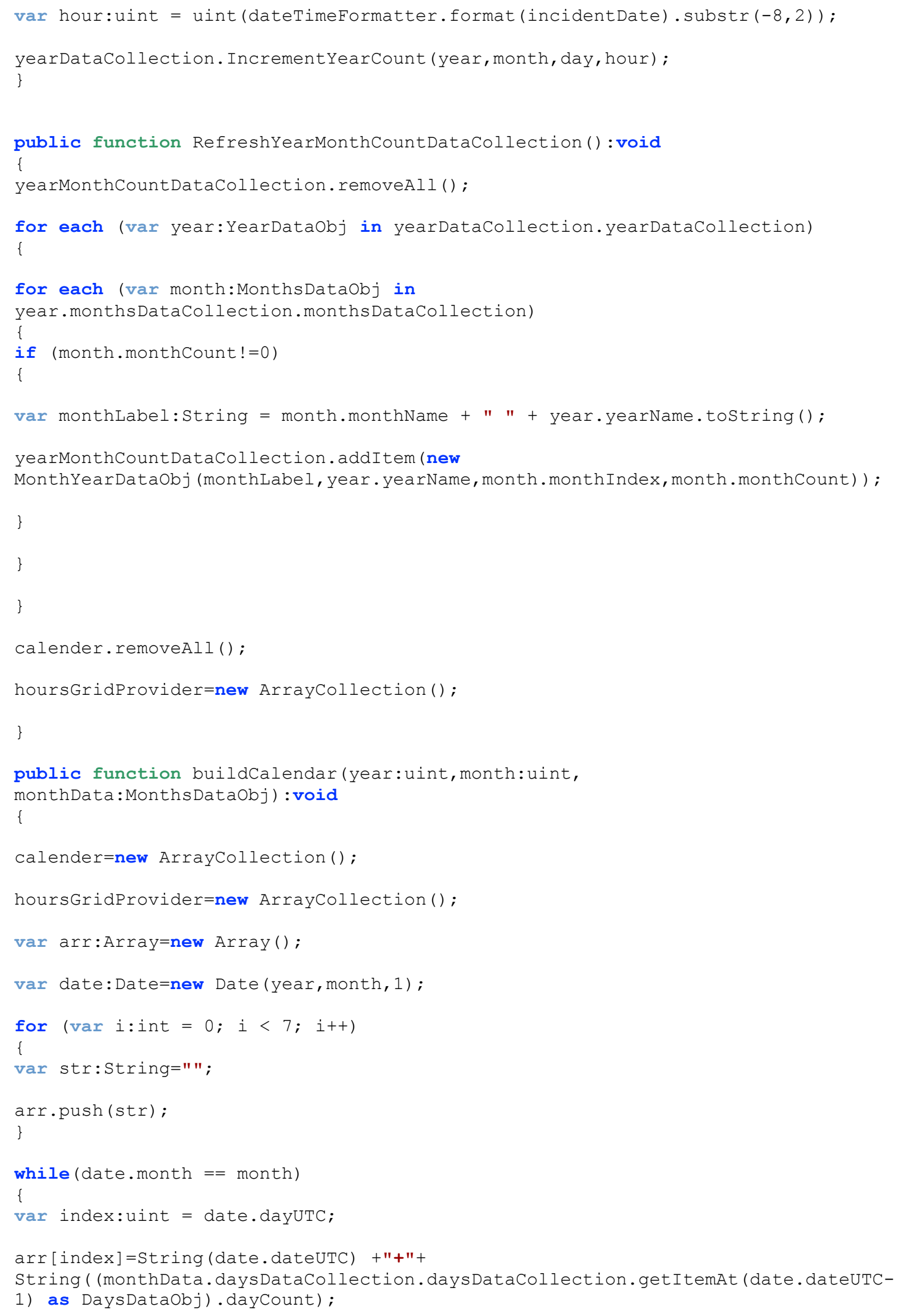




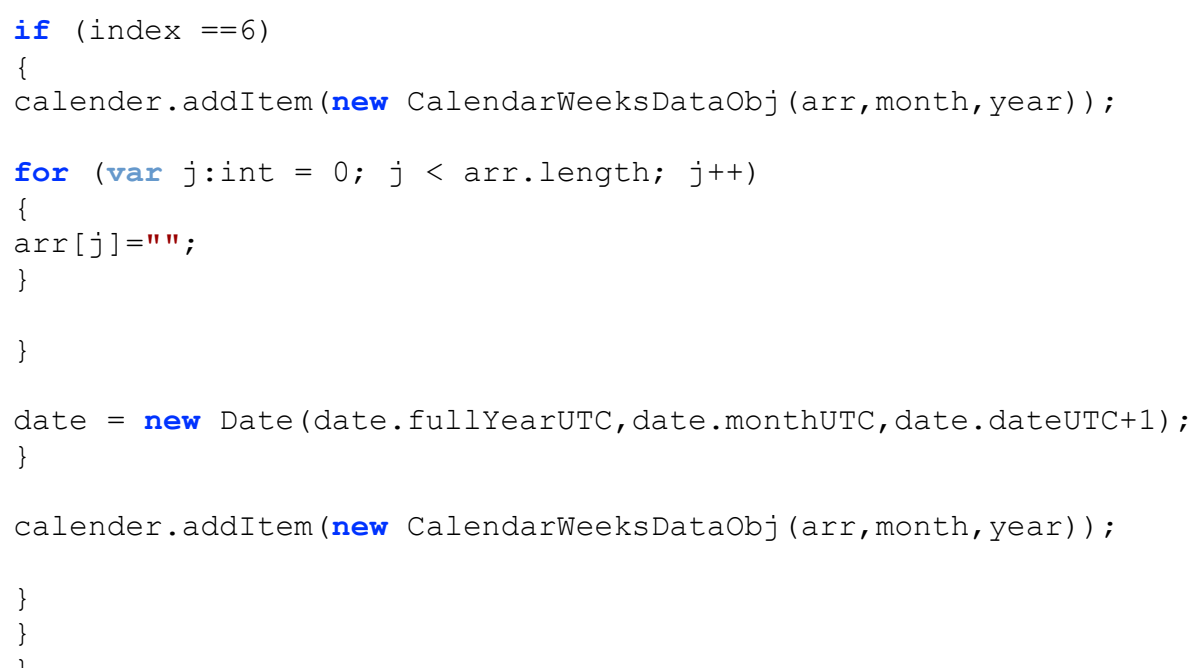




\section{DaysDataCollection.as}

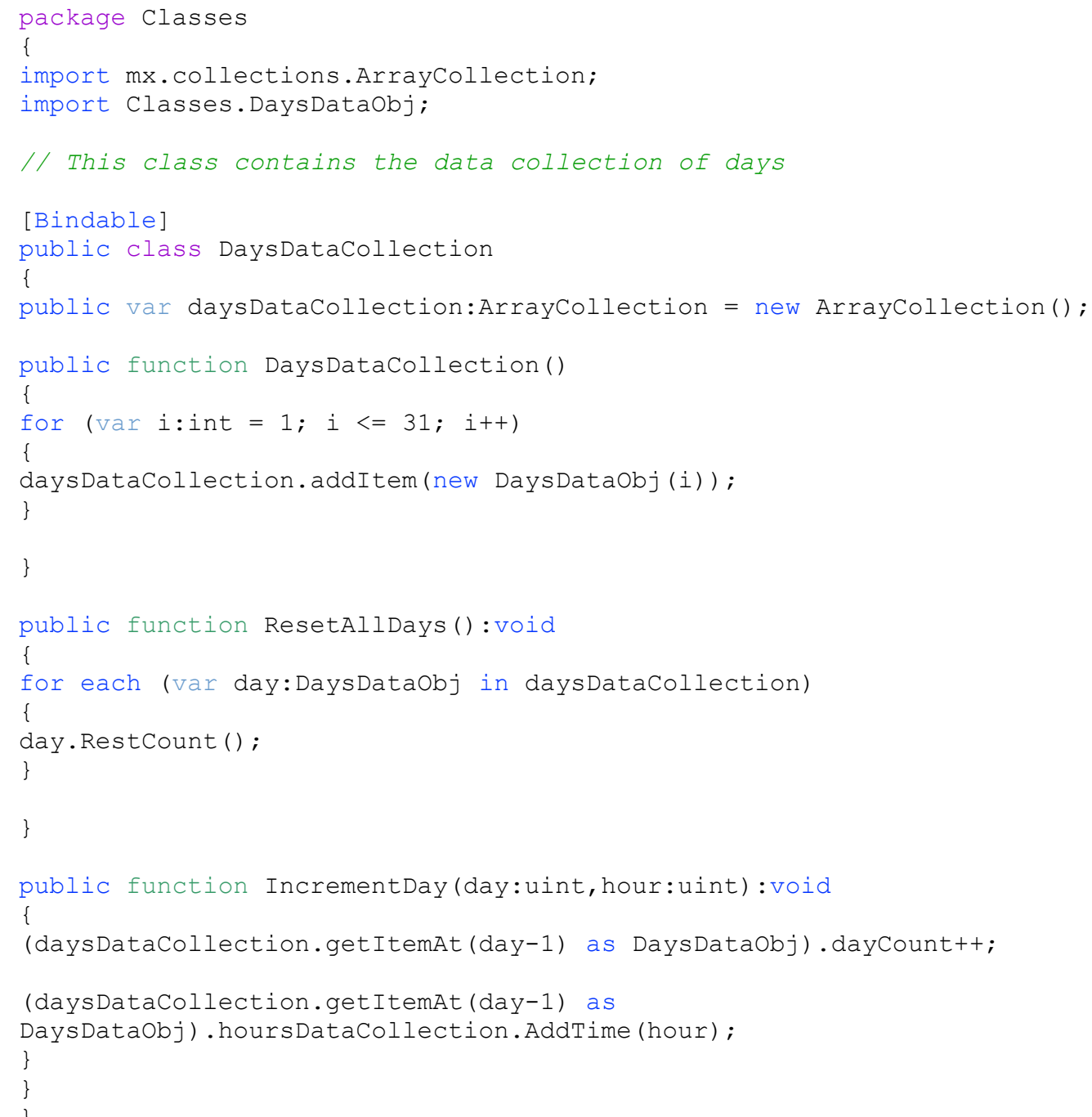




\section{DaysDataObj.as}

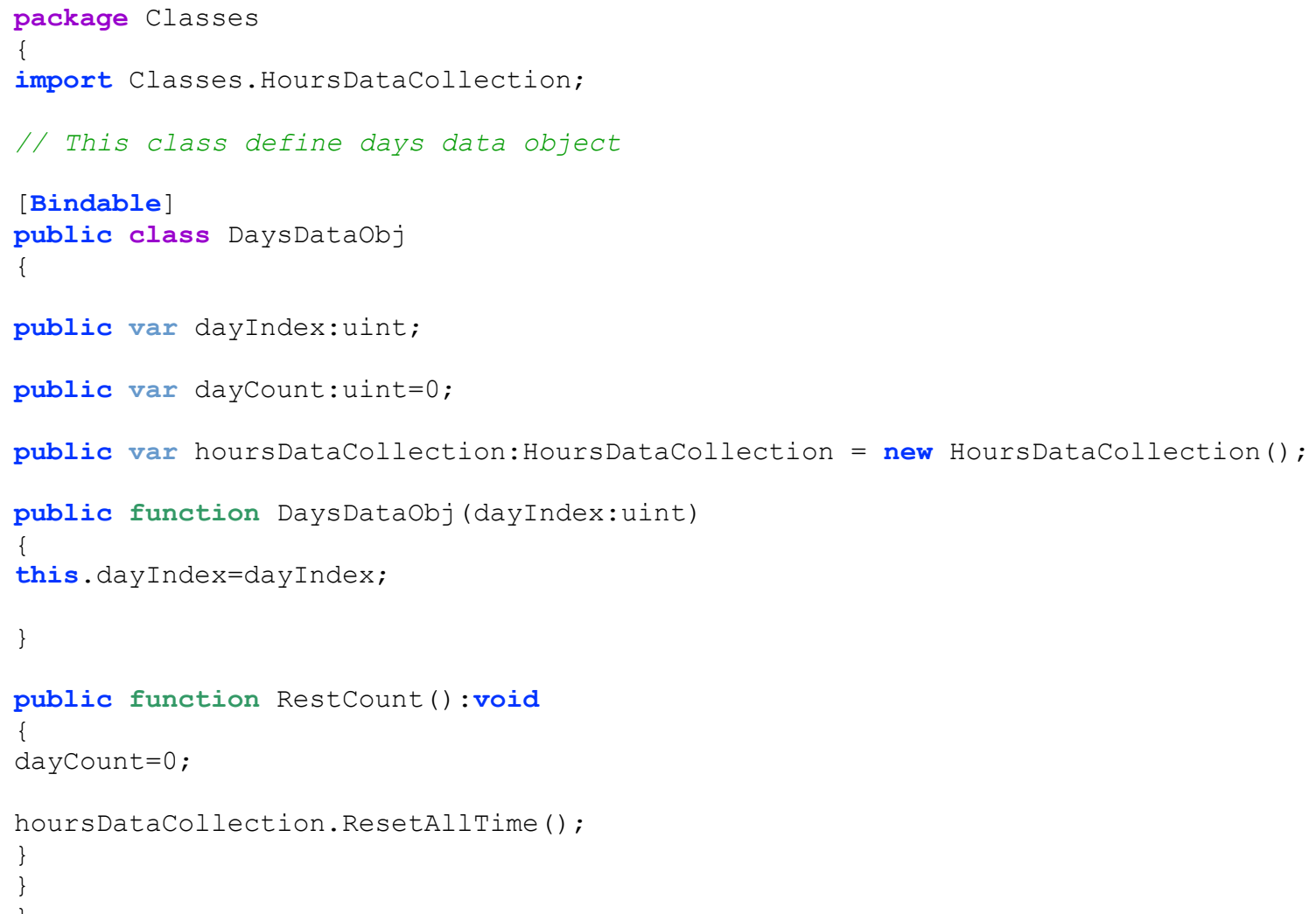




\section{FirestationCollection.as}

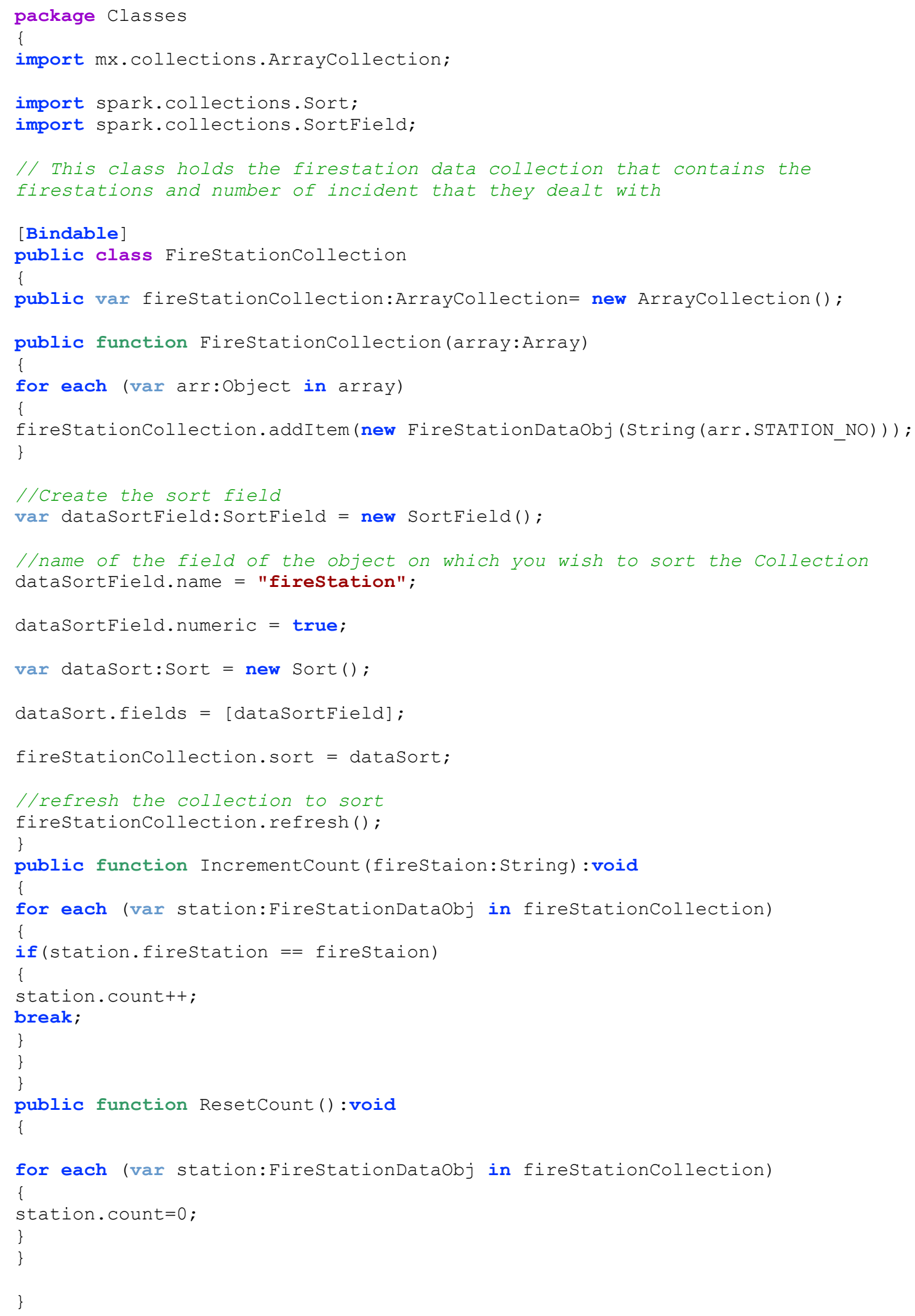




\section{FirestationDataobj.as}

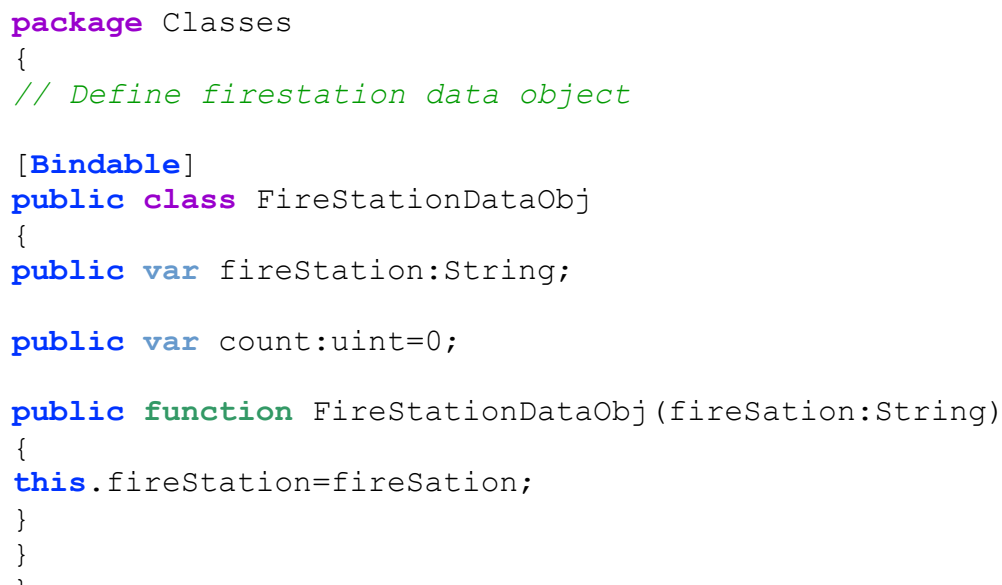




\section{HoursDataCollection.as}

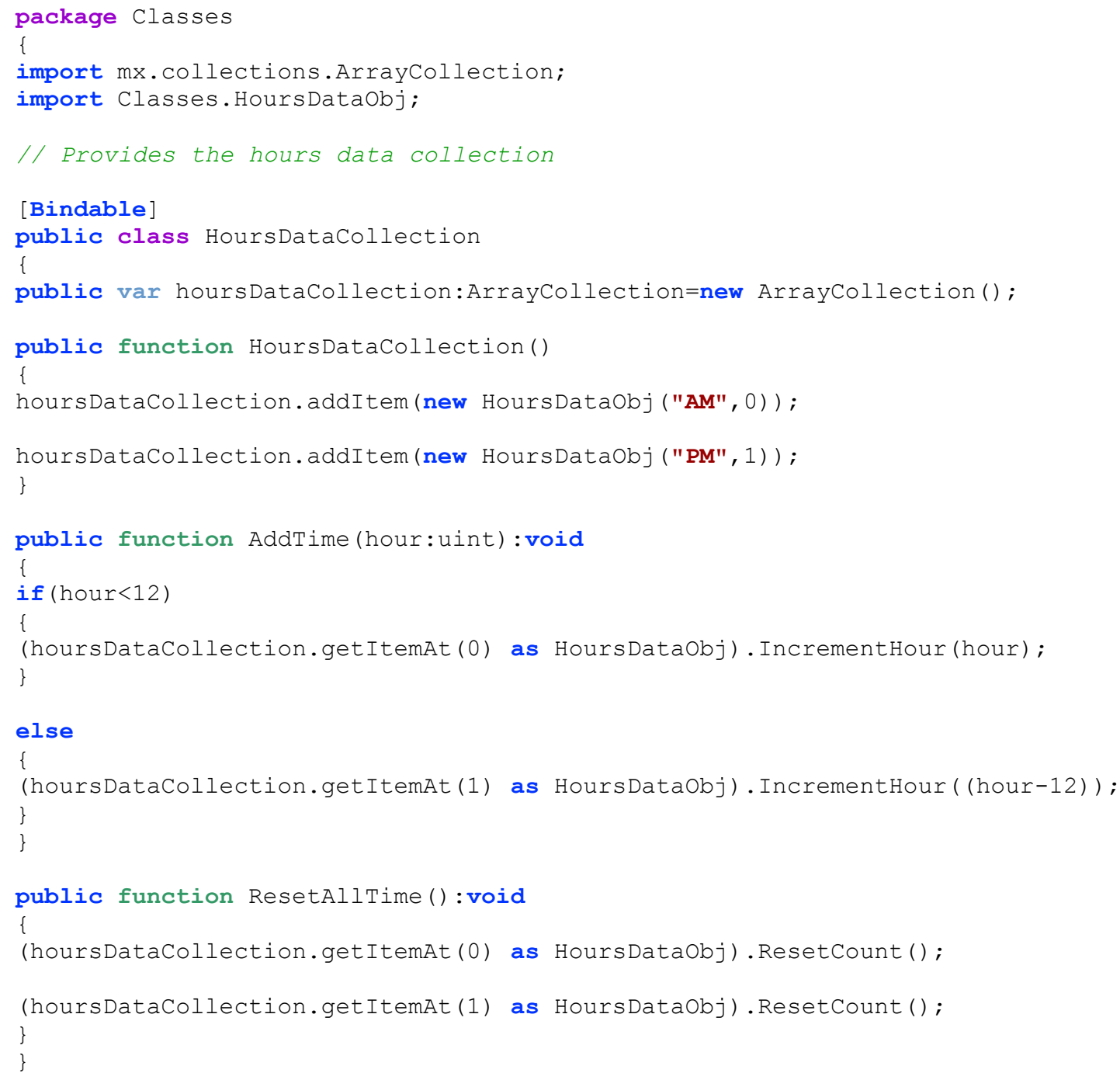




\section{HoursDataObj .as}

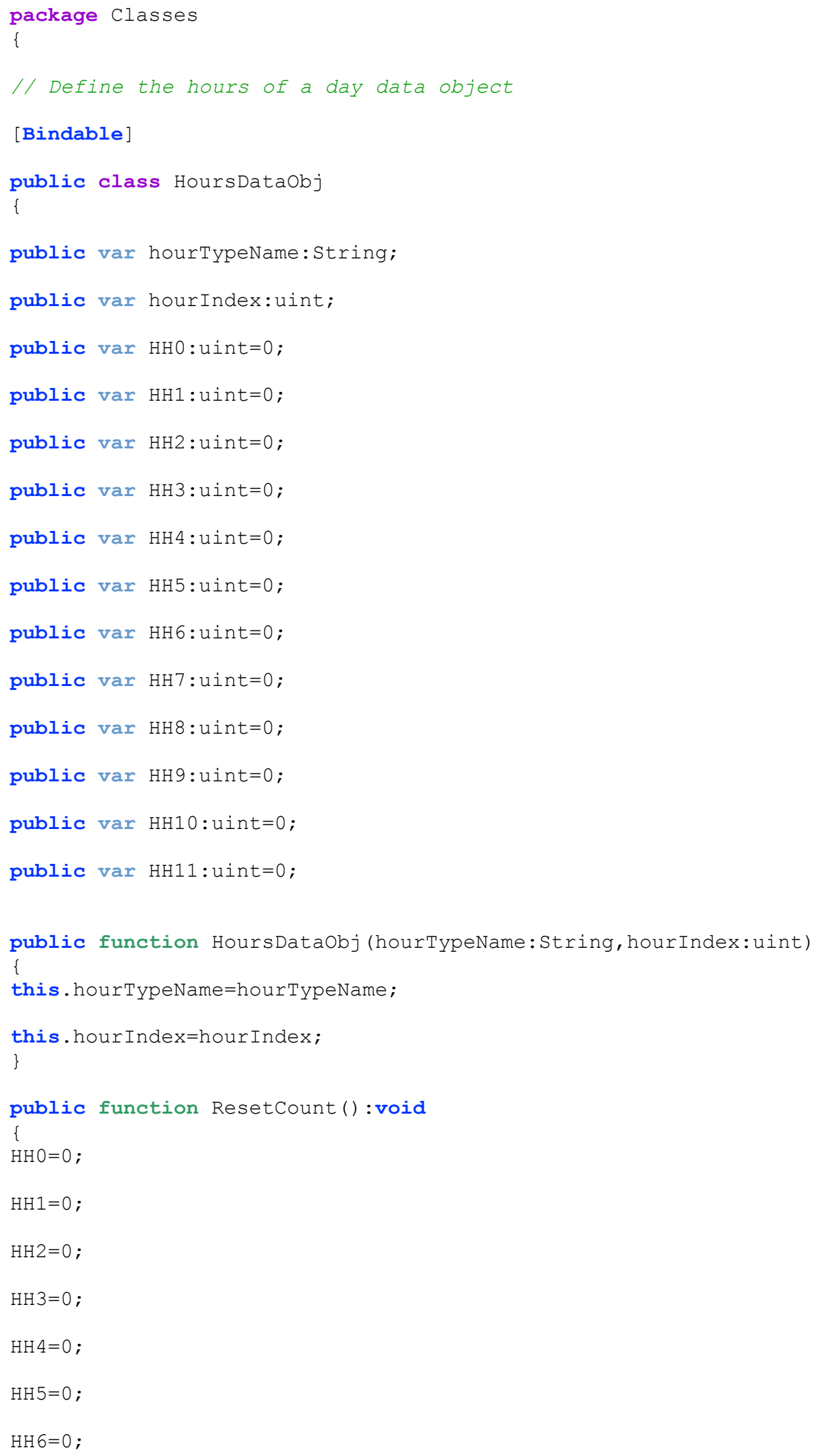




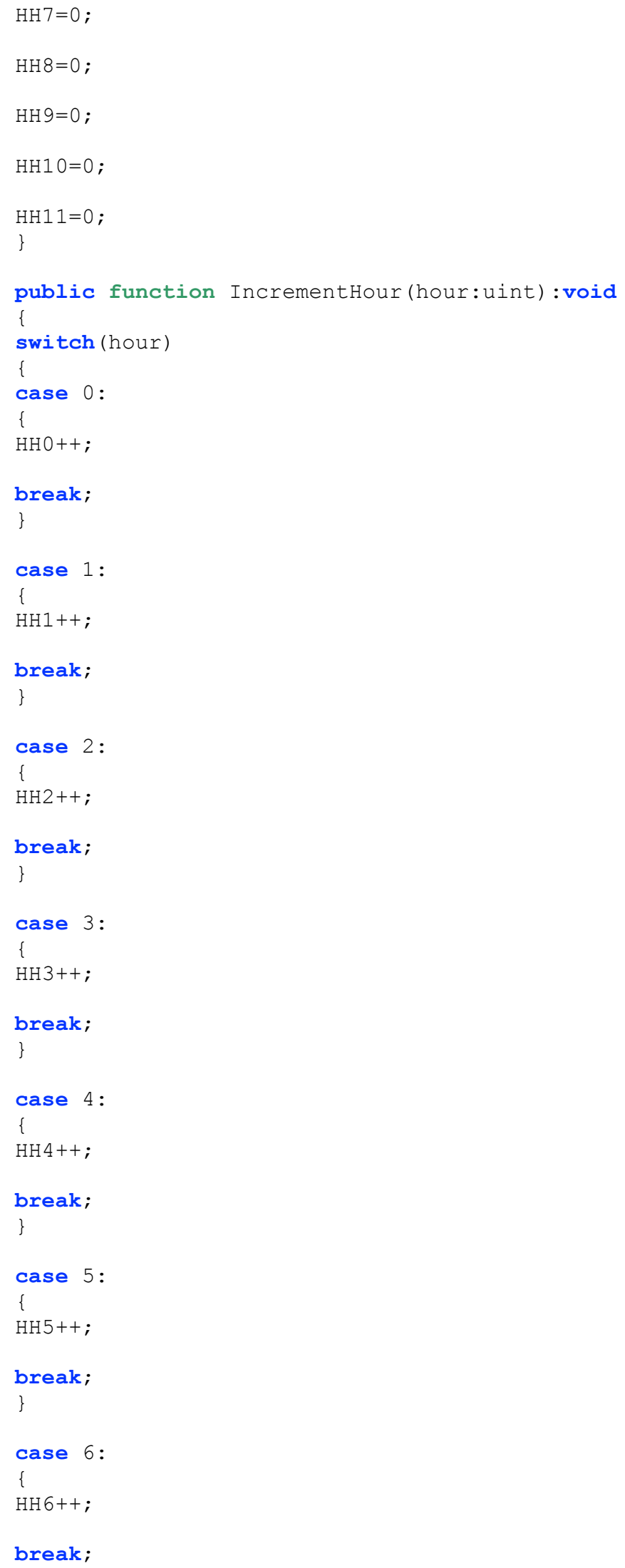




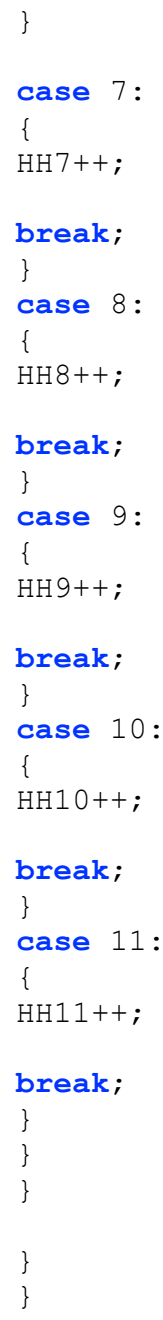




\section{IncidentDataObj.as}

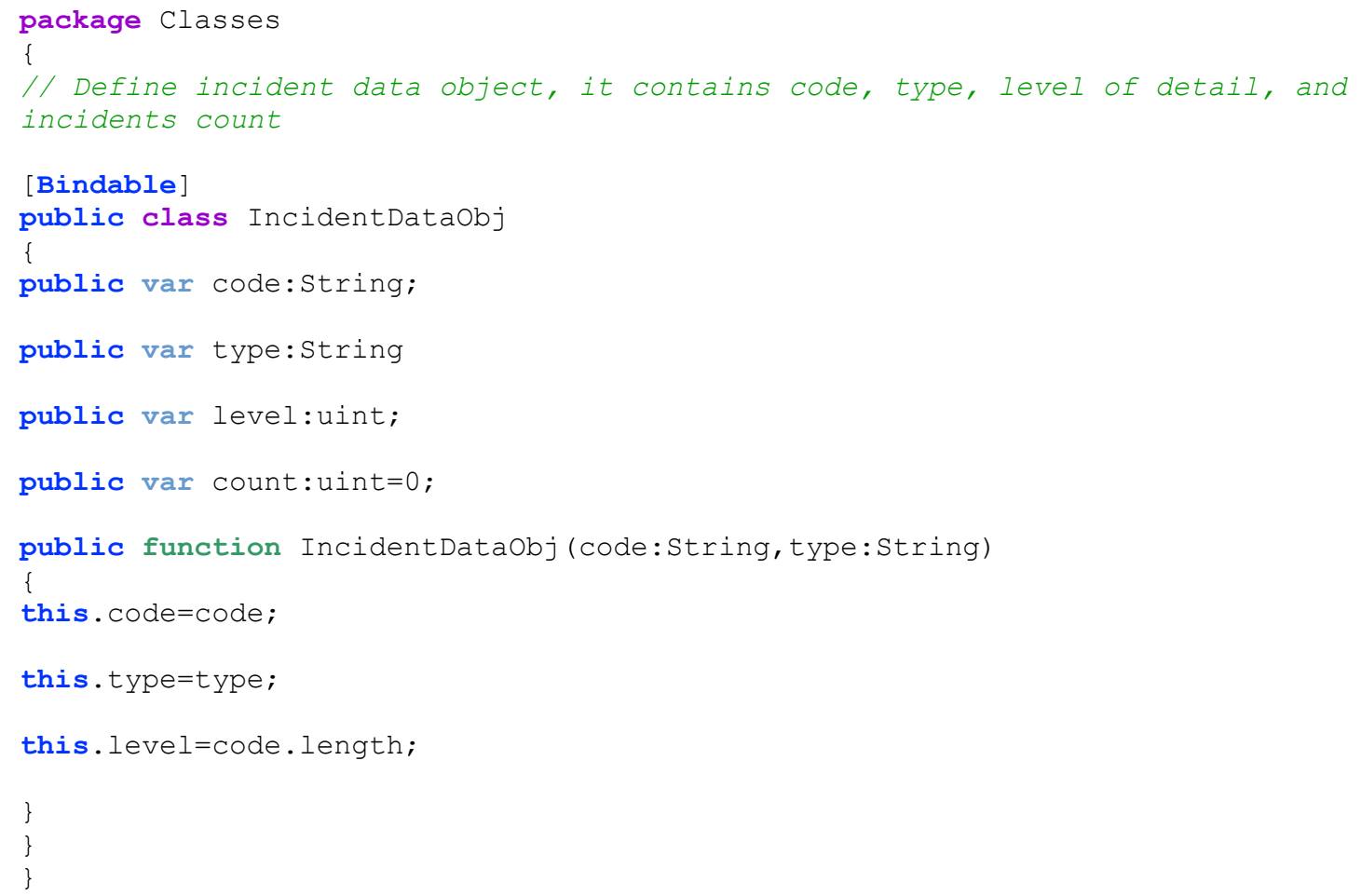




\section{IncidentsDataCollection.as}

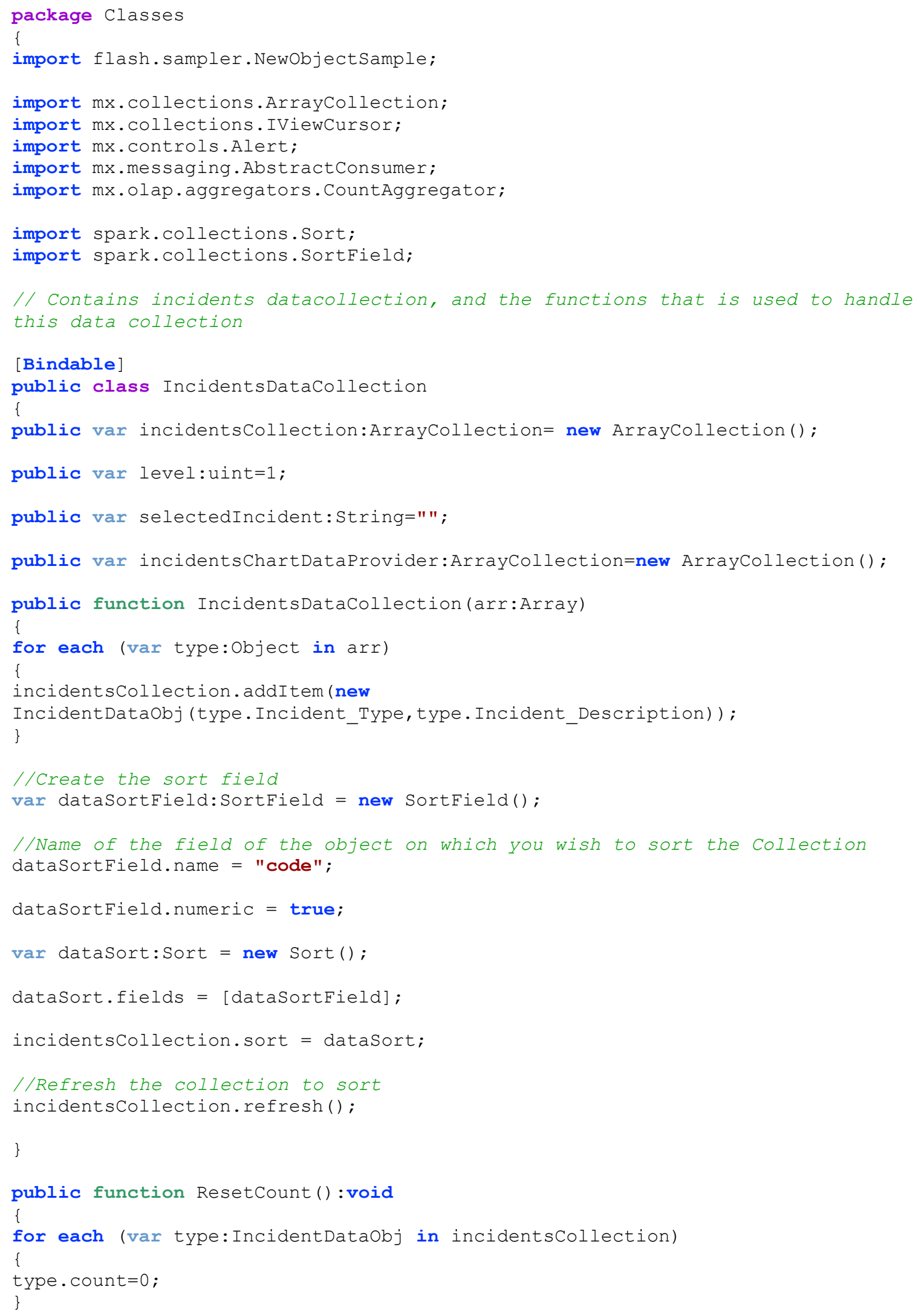




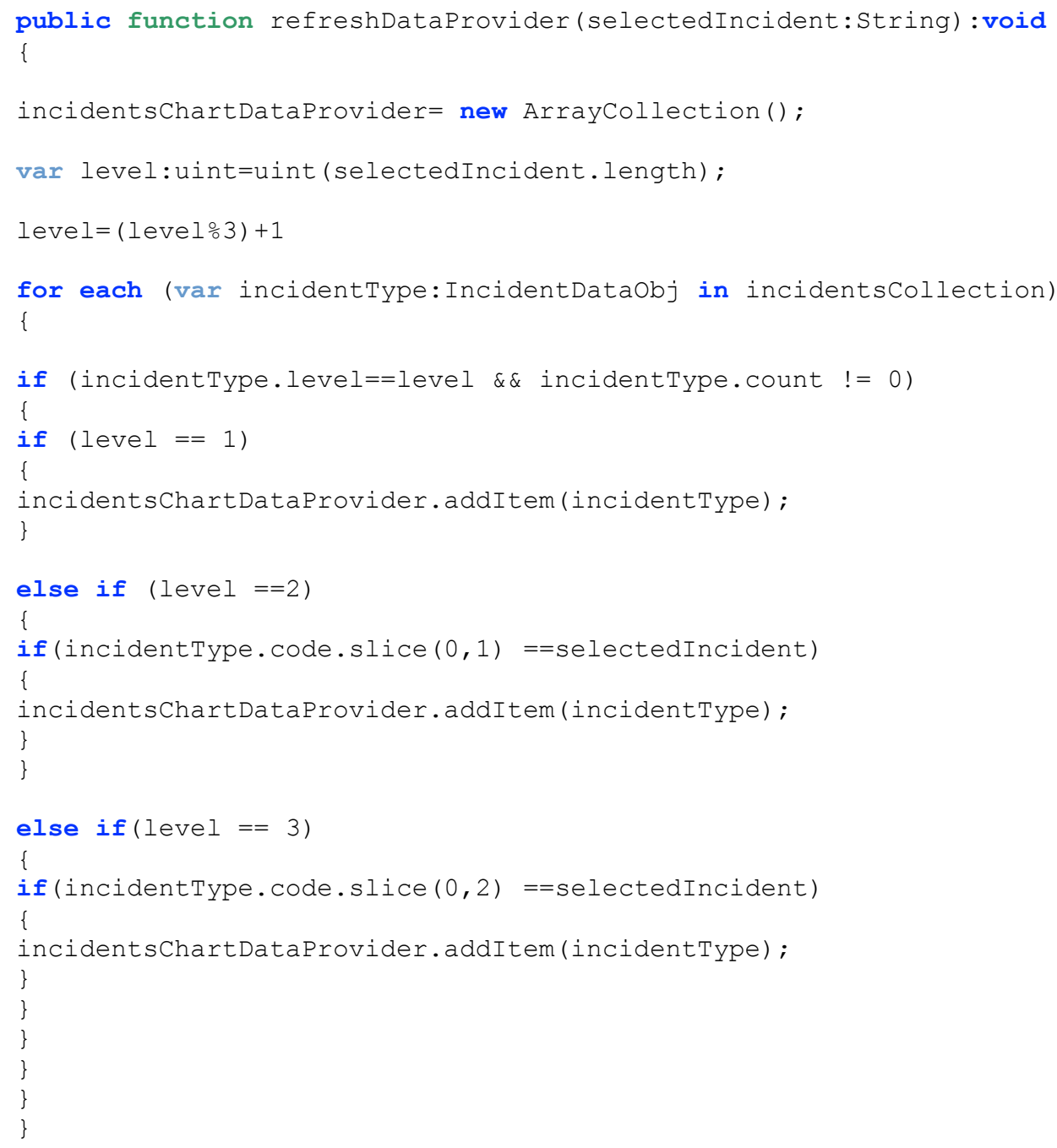




\section{MonthsDataCollection.as}

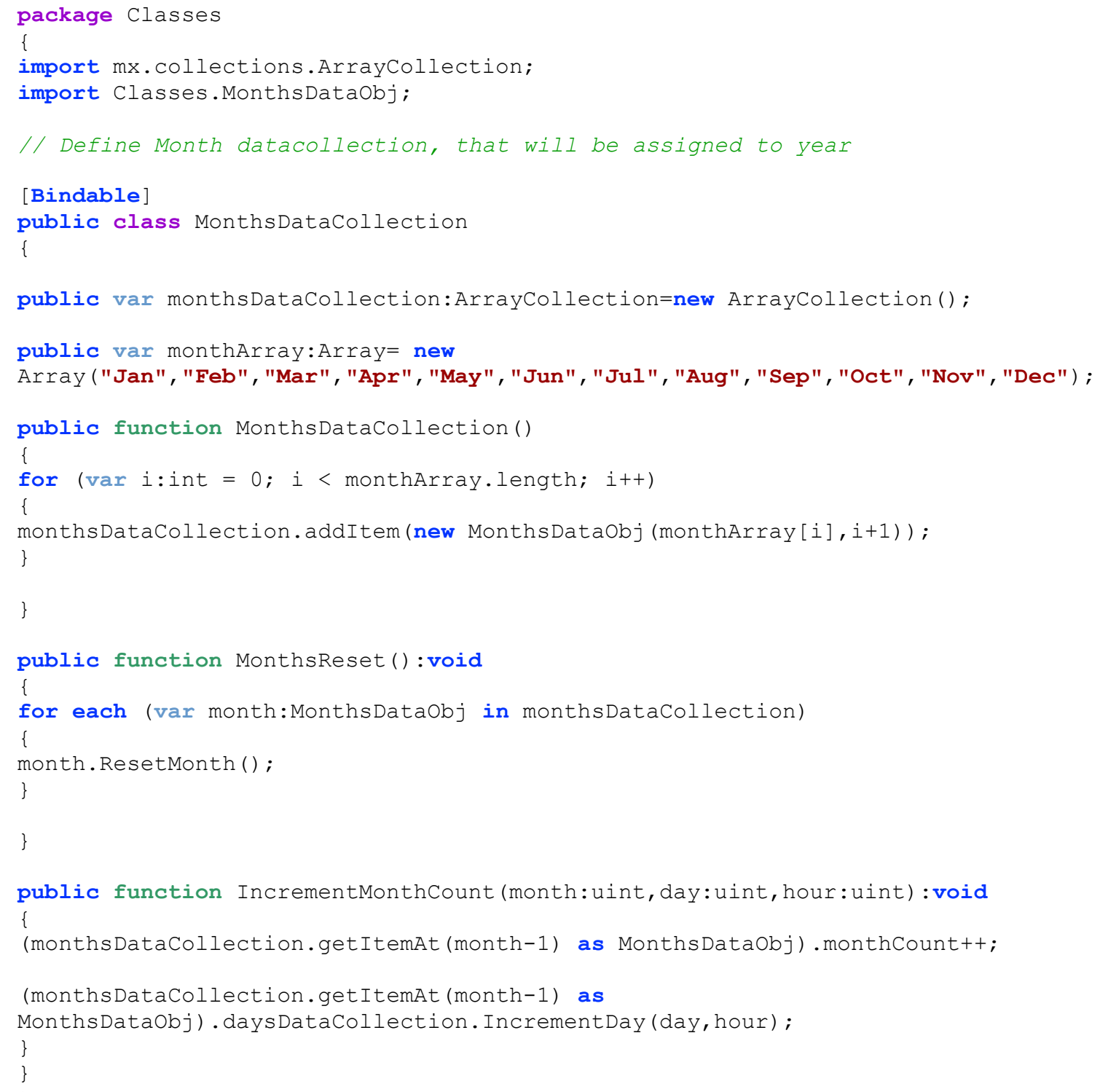




\section{MonthsDataObj.as}

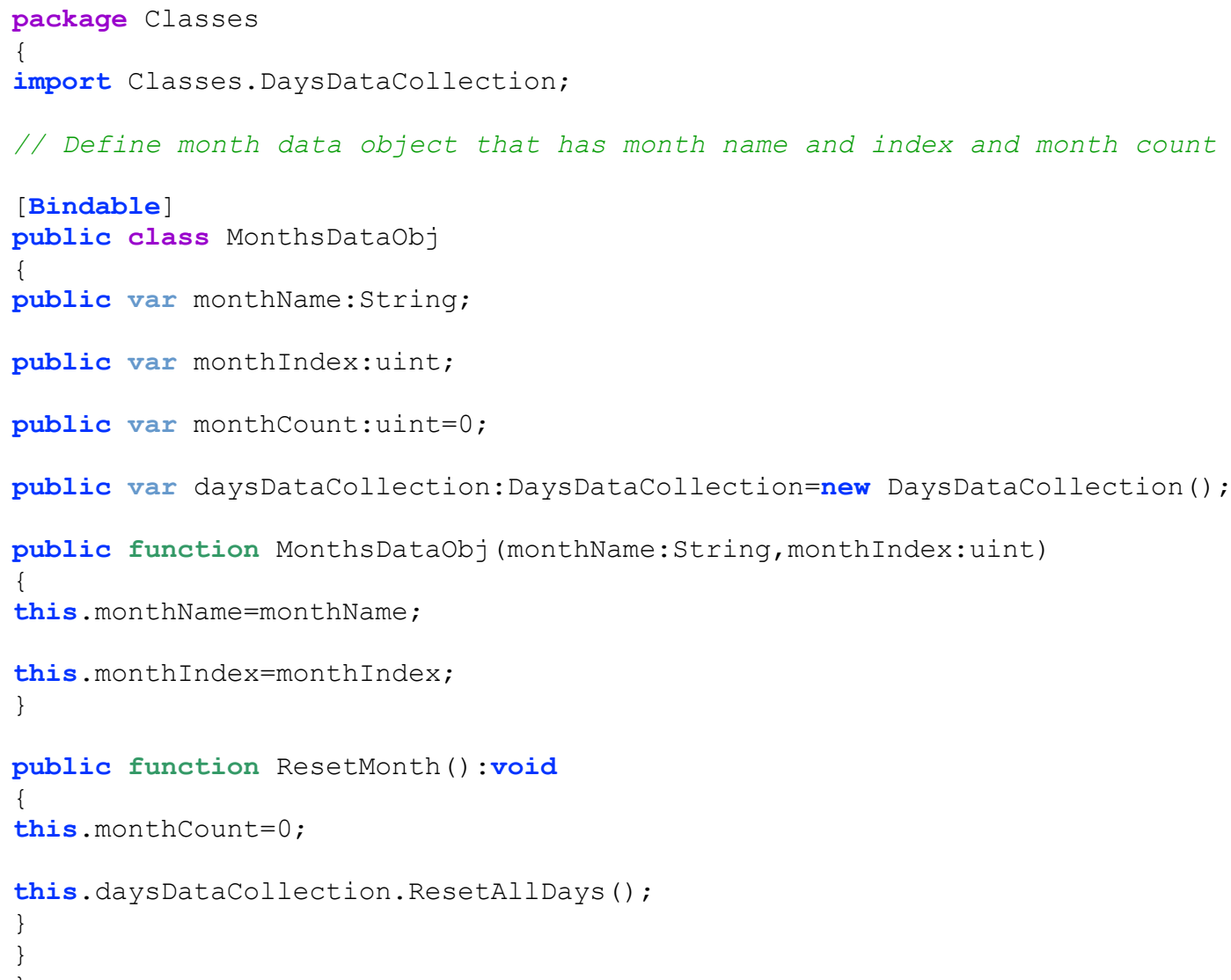




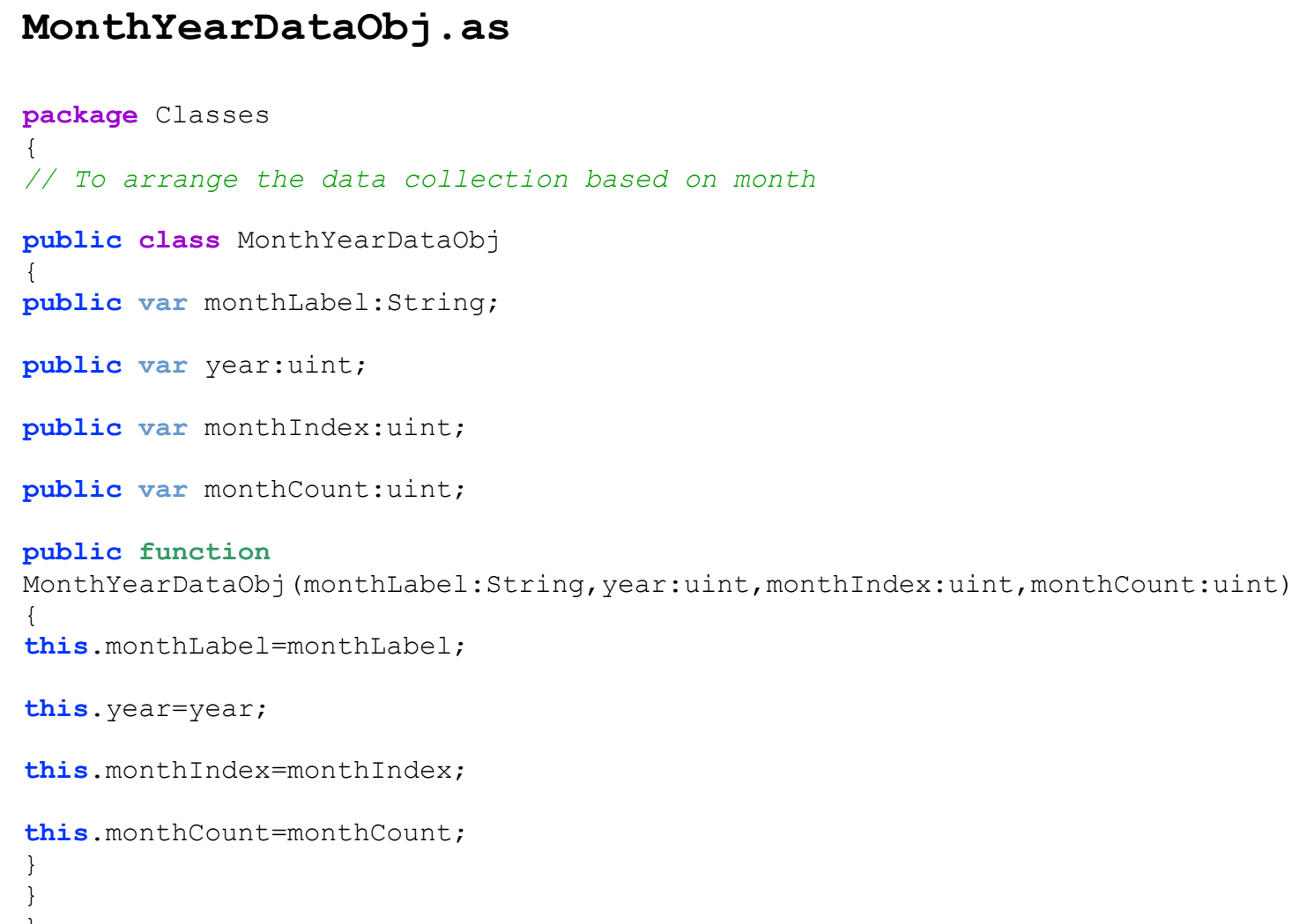




\section{TestEMSDataCollection.as}

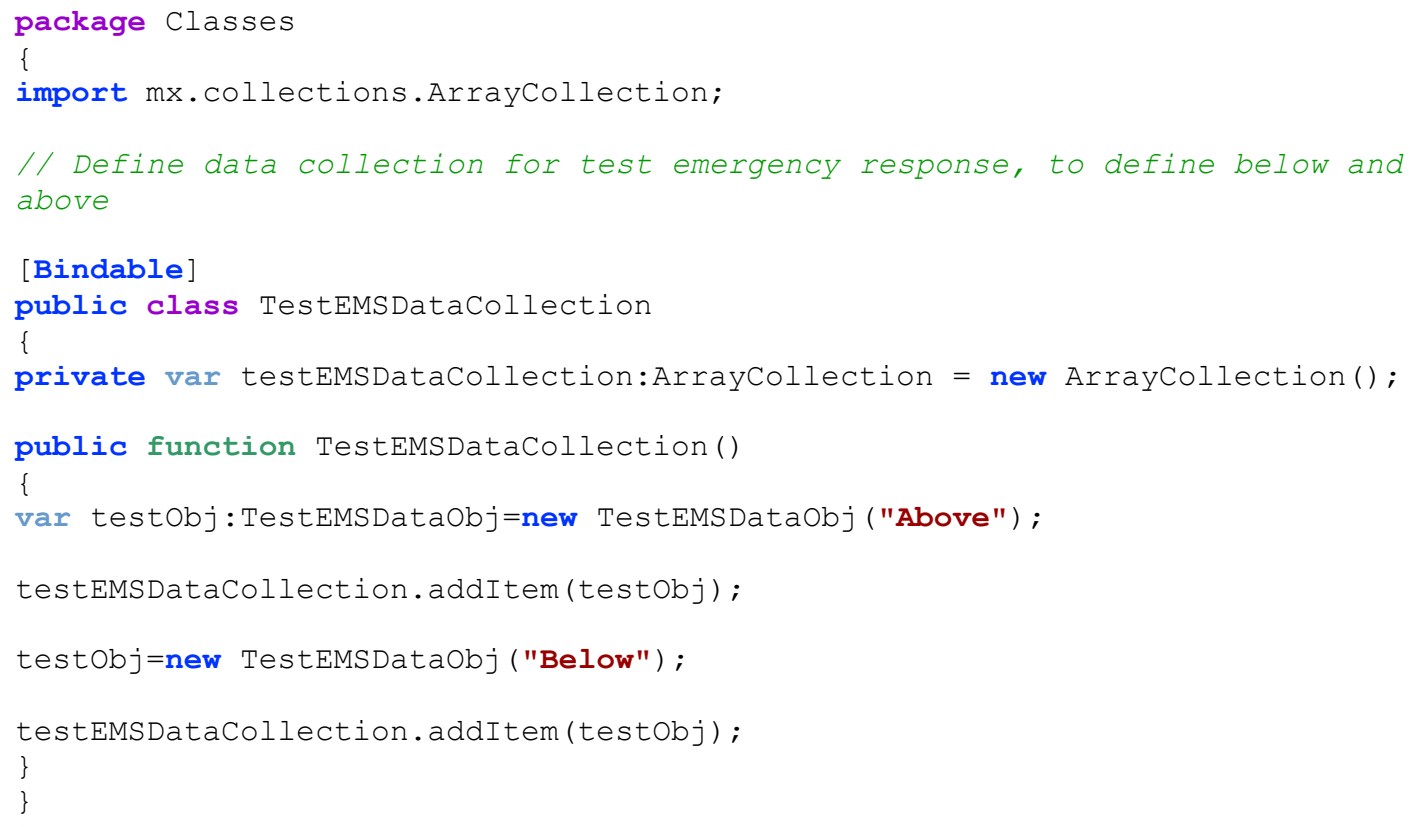




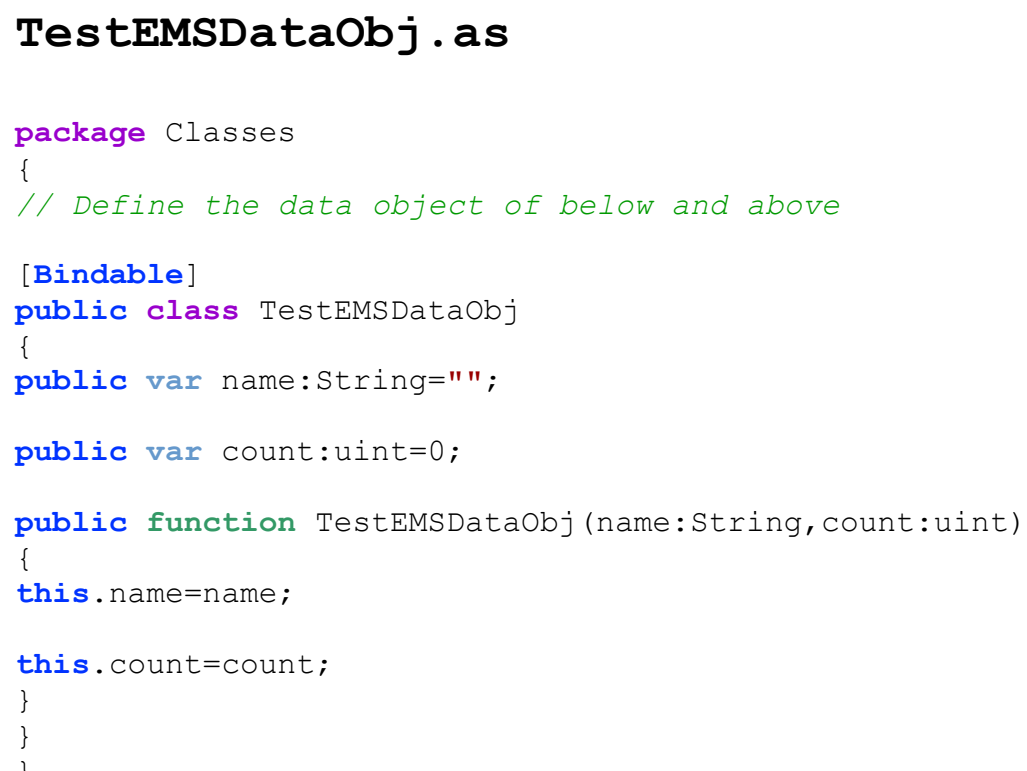




\section{YearDataCollection.as}

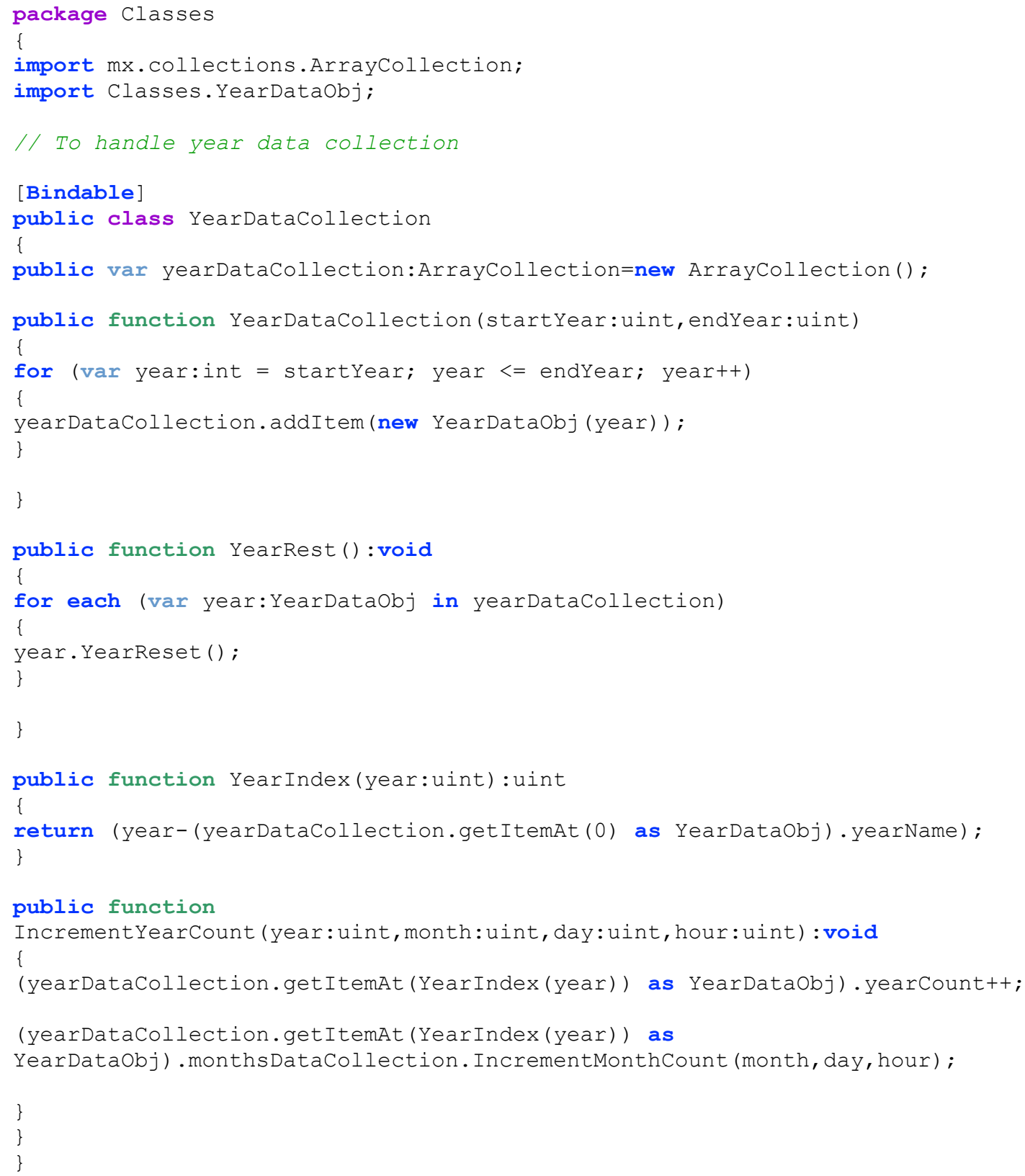




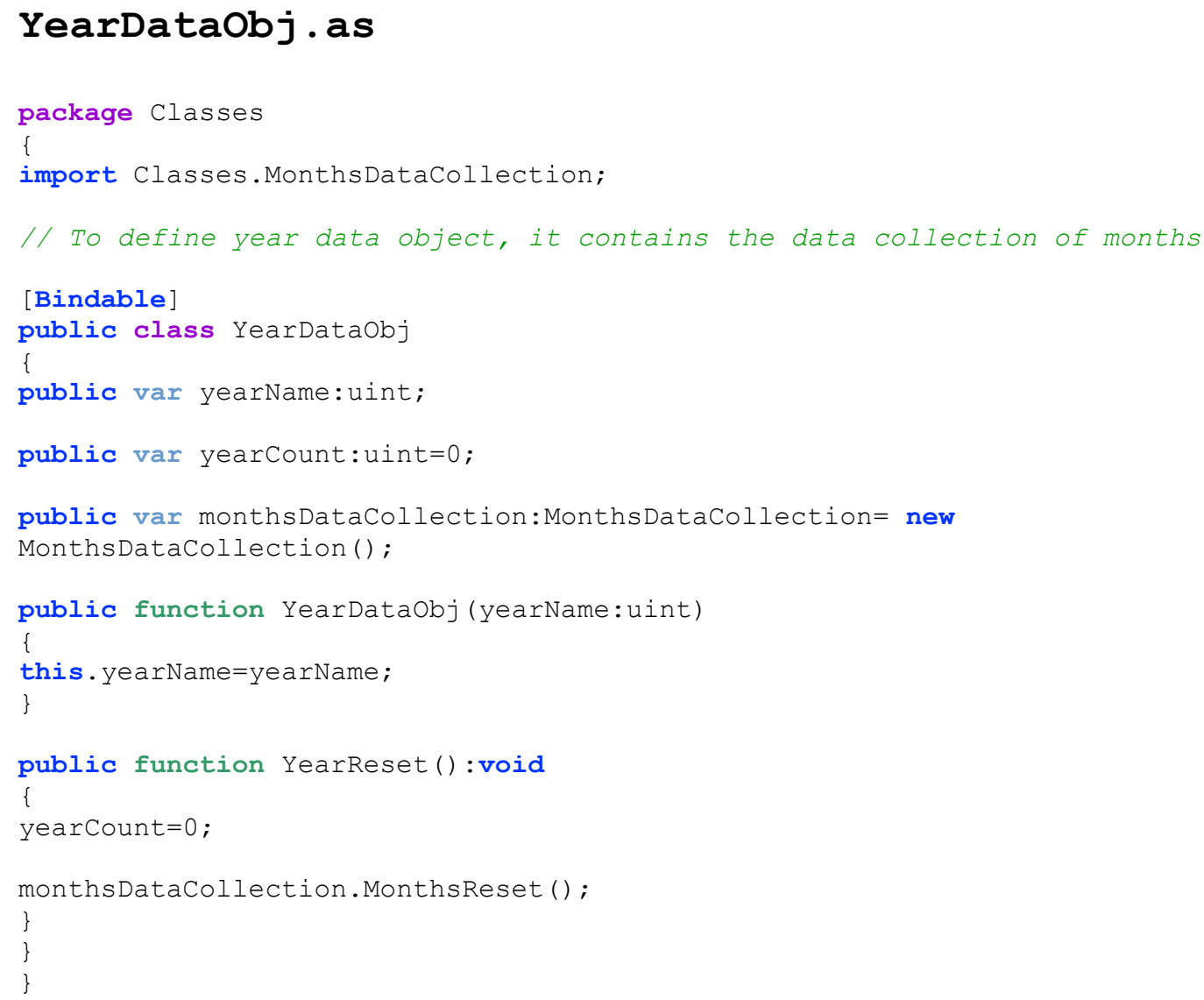




\section{YearMonthCountDataObj.as}

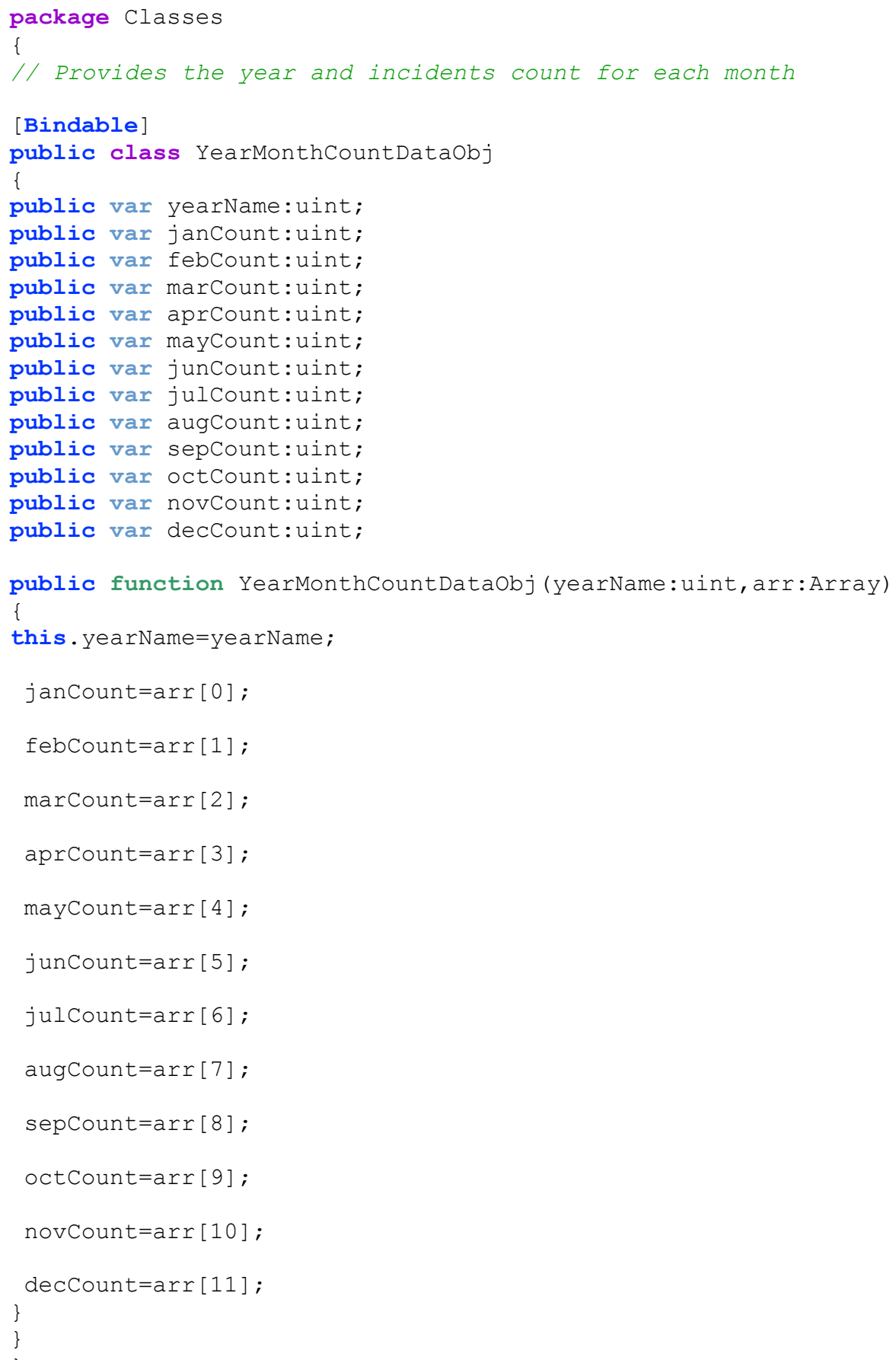

